Article

\title{
Multifunctional Donepezil Analogues as Cholinesterase and BACE1 Inhibitors
}

\author{
Keith D. Green, Marina Y. Fosso and Sylvie Garneau-Tsodikova *(D) \\ Department of Pharmaceutical Sciences, College of Pharmacy, University of Kentucky, Lexington, \\ KY 40536-0596, USA; kgr234@uky.edu (K.D.G.); marina.fosso@uky.edu (M.Y.F.) \\ * Correspondence: sylviegtsodikova@uky.edu
}

Academic Editors: Diego Muñoz-Torrero and Michael Decker

Received: 25 October 2018; Accepted: 7 December 2018; Published: 8 December 2018

\begin{abstract}
A series of 22 donepezil analogues were synthesized through alkylation/benzylation and compared to donepezil and its 6-O-desmethyl adduct. All the compounds were found to be potent inhibitors of both acetylcholinesterase (AChE) and butyrylcholinesterase (BChE), two enzymes responsible for the hydrolysis of the neurotransmitter acetylcholine in Alzheimer's disease patient brains. Many of them displayed lower inhibitory concentrations of EeAChE $\left(\mathrm{IC}_{50}=0.016 \pm 0.001 \mu \mathrm{M}\right.$ to $0.23 \pm 0.03 \mu \mathrm{M})$ and $E f B C h E\left(\mathrm{IC}_{50}=0.11 \pm 0.01 \mu \mathrm{M}\right.$ to $\left.1.3 \pm 0.2 \mu \mathrm{M}\right)$ than donepezil. One of the better compounds was tested against $H s \mathrm{AChE}$ and was found to be even more active than donepezil and inhibited HsAChE better than EeAChE. The analogues with the aromatic substituents were generally more potent than the ones with aliphatic substituents. Five of the analogues also inhibited the action of $\beta$-secretase (BACE1) enzyme.
\end{abstract}

Keywords: Alzheimer's disease; acetylcholinesterase; butyrylcholinesterase; $\beta$-secretase; inhibitors

\section{Introduction}

Alzheimer's disease (AD) is a neurodegenerative disorder that is characterized by memory loss and cognitive deficits. It is the most common form of dementia among older adults and the sixth leading cause of death in the United States [1]. In 2018, the World Health Organization (WHO) reported that there have been more than 2 million deaths associated to AD and other dementias in 2016, and this number has doubled since 2000 [2]. In the United States alone, more than 5 million people are currently living with $\mathrm{AD}$, and this number is expected to triple by 2050. Unfortunately, there is currently no cure for $\mathrm{AD}$, which contributes to the deadly nature of this disease.

Despite all the research efforts invested, the specific cause(s) of AD remain(s) unclear [3]. Several molecular mechanisms of AD have been proposed, including the $\beta$-amyloid cascade, oxidative stress, metal imbalance, and cholinergic hypothesis [4]. The latter appears to be the most efficient therapeutic avenue in providing temporary relief of AD symptoms. Indeed, five drugs have been approved by the United States Food and Drug Administration (FDA) for the symptomatic treatment of AD, four of which are acetylcholinesterase (AChE) inhibitors: rivastigmine, galantamine, donepezil, and tacrine. These drugs prevent the action of cholinesterases (ChEs), which are responsible for the hydrolysis of the neurotransmitter acetylcholine (ACh), thereby increasing the levels of $\mathrm{ACh}$ in the brain and improving the cholinergic functions in $\mathrm{AD}$ patients [5,6]. In addition to AChE, another type of enzyme involved in the hydrolysis of the neurotransmitter $\mathrm{ACh}$ is butyrylcholinesterase (BChE). The activity and expression of $\mathrm{BChE}$ have been suggested to increase throughout the progression of $\mathrm{AD}$, indicating that $\mathrm{BChE}$ may play an important role in the late stage of $\mathrm{AD}$ [7]. Therefore, inhibition of $\mathrm{AChE}$ and $\mathrm{BChE}$ remains a potential therapeutic target for AD treatment. However, targeting ChEs alone is definitely not sufficient. 
Another hallmark of AD pathology is the accumulation of amyloid- $\beta(A \beta)$ plaques on the brain [8]. These plaques are composed of $A \beta$ peptides that result from the cleavage of the transmembrane amyloid precursor protein (APP) by secretases to form $A \beta$ monomers that will aggregate to toxic fibrils [9]. $\beta$-secretase (BACE1) is an aspartyl protease that cleaves APP near the membrane surface, and it has been targeted for the development of potential therapies against AD [10].

Due to the multifactorial nature of $\mathrm{AD}$, the development of compounds that could target different pathological features of the disease appears to be a viable research avenue. We previously reported on the synthesis and biological evaluation of a number of multifunctional molecules derived from tacrine and chalcones that are capable of targeting ChEs and A $\beta$ [11-15]. Since donepezil is the most commonly prescribed medication for AD [4], and several other studies have focused on this drug to generate multifunctional compounds targeting various hallmarks of AD, including BACE1 [16-19], we decided to generate multi-targeted analogues derived from donepezil that would inhibit ChEs and $\beta$-secretase.

\section{Results and Discussion}

\subsection{Chemistry}

The synthetic route utilized for the synthesis of donepezil analogues is outlined in Scheme 1. Starting from ferulic acid (1), hydrogenation in the presence of $\mathrm{Pd} / \mathrm{C}$, followed by cyclization in the presence of methanesulfonic acid $(\mathrm{MsOH})$ produced ketone 3 with 67\% yield [20,21]. Attempts to react the ketone 3 with the aldehyde 5 through aldol condensation were met with little success. To overcome this shortcoming, the free hydroxyl group in compound 3 was protected with a TBDMS group to yield the corresponding ketone 4 with $90 \%$ yield. This was then successfully condensed with the aldehyde 5 in the presence of $\mathrm{KOH}$, to yield the $\alpha, \beta$-unsaturated ketone 6 with $65 \%$ yield. Selective reduction of the double bond in the presence of a ketone and a benzyl group was achieved through a controlled poisoning of the palladium catalyst with thioanisole to give the 6-O-desmethyl donepezil adduct 7 with $94 \%$ yield. The latter bears a free hydroxyl group that was reacted with the corresponding alkyl or benzyl halides to yield 22 donepezil analogues (8a-v) with 32-95\% yields.

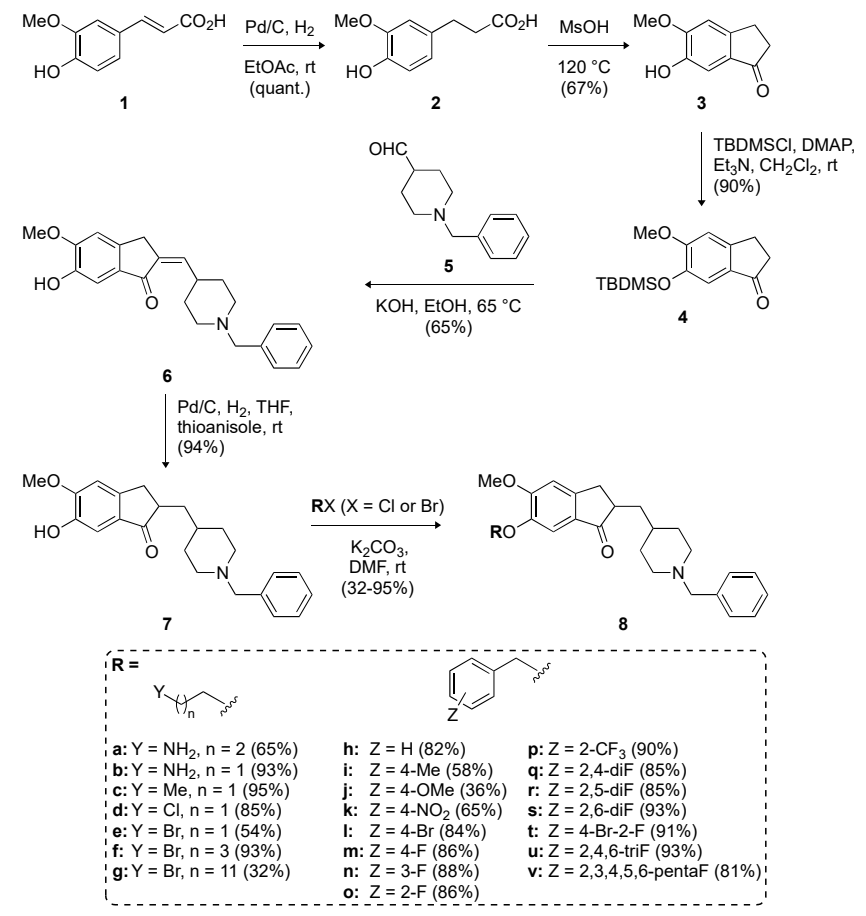

Scheme 1. Synthetic scheme for the preparation of compounds $8 \mathbf{a}-\mathbf{v}$. 


\subsection{Cholinesterase Inhibition}

To evaluate the potential cholinesterase (ChE) inhibitory activity of donepezil, 6-O-desmethyl donepezil 7 , and the 22 newly synthesized donepezil analogues $8 \mathbf{a}-\mathbf{v}$, their $\mathrm{IC}_{50}$ values were determined against AChE from Electrophorus electricus (EeAChE) (Table 1 and Figures S82-S83) and EfBChE from equine serum (Equus ferus) (Table 1 and Figures S84-S85) using the well-established Ellman method [22].

Table 1. Inhibition ( $\mathrm{IC}_{50}$ values in $\mu \mathrm{M}$, with standard error) of the activity of $E e \mathrm{AChE}$ (from Electrophorus electricus) and BChE (from Equus ferus) by donepezil and its analogues $\mathbf{7}$ and $\mathbf{8 a}-\mathbf{v}$, and the selectivity index (SI) for each inhibitor based on $\mathrm{IC}_{50}$ values.

\begin{tabular}{|c|c|c|c|}
\hline Cpd & $\mathrm{EeAChE}$ & EfBChE & SI \\
\hline Donepezil $\mathrm{HCl}$ & $0.12 \pm 0.01$ & $2.0 \pm 0.1$ & 17 \\
\hline 7 & $0.41 \pm 0.05$ & $4.3 \pm 0.4$ & 11 \\
\hline $8 a$ & $0.054 \pm 0.003$ & $0.57 \pm 0.04$ & 11 \\
\hline $8 b$ & $0.021 \pm 0.003$ & $0.48 \pm 0.03$ & 23 \\
\hline $8 c$ & $0.14 \pm 0.02$ & $2.1 \pm 0.3$ & 15 \\
\hline $8 d$ & $0.059 \pm 0.004$ & $1.3 \pm 0.1$ & 22 \\
\hline $8 e$ & $0.044 \pm 0.003$ & $1.3 \pm 0.2$ & 30 \\
\hline $8 f$ & $0.061 \pm 0.007$ & $1.3 \pm 0.2$ & 21 \\
\hline $8 g$ & $0.79 \pm 0.28$ & $5.2 \pm 1.6$ & 6.6 \\
\hline $8 \mathrm{~h}$ & $0.13 \pm 0.01$ & $0.70 \pm 0.05$ & 5.4 \\
\hline $8 \mathrm{i}$ & $0.23 \pm 0.03$ & $1.0 \pm 0.2$ & 4.3 \\
\hline $8 j$ & $0.13 \pm 0.01$ & $0.67 \pm 0.17$ & 5.2 \\
\hline $8 k$ & $0.13 \pm 0.02$ & $0.46 \pm 0.06$ & 3.5 \\
\hline 81 & $0.071 \pm 0.015$ & $0.72 \pm 0.10$ & 10 \\
\hline $8 \mathrm{~m}$ & $0.081 \pm 0.005$ & $0.57 \pm 0.10$ & 7.0 \\
\hline $8 n$ & $0.16 \pm 0.02$ & $0.96 \pm 0.15$ & 6.0 \\
\hline 80 & $0.12 \pm 0.02$ & $0.76 \pm 0.12$ & 6.3 \\
\hline $8 p$ & $0.032 \pm 0.010$ & $0.25 \pm 0.08$ & 7.8 \\
\hline $8 q$ & $0.11 \pm 0.01$ & $0.48 \pm 0.08$ & 4.4 \\
\hline $8 r$ & $0.090 \pm 0.009$ & $0.60 \pm 0.15$ & 6.7 \\
\hline $8 s$ & $0.016 \pm 0.001$ & $0.44 \pm 0.05$ & 28 \\
\hline $8 t$ & $0.054 \pm 0.007$ & $0.37 \pm 0.05$ & 6.9 \\
\hline $8 u$ & $0.027 \pm 0.004$ & $0.20 \pm 0.03$ & 7.4 \\
\hline $8 v$ & $0.17 \pm 0.02$ & $0.11 \pm 0.01$ & 0.69 \\
\hline
\end{tabular}

\subsubsection{AChE Inhibition}

When comparing the 6-O-desmethyl donepezil $7\left(\mathrm{R}=\mathrm{H} ; \mathrm{IC}_{50}=0.41 \pm 0.05 \mu \mathrm{M}\right)$ with donepezil $\left(\mathrm{R}=\mathrm{Me} ; \mathrm{IC}_{50}=0.12 \pm 0.01 \mu \mathrm{M}\right)$ and its analogues $8 \mathbf{a}-\mathbf{f}$ and $\mathbf{8 h}-\mathbf{v}(\mathrm{R}=$ various alkyl and benzylic groups; $\mathrm{IC}_{50}=0.016 \pm 0.001 \mu \mathrm{M}$ to $0.23 \pm 0.03 \mu \mathrm{M}$ ), it becomes evident that 6-O-alkylation/benzylation enhances $E e A C h E$ inhibition, with the only exception being $8 \mathrm{~g}\left(\mathrm{IC}_{50}=0.79 \pm 0.28 \mu \mathrm{M}\right)$, which bears a hydrophobic 1-bromododecyl group. Other analogues were equal to or even better than donepezil at inhibiting the action of EeAChE in vitro. With similar $\mathrm{IC}_{50}$ values, compound $8 \mathrm{c}(\mathrm{R}=n$-propyl; $\left.\mathrm{IC}_{50}=0.14 \pm 0.02 \mu \mathrm{M}\right)$ was as potent as donepezil $\left(\mathrm{R}=\mathrm{Me} ; \mathrm{IC}_{50}=0.12 \pm 0.01 \mu \mathrm{M}\right)$. However, substituting the terminal methyl in the $\mathrm{R}$ group of compound $8 \mathrm{c}\left(\mathrm{R}=n\right.$-propyl; $\mathrm{IC}_{50}=0.14 \pm 0.02$ 
$\mu \mathrm{M})$ by a terminal amine in compound $8 \mathbf{b}\left(\mathrm{R}=\mathrm{H}_{2} \mathrm{NCH}_{2} \mathrm{CH}_{2} ; \mathrm{IC}_{50}=0.021 \pm 0.003 \mu \mathrm{M}\right)$ drastically increased the potency. Indeed, a 6-fold reduction of the $\mathrm{IC}_{50}$ value of donepezil was observed. The amine group may form hydrogen bonds with Tyr70, Asp72, and Gln74 residues near the PAS [11]. Cancellation of this hydrogen bonding by replacing the terminal amine in the $\mathrm{R}$ group of compound $\mathbf{8 b}$ $\left(\mathrm{R}=\mathrm{H}_{2} \mathrm{NCH}_{2} \mathrm{CH}_{2} ; \mathrm{IC}_{50}=0.021 \pm 0.003 \mu \mathrm{M}\right)$ with a chlorine atom in $\mathbf{8 d}\left(\mathrm{R}=\mathrm{ClCH}_{2} \mathrm{CH}_{2} ; \mathrm{IC}_{50}=0.059 \pm\right.$ $0.004 \mu \mathrm{M})$ or a bromine atom in $8 \mathbf{e}\left(\mathrm{R}=\mathrm{BrCH}_{2} \mathrm{CH}_{2} ; \mathrm{IC}_{50}=0.044 \pm 0.003 \mu \mathrm{M}\right)$ resulted in an increase in the $\mathrm{IC}_{50}$ values, which only represented a 2- or 3-fold enhanced potency when compared to donepezil, respectively. Elongation of the $\mathrm{R}$ group also appeared to worsen the $\mathrm{IC}_{50}$ values. Indeed, adding an extra methylene to compound $\mathbf{8 b}\left(\mathrm{R}=\mathrm{H}_{2} \mathrm{NCH}_{2} \mathrm{CH}_{2} ; \mathrm{IC}_{50}=0.021 \pm 0.003 \mu \mathrm{M}\right)$ gives compound 8a $\left(\mathrm{R}=\mathrm{H}_{2} \mathrm{NCH}_{2} \mathrm{CH}_{2} \mathrm{CH}_{2} ; \mathrm{IC}_{50}=0.054 \pm 0.003 \mu \mathrm{M}\right)$, while the addition of two methylene groups to compound 8e $\left(\mathrm{R}=\mathrm{BrCH}_{2} \mathrm{CH}_{2} ; \mathrm{IC}_{50}=0.044 \pm 0.003 \mu \mathrm{M}\right)$ gives compound $8 \mathrm{f}\left(\mathrm{R}=\mathrm{BrCH}_{2} \mathrm{CH}_{2} \mathrm{CH}_{2} \mathrm{CH}_{2}\right.$; $\left.\mathrm{IC}_{50}=0.061 \pm 0.007 \mu \mathrm{M}\right)$. Nevertheless, all these analogues remained better inhibitors of EeAChE than donepezil.

Replacing the alkyl group in donepezil $\left(\mathrm{R}=\mathrm{Me} ; \mathrm{IC}_{50}=0.12 \pm 0.01 \mu \mathrm{M}\right)$ by an aromatic group in compound $8 \mathrm{~h}\left(\mathrm{R}=\mathrm{Bn} ; \mathrm{IC}_{50}=0.13 \pm 0.01 \mu \mathrm{M}\right)$ did not affect the $\mathrm{IC}_{50}$ value. Likewise, additional substitutions at the para-position of the benzyl group resulted in $\mathrm{IC}_{50}$ values that were similar to that of donepezil. Indeed, compounds $8 \mathbf{i}\left(\mathrm{R}=4-\mathrm{MeBn} ; \mathrm{IC}_{50}=0.23 \pm 0.03 \mu \mathrm{M}\right), \mathbf{8 j}(\mathrm{R}=4-\mathrm{OMeBn}$; $\left.\mathrm{IC}_{50}=0.13 \pm 0.01 \mu \mathrm{M}\right), 8 \mathrm{k}\left(\mathrm{R}=4-\mathrm{NO}_{2} \mathrm{Bn} ; \mathrm{IC}_{50}=0.13 \pm 0.02 \mu \mathrm{M}\right), 81\left(\mathrm{R}=4-\mathrm{BrBn} ; \mathrm{IC}_{50}=0.071 \pm\right.$ $0.015 \mu \mathrm{M})$, and $8 \mathrm{~m}\left(\mathrm{R}=4-\mathrm{FBn} ; \mathrm{IC}_{50}=0.081 \pm 0.005 \mu \mathrm{M}\right)$ displayed $\mathrm{IC}_{50}$ values that were still within 1 - to 2 -fold of that of donepezil $\left(\mathrm{R}=\mathrm{Me} ; \mathrm{IC}_{50}=0.12 \pm 0.01 \mu \mathrm{M}\right)$. Similarly, when the fluoro group was moved from the para-position in compound $8 \mathrm{~m}\left(\mathrm{R}=4-\mathrm{FBn} ; \mathrm{IC}_{50}=0.081 \pm 0.005 \mu \mathrm{M}\right)$ to the meta- or ortho-positions in compounds $8 \mathrm{n}\left(\mathrm{R}=3-\mathrm{FBn} ; \mathrm{IC}_{50}=0.16 \pm 0.02 \mu \mathrm{M}\right)$ and $8 \mathrm{o}(\mathrm{R}=2-\mathrm{FBn}$; $\left.\mathrm{IC}_{50}=0.12 \pm 0.02 \mu \mathrm{M}\right)$, respectively, the potency of these analogues was comparable to donepezil $\left(\mathrm{R}=\mathrm{Me} ; \mathrm{IC}_{50}=0.12 \pm 0.01 \mu \mathrm{M}\right)$. However, replacing the fluoro group in $8 \mathrm{o}\left(\mathrm{R}=2-\mathrm{FBn} ; \mathrm{IC}_{50}=0.12 \pm 0.02\right.$ $\mu \mathrm{M})$ by a $\mathrm{CF}_{3}$ group in $8 \mathrm{p}\left(\mathrm{R}=2-\mathrm{CF}_{3} \mathrm{Bn} ; \mathrm{IC}_{50}=0.032 \pm 0.010 \mu \mathrm{M}\right)$ improved the $\mathrm{IC}_{50}$ by 4 -fold. This may suggest that enhanced electron-withdrawing effect on the aromatic ring may improve the potency of the analogue. Attempts to spread out the electron-withdrawing effect throughout the aromatic ring led to compounds $8 \mathbf{q}\left(\mathrm{R}=2,4\right.$-diF-Bn; $\left.\mathrm{IC}_{50}=0.11 \pm 0.01 \mu \mathrm{M}\right), 8 \mathrm{r}\left(\mathrm{R}=2,5\right.$-diF-Bn; $\left.\mathrm{IC}_{50}=0.090 \pm 0.009 \mu \mathrm{M}\right)$, 8s $\left(\mathrm{R}=2,6\right.$-diF-Bn; $\left.\mathrm{IC}_{50}=0.016 \pm 0.001 \mu \mathrm{M}\right)$, and 8t $\left(\mathrm{R}=4-\mathrm{Br}-2-\mathrm{F}-\mathrm{Bn} ; \mathrm{IC}_{50}=0.054 \pm 0.007 \mu \mathrm{M}\right)$, with two electron-withdrawing groups, and compounds $8 \mathbf{u}\left(\mathrm{R}=2,4,6\right.$-triF-Bn; $\mathrm{IC}_{50}=0.027 \pm 0.004$ $\mu \mathrm{M})$ and $8 \mathbf{v}\left(\mathrm{R}=2,3,4,5\right.$-pentaF-Bn; $\left.\mathrm{IC}_{50}=0.17 \pm 0.02 \mu \mathrm{M}\right)$, with three and five electron-withdrawing groups, respectively. It thus appears that both ortho-positions on the benzyl group are very sensitive to the presence of electron-withdrawing groups, since $8 \mathrm{~s}\left(\mathrm{R}=2,6\right.$-diF-Bn; $\left.\mathrm{IC}_{50}=0.016 \pm 0.001 \mu \mathrm{M}\right)$ and $8 \mathbf{u}\left(\mathrm{R}=2,4,6\right.$-triF-Bn; $\left.\mathrm{IC}_{50}=0.027 \pm 0.004 \mu \mathrm{M}\right)$ were eight and five times more potent than donepezil, respectively.

In order to confirm that the data obtained with EeAChE would also apply to HsAChE (from Homo sapiens), we tested donepezil along with a compound that displayed better inhibition than donepezil, 8t. We found that both donepezil and compound $\mathbf{8 t}$ inhibited HsAChE better than the EeAChE (Table 2). Compound 8t $\left(\mathrm{R}=4-\mathrm{Br}-2-\mathrm{F}-\mathrm{Bn} ; \mathrm{IC}_{50}=0.0018 \pm 0.0006 \mu \mathrm{M}\right)$ inhibited HsAChE 18-fold better than donepezil $\left(\mathrm{R}=\mathrm{Me} ; \mathrm{IC}_{50}=0.032 \pm 0.011 \mu \mathrm{M}\right)$. In the case of EeAChE, compound $8 \mathrm{t}(\mathrm{R}=4-\mathrm{Br}-2-\mathrm{F}-\mathrm{Bn}$; $\left.\mathrm{IC}_{50}=0.054 \pm 0.007 \mu \mathrm{M}\right)$ had an $\mathrm{IC}_{50}$ value that was 2.2 -fold better than donepezil $\left(\mathrm{R}=\mathrm{Me} ; \mathrm{IC}_{50}=0.12\right.$ $\pm 0.01 \mu \mathrm{M})$. These data would suggest that our inhibitors are well suited for working with $H s A C h E$.

Table 2. Inhibition ( $\mathrm{IC}_{50}$ values in $\mu \mathrm{M}$ ) of the activity of $\mathrm{HsAChE}_{\mathrm{A}}$ donepezil and its analogue $\mathbf{8 t}$.

\begin{tabular}{ccc}
\hline Cpd & IC $_{50}(\boldsymbol{\mu M})$ & SI $^{\mathbf{a}}$ \\
\hline Donepezil HCl & $0.032 \pm 0.011$ & 3.8 \\
\hline $\mathbf{8 t}$ & $0.0018 \pm 0.0006$ & 30
\end{tabular}

a Selectivity index of EeAChE versus HsAChE, based on $\mathrm{IC}_{50}$ values. 


\subsubsection{EfBChE Inhibition}

As expected, donepezil analogues 8a-v were less effective against $E f B C h E$ than $E e A C h E$. Indeed, donepezil is highly selective for EeAChE over $E f \mathrm{BChE}$ [23], and as a result, it is expected for its analogues to behave similarly. However, when compared to donepezil $\left(\mathrm{R}=\mathrm{Me} ; \mathrm{IC}_{50}=2.0 \pm 0.1 \mu \mathrm{M}\right)$, all but compounds $8 \mathrm{c}\left(\mathrm{R}=\mathrm{CH}_{3} \mathrm{CH}_{2} \mathrm{CH}_{2} ; \mathrm{IC}_{50}=2.1 \pm 0.3 \mu \mathrm{M}\right)$ and $8 \mathrm{~g}\left(\mathrm{IC}_{50}=5.2 \pm 1.6 \mu \mathrm{M}\right)$ appeared to be more effective at inhibiting the action of $\mathrm{BChE}$. The presence of a terminal amine in compounds $8 \mathrm{a}$ $\left(\mathrm{R}=\mathrm{H}_{2} \mathrm{NCH}_{2} \mathrm{CH}_{2} \mathrm{CH}_{2} ; \mathrm{IC}_{50}=0.57 \pm 0.04 \mu \mathrm{M}\right)$ and $\mathbf{8 b}\left(\mathrm{R}=\mathrm{H}_{2} \mathrm{NCH}_{2} \mathrm{CH}_{2} ; \mathrm{IC}_{50}=0.48 \pm 0.03 \mu \mathrm{M}\right)$ still drastically increased their potency by 4 -fold when compared to donepezil. Substitution of the amine group in $8 \mathbf{b}\left(\mathrm{R}=\mathrm{H}_{2} \mathrm{NCH}_{2} \mathrm{CH}_{2} ; \mathrm{IC}_{50}=0.48 \pm 0.03 \mu \mathrm{M}\right)$ with a chlorine atom in $8 \mathrm{~d}\left(\mathrm{R}=\mathrm{ClCH}_{2} \mathrm{CH}_{2}\right.$; $\left.\mathrm{IC}_{50}=1.3 \pm 0.1 \mu \mathrm{M}\right)$ or a bromine atom in $8 \mathrm{e}\left(\mathrm{R}=\mathrm{BrCH}_{2} \mathrm{CH}_{2} ; \mathrm{IC}_{50}=1.3 \pm 0.2 \mu \mathrm{M}\right)$ resulted again in an increase in the $\mathrm{IC}_{50}$ values, which only represented a 2 -fold enhanced potency when compared to donepezil. Elongation of the R group did not have much effect, as the $\mathrm{IC}_{50}$ value of $\mathbf{8 f}$ $\left(\mathrm{R}=\mathrm{BrCH}_{2} \mathrm{CH}_{2} \mathrm{CH}_{2} \mathrm{CH}_{2} ; \mathrm{IC}_{50}=1.3 \pm 0.2 \mu \mathrm{M}\right)$ still remained within 2-fold that of donepezil.

A greater improvement of the $\mathrm{IC}_{50}$ values was more noticeable when the alkyl group in donepezil $\left(\mathrm{R}=\mathrm{Me} ; \mathrm{IC}_{50}=2.0 \pm 0.1 \mu \mathrm{M}\right)$ was replaced by an aromatic group. Compound $8 \mathbf{h}\left(\mathrm{R}=\mathrm{Bn} ; \mathrm{IC}_{50}=0.70 \pm\right.$ $0.05 \mu \mathrm{M})$ was 3-fold more potent than donepezil. Substitutions at the para-position of the benzyl group also contributed to reducing the $\mathrm{IC}_{50}$ values. Indeed, compounds $8 \mathbf{i}\left(\mathrm{R}=4-\mathrm{Me}-\mathrm{Bn} ; \mathrm{IC}_{50}=1.0\right.$ $\pm 0.2 \mu \mathrm{M}), 8 \mathrm{j}\left(\mathrm{R}=4-\mathrm{OMe}-\mathrm{Bn} ; \mathrm{IC}_{50}=0.67 \pm 0.17 \mu \mathrm{M}\right), 8 \mathrm{k}\left(\mathrm{R}=4-\mathrm{NO}_{2} \mathrm{Bn} ; \mathrm{IC}_{50}=0.46 \pm 0.06 \mu \mathrm{M}\right)$, $81\left(\mathrm{R}=4-\mathrm{Br}-\mathrm{Bn} ; \mathrm{IC}_{50}=0.72 \pm 0.10 \mu \mathrm{M}\right)$, and $8 \mathrm{~m}\left(\mathrm{R}=4-\mathrm{F}-\mathrm{Bn} ; \mathrm{IC}_{50}=0.57 \pm 0.10 \mu \mathrm{M}\right)$ displayed inhibitory efficacies of 2- to 4 -fold better than donepezil $\left(\mathrm{R}=\mathrm{Me} ; \mathrm{IC}_{50}=2.0 \pm 0.1 \mu \mathrm{M}\right)$. Similarly, when the fluoro group was moved from the para-position in compound $8 \mathrm{~m}\left(\mathrm{R}=4-\mathrm{F}-\mathrm{Bn} ; \mathrm{IC}_{50}=0.57\right.$ $\pm 0.10 \mu \mathrm{M})$ to the meta- or ortho-positions in compounds $8 \mathbf{n}\left(\mathrm{R}=3\right.$-F-Bn; $\left.\mathrm{IC}_{50}=0.96 \pm 0.15 \mu \mathrm{M}\right)$ and $8 \mathbf{o}\left(\mathrm{R}=2-\mathrm{F}-\mathrm{Bn} ; \mathrm{IC}_{50}=0.76 \pm 0.12 \mu \mathrm{M}\right)$, respectively, the potency of these analogues was reduced by 1 - to 2 -fold. Replacing the fluoro group in $80\left(\mathrm{R}=2-\mathrm{F}-\mathrm{Bn} ; \mathrm{IC}_{50}=0.76 \pm 0.12 \mu \mathrm{M}\right)$ by a $\mathrm{CF}_{3}$ group in $8 \mathbf{p}\left(\mathrm{R}=2-\mathrm{CF}_{3} \mathrm{Bn} ; \mathrm{IC}_{50}=0.25 \pm 0.08 \mu \mathrm{M}\right)$ once again improved the $\mathrm{IC}_{50}$ by 8 -fold. This is in agreement with the trend observed in $E e \mathrm{AChE}$ inhibition. Indeed, the additional electron-withdrawing effect on the aromatic ring still appeared to increase the potency of the analogue. Compounds $\mathbf{8 q}$ $\left(\mathrm{R}=2,4-\right.$ diF-Bn; $\left.\mathrm{IC}_{50}=0.48 \pm 0.08 \mu \mathrm{M}\right), 8 \mathbf{r}\left(\mathrm{R}=2,5\right.$-diF-Bn; $\left.\mathrm{IC}_{50}=0.60 \pm 0.15 \mu \mathrm{M}\right), 8 \mathbf{s}(\mathrm{R}=2,6$-diF-Bn; $\left.\mathrm{IC}_{50}=0.44 \pm 0.05 \mu \mathrm{M}\right)$, and $8 \mathbf{t}\left(\mathrm{R}=4\right.$-Br-2-F-Bn; $\left.\mathrm{IC}_{50}=0.37 \pm 0.05 \mu \mathrm{M}\right)$, with two electron-withdrawing groups, and compounds $8 \mathbf{u}\left(\mathrm{R}=2,4,6\right.$-triF-Bn; $\left.\mathrm{IC}_{50}=0.20 \pm 0.03 \mu \mathrm{M}\right)$ and $8 \mathbf{v}(\mathrm{R}=2,3,4,5$-pentaF-Bn; $\mathrm{IC}_{50}=0.11 \pm 0.01 \mu \mathrm{M}$ ), with three and five electron-withdrawing groups, respectively, were all better EfBChE inhibitors than donepezil $\left(\mathrm{R}=\mathrm{Me} ; \mathrm{IC}_{50}=2.0 \pm 0.1 \mu \mathrm{M}\right)$. Compound $8 \mathrm{q}(\mathrm{R}=2,4-\mathrm{diF}-\mathrm{Bn}$; $\left.\mathrm{IC}_{50}=0.48 \pm 0.08 \mu \mathrm{M}\right)$ was 4 -fold better than donepezil, while $8 \mathbf{r}\left(\mathrm{R}=2,5-\mathrm{diF}-\mathrm{Bn} ; \mathrm{IC}_{50}=0.60 \pm 0.15\right.$ $\mu \mathrm{M})$ and $8 \mathrm{~s}\left(\mathrm{R}=2,6\right.$-diF-Bn; $\left.\mathrm{IC}_{50}=0.44 \pm 0.05 \mu \mathrm{M}\right)$ were 3- and 5-fold better, respectively. Replacing the fluorine atom at the para-position in $\mathbf{8 q}\left(\mathrm{R}=2\right.$,4-diF-Bn; $\left.\mathrm{IC}_{50}=0.48 \pm 0.08 \mu \mathrm{M}\right)$ with a bromine atom in $8 \mathbf{t}\left(\mathrm{R}=4-\mathrm{Br}-2-\mathrm{F}-\mathrm{Bn} ; \mathrm{IC}_{50}=0.37 \pm 0.05 \mu \mathrm{M}\right)$ did not impart a noticeable change. Compounds $8 \mathbf{u}\left(\mathrm{R}=2,4,6\right.$-triF-Bn; $\left.\mathrm{IC}_{50}=0.20 \pm 0.03 \mu \mathrm{M}\right)$ and $\mathbf{8 v}\left(\mathrm{R}=2,3,4,5\right.$-pentaF-Bn; $\left.\mathrm{IC}_{50}=0.11 \pm 0.01 \mu \mathrm{M}\right)$, with three and five electron-withdrawing groups, respectively, were 10- and 18-fold better than donepezil. The active site gorge of $\mathrm{BChE}$ is less constrained than that of $\mathrm{AChE}$, allowing $\mathrm{BChE}$ to better accommodate bulky inhibitors [24]. This supports our observations that additional substitution on the aromatic ring increased the potency of the donepezil analogues against $E f B C h E$ more than against $E e A C h E$.

We also calculated the selectivity index (SI) to understand the utility of the compounds. For all but one compound, 8v, EeAChE was inhibited 3.5- to 30-fold better than EfBChE. Interestingly, compound $8 \mathbf{v}$ was 1.5 -fold more selective for $E f B C h E$. Clearly the donepezil analogues are better suited for inhibiting EeAChE. We also looked at the selectivity of the inhibitors for EeAChE versus HsAChE. We observed that donepezil was 3-fold more selective for HsAChE. Perhaps more interesting, compound $\mathbf{8 t}$ was 30 -fold more selective for HsAChE over EeAChE. 


\subsection{BACE1 Inhibition}

It has previously been reported that donepezil has some BACE1 inhibitory activity [19]. Keeping this in mind we decided to test these compounds for BACE1 inhibitory activity (Table 3). Unlike with $\mathrm{AChE}$ and $\mathrm{BChE}$, in general, donepezil analogues $\mathbf{8 a} \mathbf{a}-\mathbf{v}$ were not better than the parent donepezil at inhibiting the action of BACE1 in vitro, with the exception of $\mathbf{8 c}, \mathbf{8 e}, \mathbf{8 f}$, and $\mathbf{8 1}$, which were in the low micromolar range. Indeed, $8 \mathbf{c}\left(\mathrm{R}=\mathrm{CH}_{3} \mathrm{CH}_{2} \mathrm{CH}_{2} ; \mathrm{IC}_{50}=6.1 \pm 0.1 \mu \mathrm{M}\right), 8 \mathbf{e}\left(\mathrm{R}=\mathrm{BrCH}_{2} \mathrm{CH}_{2}\right.$; $\left.\mathrm{IC}_{50}=7.9 \pm 0.9 \mu \mathrm{M}\right), 8 \mathrm{f}\left(\mathrm{R}=\mathrm{BrCH}_{2} \mathrm{CH}_{2} \mathrm{CH}_{2} \mathrm{CH}_{2} ; \mathrm{IC}_{50}=7.9 \pm 2.4 \mu \mathrm{M}\right)$, and $81\left(\mathrm{R}=4-\mathrm{Br}-\mathrm{Bn} ; \mathrm{IC}_{50}=3.4 \pm\right.$ $0.1 \mu \mathrm{M}$ ) were within 5 -fold of the $\mathrm{IC}_{50}$ values of donepezil. This suggests that our analogues are more selective in targeting the ChEs, but they do still target BACE1. As a control for the BACE1 inhibition assays, we used BACE inhibitor IV. Our inhibitors were poorer inhibitors than BACE inhibitor IV $\left(\mathrm{IC}_{50}=0.63 \pm 0.18 \mathrm{nM}\right)$. While BACE inhibitor IV is better, it was designed to be very specific for that one target. However, with an illness such as Alzheimer's disease, which has many facets and contributing factors, having multifunctional inhibitors that display activity against BACE1 and ChEs is beneficial.

Table 3. Inhibition (IC50 values in $\mu \mathrm{M}$, unless otherwise noted) of the activity of BACE1 by donepezil and its analogues $\mathbf{7}$, and $\mathbf{8 a - v}$. BACE inhibitor IV was used as a control.

\begin{tabular}{|c|c|}
\hline Cpd & $\mathrm{IC}_{50}(\mu \mathrm{M})$ \\
\hline Donepezil HCl & $1.5 \pm 0.3$ \\
\hline 7 & - \\
\hline $8 \mathbf{a}$ & $95 \pm 12$ \\
\hline $8 b$ & $\sim 100$ \\
\hline $8 c$ & $6.1 \pm 0.1$ \\
\hline $8 d$ & $\sim 100$ \\
\hline $8 \mathbf{e}$ & $7.9 \pm 0.9$ \\
\hline $8 f$ & $7.9 \pm 2.4$ \\
\hline $8 g$ & - \\
\hline $8 \mathrm{~h}$ & $58 \pm 1$ \\
\hline $8 \mathrm{i}$ & $58 \pm 2$ \\
\hline $8 j$ & - \\
\hline $8 k$ & - \\
\hline 81 & $3.4 \pm 0.1$ \\
\hline $8 \mathrm{~m}$ & $\sim 100$ \\
\hline $8 n$ & $12 \pm 3$ \\
\hline 80 & $21 \pm 4$ \\
\hline $8 p$ & $34 \pm 9$ \\
\hline $8 q$ & $37 \pm 5$ \\
\hline $8 \mathbf{r}$ & $\sim 100$ \\
\hline $8 s$ & $30 \pm 8$ \\
\hline $8 t$ & $169 \pm 2$ \\
\hline $8 u$ & $91 \pm 14$ \\
\hline $8 v$ & $29 \pm 6$ \\
\hline BACE1 inhibitor IV & $0.63 \pm 0.18 \mathrm{nM}$ \\
\hline
\end{tabular}




\subsection{BACE1 Modeling}

To aid in the understanding of donepezil and its analogues' inhibitory activity of BACE1, we used SwissDock to perform some modeling studies. Figure 1 shows the crystal structure (PDB\# 4FM7 [25], with a published inhibitor of BACE1 (published $\mathrm{IC}_{50}$ value $=0.1 \mu \mathrm{M}$ ). This inhibitor shares the vicinyl dioxygen-substituted phenyl ring found in donepezil. Based on the results of the modeling, the aromatic ring of donepezil aligns with that of the inhibitor originally co-crystallized with BACE1 (Figure 1A,B). When looking at the docking of donepezil (Figure 1C), it is apparent that is binds in a similar location to the reported co-crystallized inhibitor (Figure 1B), albeit not as tightly as apparent by the $\mathrm{IC}_{50}$ values, which are 10-fold different. When examining the docking of compound 81 (Figure 1D), it is slightly twisted, likely due to the bulky 4-bromobenzyl substitution. This slight torsion could explain the roughly doubled $\mathrm{IC}_{50}$ value of compound $\mathbf{8 1}$ when compared to that of donepezil. Based on the modeling, there is also room for more optimization at this location, reasoning that modifications of donepezil have the potential to yield better inhibitors than the parent compound if modified correctly.

A

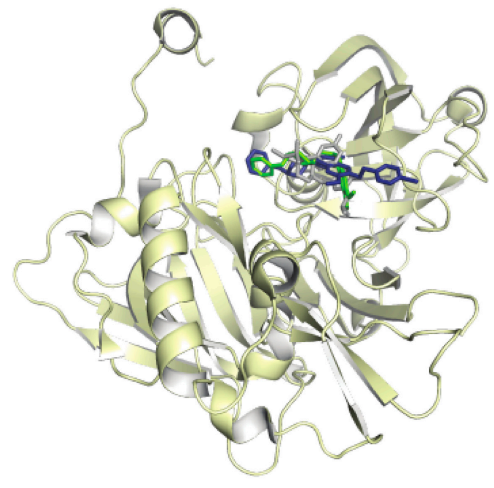

C

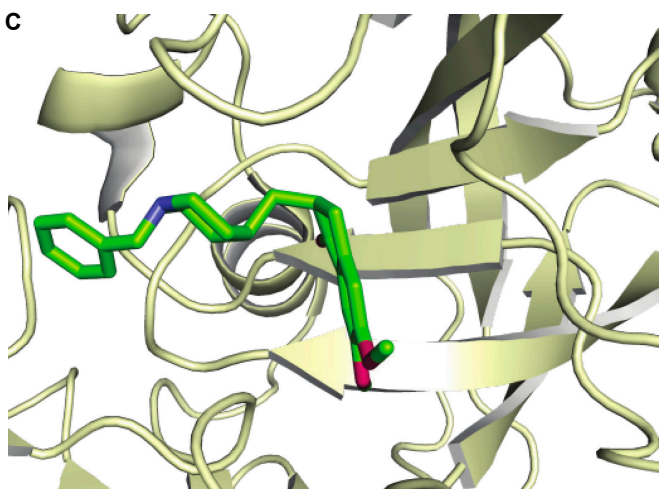

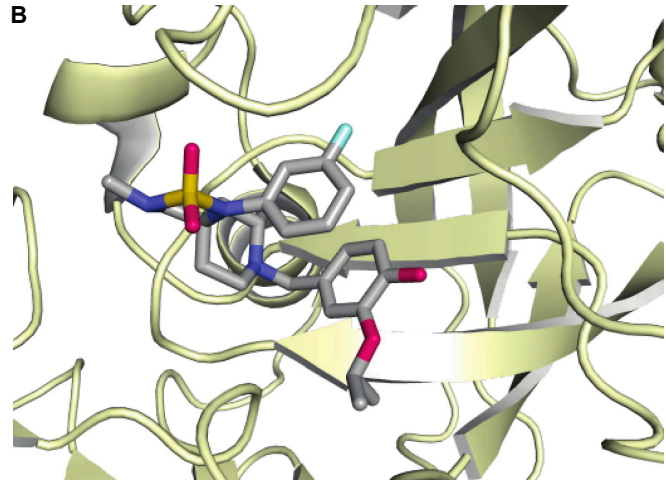

B

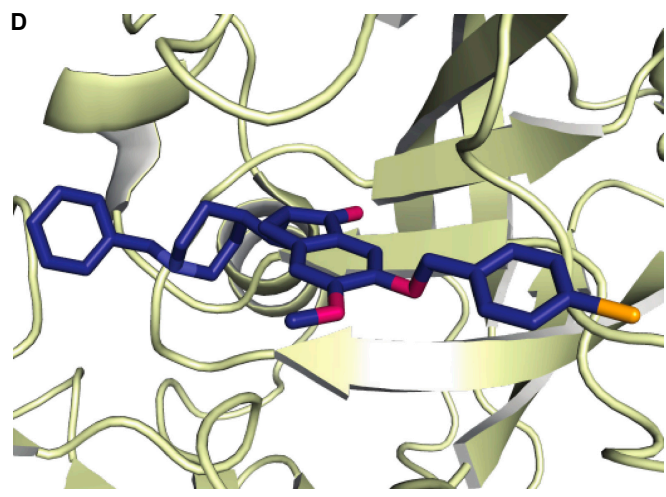

Figure 1. Molecular docking showing the overlay of donepezil (green) and compound $\mathbf{8 1}$ (navy blue) with the known BACE1 inhibitor (gray) crystallized with BACE1 (PDB\# 4FM7 [25]), shown as ribbons. Panel A shows the three compounds in the active site of BACE1. Panels B-D show the zoomed-in view of the known inhibitor (B), donepezil (C), and compound 81 (D).

\section{Materials and Methods}

\subsection{General Information}

All chemicals were purchased from Sigma Aldrich (St. Louis, MO, USA), Alfa Aesar (Ward Hill, MA, USA), and AK scientific (Union, CA, USA), and used without further purification. Chemical reactions were monitored by thin layer chromatography (TLC) using Merck (Darmstadt, Germany), Silica gel $60 \mathrm{~F}_{250}$ plates. Visualization was achieved using UV (model UVGL-58, UVP, Upland, CA, USA) light and a ceric molybdate stain $\left(5 \mathrm{~g}\left(\mathrm{NH}_{4}\right)_{2} \mathrm{Ce}\left(\mathrm{NO}_{3}\right)_{6}, 120 \mathrm{~g}\left(\mathrm{NH}_{4}\right)_{6} \mathrm{Mo}_{7} \mathrm{O}_{24} 4 \mathrm{H}_{2} \mathrm{O}, 80 \mathrm{~mL}\right.$ $\mathrm{H}_{2} \mathrm{SO}_{4}, 720 \mathrm{~mL} \mathrm{H}_{2} \mathrm{O}$ ). ${ }^{1} \mathrm{H}$ and ${ }^{13} \mathrm{C}-\mathrm{NMR}$ spectra were recorded at 400 and $100 \mathrm{MHz}$, respectively, on a Varian $400 \mathrm{MHz}$ spectrometer (Varian, Palo Alto, CA, USA), using the indicated deuterated solvents. 
Chemical shifts $(\delta)$ are given in parts per million (ppm). Coupling constants $(\mathrm{J})$ are given in $\mathrm{Hertz}(\mathrm{Hz})$, and conventional abbreviations used for signal shape are as follows: $\mathrm{s}=$ singlet; $\mathrm{d}=\mathrm{doublet}$; $\mathrm{t}=\mathrm{triplet}$; $\mathrm{m}$ = multiplet; $\mathrm{dd}=$ doublet of doublets; $\mathrm{ddd}=$ doublet of doublet of doublets; br s = broad singlet; $\mathrm{dt}=$ doublet of triplets. High-resolution mass spectra were recorded on an AB SCIEX Triple TOF 5600 System (AB SCIEX, Framingham, MA, USA). The purity of the compound was further confirmed to be $\geq 95 \%$ by RP-HPLC (model 1260 Infinity, Agilent, Santa Clara, CA, USA) by using the following method: Flow rate $=0.5 \mathrm{~mL} / \mathrm{min} ; \lambda=254 \mathrm{~nm}$; column $=$ Vydac $201 \mathrm{SP}^{\mathrm{TM}} \mathrm{C} 18,250 \times 4.6 \mathrm{~mm}, 90 \mathrm{~A} 5 \mu \mathrm{m}$; eluents: $\mathrm{A}=\mathrm{H}_{2} \mathrm{O}+0.1 \%$ TFA, $\mathrm{B}=\mathrm{MeCN}$; gradient profile: starting from $5 \% \mathrm{~B}$, increasing from $5 \%$ to $100 \%$ B over $17 \mathrm{~min}$, holding at $100 \%$ for $5 \mathrm{~min}$, decreasing from $100 \%$ to $5 \%$ over $3 \mathrm{~min}$. Prior to each injection, the HPLC column was equilibrated for 5 min with $5 \% \mathrm{~B}$.

\subsection{Synthesis of Compounds $\mathbf{2}-\mathbf{8 v}$}

\subsubsection{3-(4-Hydroxy-3-methoxyphenyl)propanoic acid (2)}

A catalytic amount of $10 \% \mathrm{Pd} / \mathrm{C}(0.43 \mathrm{~g})$ was added to a solution of ferulic acid $(\mathbf{1}, 6.0 \mathrm{~g}, 30.9 \mathrm{mmol})$ in degassed EtOAc $(100 \mathrm{~mL})$. The reaction flask was then sealed with a rubber septum and freed of air. The reaction mixture was stirred at room temperature (RT) overnight under $\mathrm{H}_{2}$ atmosphere. Upon completion, the reaction mixture was filtered through a bed of celite, and concentrated to afford the known compound 2 [26] (6.1 g, quant.) as an off-white solid: ${ }^{1} \mathrm{H}-\mathrm{NMR}\left(400 \mathrm{MHz}, \mathrm{CDCl}_{3}\right.$, which matches the literature [26], Figure S1) $\delta 10.50$ (very br s, $\left.1 \mathrm{H}, \mathrm{CO}_{2} \underline{\mathrm{H}}\right), 6.82(\mathrm{~d}, J=7.6 \mathrm{~Hz}, 1 \mathrm{H}$, aromatic), 6.69 (s, $1 \mathrm{H}$, aromatic), $6.68(\mathrm{~d}, J=7.6 \mathrm{~Hz}, 1 \mathrm{H}$, aromatic), 5.60 (very br s, $1 \mathrm{H}, \mathrm{OH}), 3.85(\mathrm{~s}, 3 \mathrm{H}$, $\left.\mathrm{PhOC}_{3}\right), 2.87\left(\mathrm{t}, J=7.2 \mathrm{~Hz}, 2 \mathrm{H}, \mathrm{PhCH}_{2} \mathrm{CH}_{2} \mathrm{CO}_{2} \mathrm{H}\right), 2.64\left(\mathrm{t}, J=7.2 \mathrm{~Hz}, 2 \mathrm{H}, \mathrm{PhCH}_{2} \underline{\mathrm{CH}}_{2} \mathrm{CO}_{2} \mathrm{H}\right)$.

3.2.2. 6-Hydroxy-5-methoxy-2,3-dihydroinden-1-one (3)

A solution of compound $2(6.3 \mathrm{~g}, 32.1 \mathrm{mmol})$ in methanesulfonic acid (50 mL) was refluxed at $120^{\circ} \mathrm{C}$ for $1 \mathrm{~h}$. After cooling to RT, the reaction mixture was poured into ice-water, stirred for $5 \mathrm{~min}$, and filtered to afford a crude dark brown solid, which was recrystallized from EtOH to afford the known compound 3 [20] $(3.8 \mathrm{~g}, 67 \%)$ as a yellow solid: ${ }^{1} \mathrm{H}-\mathrm{NMR}\left(400 \mathrm{MHz},\left(\mathrm{CD}_{3}\right)_{2} \mathrm{SO}\right.$, which matches the lit. [20], Figure S2) $\delta 9.38(\mathrm{~s}, 1 \mathrm{H}, \mathrm{OH}), 7.03(\mathrm{~s}, 1 \mathrm{H}$, aromatic), 6.89 (s, 1H, aromatic), 3.83 (s, 3H, $\left.\mathrm{OC}_{3}\right), 2.92\left(\mathrm{t}, J=5.6 \mathrm{~Hz}, 2 \mathrm{H}, \mathrm{CH}_{2} \mathrm{CH}_{2} \mathrm{C}=\mathrm{O}\right), 2.49\left(\mathrm{t}, J=5.6 \mathrm{~Hz}, 2 \mathrm{H}, \mathrm{CH}_{2} \underline{\mathrm{CH}}_{2} \mathrm{C}=\mathrm{O}\right)$.

\subsubsection{6-[tert-Butyl(dimethyl)silyl]oxy-5-methoxy-2,3-dihydroinden-1-one (4)}

TBDMSCl (3.2 g, $21.3 \mathrm{mmol})$ was added to a solution of compound $3(1.9 \mathrm{~g}, 10.7 \mathrm{mmol})$, $\operatorname{DMAP}(0.5 \mathrm{~g}, 4.3 \mathrm{mmol})$ and $\mathrm{Et}_{3} \mathrm{~N}(3.0 \mathrm{~mL}, 21.3 \mathrm{mmol})$ in freshly distilled $\mathrm{CH}_{2} \mathrm{Cl}_{2}(100 \mathrm{~mL})$. The reaction mixture was stirred at RT overnight before being quenched with $\mathrm{H}_{2} \mathrm{O}(100 \mathrm{~mL})$. The organic layer was separated, washed with $\mathrm{H}_{2} \mathrm{O}(2 \times 100 \mathrm{~mL})$ and brine $(100 \mathrm{~mL})$, dried over anhydrous $\mathrm{Mg}_{2} \mathrm{SO}_{4}$, filtered, and concentrated under reduced pressure to afford a crude dark brown solid, which was purified by flash column chromatography $\left(\mathrm{SiO}_{2}\right.$ gel, pure hexanes to hexanes:EtOAc/3:1, $\mathrm{R}_{\mathrm{f}} 0.44$ in Hexanes:EtOAc/3:1) to yield a brown solid, which was further triturated in hexanes to give compound $4(2.8 \mathrm{~g}, 90 \%)$ as a white solid: ${ }^{1} \mathrm{H}-\mathrm{NMR}\left(400 \mathrm{MHz}, \mathrm{CDCl}_{3}\right.$, Figure S3) $\delta 7.17$ (s, 1H, aromatic), $6.84(\mathrm{~s}, 1 \mathrm{H}$, aromatic), 3.87 (s, 3H, $\mathrm{PhOCH}_{3}$ ), 3.02 (app. $\mathrm{t}, J=5.6 \mathrm{~Hz}, 2 \mathrm{H}, \mathrm{CH}_{2} \mathrm{CH}_{2} \mathrm{C}=\mathrm{O}$ ), 2.64 (app. $\mathrm{t}, J=5.6 \mathrm{~Hz}, 2 \mathrm{H}$, $\left.\mathrm{CH}_{2} \mathrm{CH}_{2} \mathrm{C}=\mathrm{O}\right), 0.98\left(\mathrm{~s}, 9 \mathrm{H}, \mathrm{SiC}\left(\mathrm{CH}_{3}\right)_{3}\right), 0.14\left(\mathrm{~s}, 6 \mathrm{H}, \mathrm{Si}\left(\mathrm{CH}_{3}\right)_{2}\right) ;{ }^{13} \mathrm{C}-\mathrm{NMR}\left(100 \mathrm{MHz}, \mathrm{CDCl}_{3}\right.$, Figure S4) $\delta 205.7(\mathrm{C}=\mathrm{O}), 157.5(\mathrm{C}), 150.9(\mathrm{C}), 145.2(\mathrm{C}), 130.0(\mathrm{C}), 114.1(\mathrm{CH}), 107.8(\mathrm{CH}), 55.6\left(\mathrm{CH}_{3}\right), 36.6\left(\mathrm{CH}_{2}\right)$, $25.62\left(\mathrm{CH}_{3}\right.$, three carbons), $25.56\left(\mathrm{CH}_{2}\right), 18.4(\mathrm{C}),-4.7\left(\mathrm{CH}_{3}\right.$, two carbons); $m / z$ calcd. for $\mathrm{C}_{16} \mathrm{H}_{25} \mathrm{O}_{3} \mathrm{Si}^{+}$ $[\mathrm{M}+\mathrm{H}]^{+}$293.1567; found 293.1563.

\subsection{4. (E)-2-[(1-Benzylpiperidin-4-yl)methylene]-6-hydroxy-5-methoxy-2,3-dihydroinden-1-one (6)}

To a solution of compound $4(1.00 \mathrm{~g}, 3.42 \mathrm{mmol})$ and $N$-benzylpiperidine-4-carboxaldehyde (5, $0.68 \mathrm{~mL}, 3.42 \mathrm{mmol})$ in $\mathrm{EtOH}(10 \mathrm{~mL})$ was added $\mathrm{KOH}(0.5 \mathrm{~g})$, and the mixture was refluxed at $65^{\circ} \mathrm{C}$. After $1 \mathrm{~h}$, the reaction was analyzed by TLC $\left(\mathrm{CH}_{2} \mathrm{Cl}_{2}: \mathrm{MeOH} / 19: 1, \mathrm{R}_{\mathrm{f}} 0.30\right.$ in $\left.\mathrm{CH}_{2} \mathrm{Cl}_{2}: \mathrm{MeOH} / 19: 1\right)$. 
The reaction mixture was concentrated under reduced pressure to give a crude yellow solid, which was re-dissolved in $\mathrm{H}_{2} \mathrm{O}(10 \mathrm{~mL}) .1 \mathrm{~N}$ aqueous $\mathrm{HCl}$ was then slowly added until $\mathrm{pH} 5$ to yield a yellow precipitate, which was recrystallized in MeCN to afford compound $6(0.81 \mathrm{~g}, 65 \%)$ as a yellow solid: ${ }^{1} \mathrm{H}-\mathrm{NMR}\left(400 \mathrm{MHz}, \mathrm{CDCl}_{3}\right.$, Figure S5) $\delta 7.32-7.24(\mathrm{~m}, 6 \mathrm{H}$, aromatic), 6.87 (s, 1H, aromatic), 6.63 (d, $J=10.0 \mathrm{~Hz}, 1 \mathrm{H}, \mathrm{C}=\mathrm{CH}), 5.70($ br s, $1 \mathrm{H}, \mathrm{OH}), 3.98\left(\mathrm{~s}, 3 \mathrm{H}, \mathrm{OCH}_{3}\right), 3.56(\mathrm{~s}, 2 \mathrm{H}), 3.51(\mathrm{~s}, 2 \mathrm{H}), 2.91(\mathrm{~d}$, $J=11.6 \mathrm{~Hz}, 2 \mathrm{H}), 2.30(\mathrm{~m}, 1 \mathrm{H}), 2.04(\mathrm{t}, J=11.6 \mathrm{~Hz}, 2 \mathrm{H}), 1.70-1.60(\mathrm{~m}, 4 \mathrm{H}) ; 13 \mathrm{C}-\mathrm{NMR}\left(100 \mathrm{MHz}, \mathrm{CDCl}_{3}\right.$, Figure S6) $\delta 192.6(\mathrm{C}=\mathrm{O}), 152.6(\mathrm{C}), 145.8(\mathrm{C}), 143.4(\mathrm{C}), 139.9(\mathrm{C}), 138.2(\mathrm{C}), 135.5(\mathrm{CH}), 132.5(\mathrm{CH})$, 129.2 (CH, two carbons), 128.2 (CH, two carbons), $127.0(\mathrm{C}), 108.7(\mathrm{CH}), 106.8(\mathrm{CH}), 63.5\left(\mathrm{CH}_{2}\right)$, $56.2\left(\mathrm{CH}_{3}\right), 53.1\left(\mathrm{CH}_{2}\right.$, two carbons $), 37.2\left(\mathrm{CH}_{2}\right), 31.2\left(\mathrm{CH}_{2}\right.$, two carbons $), 29.5(\mathrm{CH}) ; \mathrm{m} / z$ calcd. for $\mathrm{C}_{23} \mathrm{H}_{26} \mathrm{NO}_{3}{ }^{+}[\mathrm{M}+\mathrm{H}]^{+}$364.1907; found 364.1909.

\subsubsection{2-[(1-Benzylpiperidin-4-yl)methyl]-6-hydroxy-5-methoxy-2,3-dihydroinden-1-one (7)}

To a solution of compound 6 (101 mg, $0.28 \mathrm{mmol})$ in degassed THF $(2.5 \mathrm{~mL}), 10 \% \mathrm{Pd} / \mathrm{C}$ was added (wet support, Sigma 520829-10G, $10 \mathrm{mg}$ ). The reaction flask was then sealed with a rubber septum and freed of air. Thioanisole $\left(14.2 \times 10^{-7} \mathrm{~mL}\right.$, obtained using $5 \mu \mathrm{L}$ of a stock solution comprising $14.2 \mu \mathrm{L}$ of thioanisole in $50 \mathrm{~mL}$ of anhydrous THF) was added, and the reaction mixture was stirred at RT overnight under $\mathrm{H}_{2}$ atmosphere. Upon completion, the reaction mixture was filtered through a bed of celite, and concentrated to yield the known compound 7 (96 $\mathrm{mg}, 94 \%)$ as a yellow solid: ${ }^{1} \mathrm{H}-\mathrm{NMR}\left(400 \mathrm{MHz}, \mathrm{CDCl}_{3}\right.$, Figure S7) $\delta 7.30-7.20$ (m, 6H, aromatic), 6.82 (s, 1H, aromatic), 3.96 (s, $\left.3 \mathrm{H}, \mathrm{OCH}_{3}\right), 3.49\left(\mathrm{~s}, 2 \mathrm{H}, \mathrm{NCH}_{2} \mathrm{Ph}\right), 3.20\left(\mathrm{dd}, J_{1}=18.0 \mathrm{~Hz}, J_{2}=7.6 \mathrm{~Hz}, 1 \mathrm{H}\right), 2.87(\mathrm{~m}, 2 \mathrm{H}), 2.66(\mathrm{dt}$, $\left.J_{1}=13.6 \mathrm{~Hz}, J_{2}=3.6 \mathrm{~Hz}, 2 \mathrm{H}\right), 1.98-1.82(\mathrm{~m}, 3 \mathrm{H}), 1.72-1.63(\mathrm{~m}, 2 \mathrm{H}), 1.48(\mathrm{~m}, 1 \mathrm{H}), 1.39-1.24(\mathrm{~m}, 3 \mathrm{H})$; 13C-NMR (100 MHz, $\mathrm{CDCl}_{3}$, Figure S8) $\delta 207.8(\mathrm{C}=\mathrm{O}), 152.9(\mathrm{C}), 147.6(\mathrm{C}), 145.8(\mathrm{C}), 138.3(\mathrm{C}), 130.0(\mathrm{C})$, $129.3\left(\mathrm{CH}\right.$, two carbons), $128.1\left(\mathrm{CH}\right.$, two carbons), $126.9(\mathrm{CH}), 108.1(\mathrm{CH}), 106.9(\mathrm{CH}), 63.4\left(\mathrm{CH}_{2}\right)$, $56.2\left(\mathrm{CH}_{3}\right), 53.7\left(\mathrm{CH}_{2}\right.$, two carbons), $45.3(\mathrm{CH}), 38.7\left(\mathrm{CH}_{2}\right), 34.4\left(\mathrm{CH}_{2}\right), 33.4\left(\mathrm{CH}_{2}\right), 32.9\left(\mathrm{CH}_{2}\right), 31.7(\mathrm{CH})$; $m / z$ calcd. for $\mathrm{C}_{23} \mathrm{H}_{28} \mathrm{NO}_{3}{ }^{+}[\mathrm{M}+\mathrm{H}]^{+}$366.2064; found 366.2065. The purity of the compound was further confirmed by RP-HPLC: $\mathrm{R}_{\mathrm{t}}=17.17 \mathrm{~min}(96 \%$; Figure S9).

\subsection{6. tert-Butyl N-(3-chloropropyl)carbamate (Boc-protected 3-chloropropylamine).}

A solution of $\mathrm{NaHCO}_{3}(5.9 \mathrm{~g}, 70.8 \mathrm{mmol})$ in $\mathrm{H}_{2} \mathrm{O}(15 \mathrm{~mL})$ was slowly added to a mixture of 3-chloropropylamine hydrochloride $(1.0 \mathrm{~g}, 7.69 \mathrm{mmol}), \mathrm{Boc}_{2} \mathrm{O}(3.0 \mathrm{~g}, 13.8 \mathrm{mmol})$ and 1,4-dioxane $(10 \mathrm{~mL})$. The resulting mixture was stirred at $60^{\circ} \mathrm{C}$ for $3 \mathrm{~h}$. The reaction mixture was then diluted with $\mathrm{H}_{2} \mathrm{O}$, and extracted with EtOAc $(3 \times)$. The combined organic layers were washed with $\mathrm{H}_{2} \mathrm{O}(3 \times)$ and brine $(3 \times)$, dried over anhydrous $\mathrm{MgSO}_{4}$, filtered, and concentrated under reduced pressure. The crude product obtained was purified by column chromatography $\left(\mathrm{SiO}_{2}\right.$ gel, hexanes:EtOAc/5:1; $\mathrm{R}_{\mathrm{f}} 0.31$ in hexanes:EtOAc/5:1) to yield the known compound tert-butyl $N$-(3-chloropropyl)carbamate [27] (0.55 g, $36 \%$ ) as a colorless oil: ${ }^{1} \mathrm{H}-\mathrm{NMR}\left(400 \mathrm{MHz}, \mathrm{CDCl}_{3}\right.$, which matches the lit. [27], Figure S10) $\delta 4.65$ (br s, 1H, $\underline{\mathrm{H}}$ ), $3.56\left(\mathrm{t}, J=6.4 \mathrm{~Hz}, 2 \mathrm{H}, \mathrm{ClCH}_{2} \mathrm{CH}_{2}\right), 3.26$ (q, J=6.4 Hz, 2H, $\left.\mathrm{CH}_{2} \mathrm{CH}_{2} \mathrm{NHBoc}\right), 1.94$ (p, $\left.J=6.4 \mathrm{~Hz}, 2 \mathrm{H}, \mathrm{CH}_{2} \mathrm{CH}_{2} \mathrm{CH}_{2}\right), 1.42\left(\mathrm{~s}, 9 \mathrm{H}, \mathrm{C}\left(\mathrm{CH}_{3}\right)_{3}\right)$.

3.2.7. 2-[(1-Benzylpiperidin-4-yl)methyl]-6-[(3-tert-butyl-N-propylcarbamate)oxy]-5-methoxy-2,3dihydroinden-1-one (Boc-protected compound 8a)

A solution of compound 7 (215 mg, $0.59 \mathrm{mmol})$, tert-butyl $\mathrm{N}$-(3-chloropropyl)carbamate (228 $\mathrm{mg}$, $1.18 \mathrm{mmol}), \mathrm{Cs}_{2} \mathrm{CO}_{3}(575 \mathrm{mg}, 1.76 \mathrm{mmol})$, and TBAI $(109 \mathrm{mg}, 0.29 \mathrm{mmol})$ in anhydrous DMF $(5 \mathrm{~mL})$ was stirred at RT overnight. The reaction mixture was then diluted with $\mathrm{H}_{2} \mathrm{O}$, and extracted with EtOAc $(3 \times)$. The combined organic layers were washed with $\mathrm{H}_{2} \mathrm{O}(3 \times)$ and brine $(3 \times)$, dried over anhydrous $\mathrm{MgSO}_{4}$, filtered, and concentrated under reduced pressure. The crude product obtained was purified by column chromatography ( $\mathrm{SiO}_{2}$ gel, pure $\mathrm{CH}_{2} \mathrm{Cl}_{2}$ to $\mathrm{CH}_{2} \mathrm{Cl}_{2}: \mathrm{MeOH} / 19: 1 ; \mathrm{R}_{\mathrm{f}} 0.55$ in $\mathrm{CH}_{2} \mathrm{Cl}_{2}: \mathrm{MeOH} / 9: 1$ ) to yield 2-[(1-benzylpiperidin-4-yl)methyl]-6-[(3-tert-butyl-N-propylcarbamate)oxy]-5-methoxy-2,3-dihydroinden1-one (276 mg, 90\%) as a white foam: ${ }^{1} \mathrm{H}-\mathrm{NMR}\left(400 \mathrm{MHz}, \mathrm{CDCl}_{3}\right.$, Figure S11) $\delta 7.30-7.20$ (m, 5H, aromatic), 7.11 (s, 1H, aromatic), $6.82(\mathrm{~s}, 1 \mathrm{H}$, aromatic), 5.52 (very br t, $1 \mathrm{H}, \mathrm{NH}), 4.08\left(\mathrm{t}, J=5.6 \mathrm{~Hz}, 2 \mathrm{H}, \mathrm{OC}_{2} \mathrm{CH}_{2}\right)$, 
$3.93\left(\mathrm{~s}, 3 \mathrm{H}, \mathrm{OCH}_{3}\right), 3.49\left(\mathrm{~s}, 2 \mathrm{H}, \mathrm{NCH}_{2} \mathrm{Ph}\right), 3.34\left(\mathrm{q}, J=5.2 \mathrm{~Hz}, 2 \mathrm{H}, \mathrm{CH}_{2} \mathrm{CH}_{2} \mathrm{NHBoc}\right), 3.20$ (dd, $J_{1}=17.6 \mathrm{~Hz}$, $\left.J_{2}=8.0 \mathrm{~Hz}, 1 \mathrm{H}\right), 2.88(\mathrm{~m}, 2 \mathrm{H}), 2.67(\mathrm{~m}, 2 \mathrm{H}), 2.02-1.85(\mathrm{~m}, 5 \mathrm{H}), 1.72-1.62(\mathrm{~m}, 2 \mathrm{H}), 1.44\left(\mathrm{~s}, 9 \mathrm{H}, \mathrm{C}\left(\mathrm{CH}_{3}\right)_{3}\right)$, 1.36-1.02 (m, 4H); 13C-NMR (100 MHz, $\mathrm{CDCl}_{3}$, Figure S12) \& $207.7(\mathrm{C}=\mathrm{O}), 156.0(\mathrm{CH}), 155.6(\mathrm{C}=\mathrm{O})$, $148.9(\mathrm{C}), 148.4(\mathrm{C}), 138.3(\mathrm{C}), 129.2(\mathrm{CH}$, two carbons), $128.1(\mathrm{CH}$, three carbons), $126.9(\mathrm{C}), 107.4(\mathrm{CH})$, 105.3 (CH), $78.9(\mathrm{C}), 68.3\left(\mathrm{CH}_{2}\right), 63.4\left(\mathrm{CH}_{2}\right), 56.0\left(\mathrm{CH}_{3}\right), 53.74\left(\mathrm{CH}_{2}\right), 53.72\left(\mathrm{CH}_{2}\right), 45.4(\mathrm{CH}), 39.1\left(\mathrm{CH}_{2}\right)$, $38.7\left(\mathrm{CH}_{2}\right), 34.4\left(\mathrm{CH}_{2}\right), 33.4\left(\mathrm{CH}_{2}\right), 33.0\left(\mathrm{CH}_{2}\right), 31.7(\mathrm{CH}), 29.0\left(\mathrm{CH}_{2}\right), 28.5\left(\mathrm{CH}_{3}\right.$, three carbons); $\mathrm{m} / z$ calcd. for $\mathrm{C}_{31} \mathrm{H}_{43} \mathrm{~N}_{2} \mathrm{O}_{5}^{+}[\mathrm{M}+\mathrm{H}]^{+}$523.3166; found 523.3131.

3.2.8. 6-[(3-Aminopropyl)oxy]-2-[(1-benzylpiperidin-4-yl)methyl]-5-methoxy-2,3-dihydroinden-1one $(8 \mathbf{a})$

A solution of the 2-[(1-benzylpiperidin-4-yl)methyl]-6-[(3-tert-butyl- $N$-propylcarbamate)oxy]-5methoxy-2,3-dihydroinden-1-one (100 mg, $0.19 \mathrm{mmol})$ in $\mathrm{CH}_{2} \mathrm{Cl}_{2}(2 \mathrm{~mL})$ was treated with TFA (1 mL) and allowed to stir at RT for $5 \mathrm{~min}$. The reaction was then quenched by addition of saturated aqueous $\mathrm{NaHCO}_{3}$ and the resulting mixture was extracted with $\mathrm{CH}_{2} \mathrm{Cl}_{2}(3 \times)$. The combined organic layers were washed with brine, dried over anhydrous $\mathrm{MgSO}_{4}$, filtered, and concentrated under reduced pressure. The crude product obtained was purified by column chromatography $\left(\mathrm{SiO}_{2}\right.$ gel, pure $\mathrm{CH}_{2} \mathrm{Cl}_{2}$ to $\mathrm{CH}_{2} \mathrm{Cl}_{2}: \mathrm{MeOH} / 19: 1 ; \mathrm{R}_{\mathrm{f}} 0.12$ in $\left.\mathrm{CH}_{2} \mathrm{Cl}_{2}: \mathrm{MeOH} / 9: 1\right)$ to yield compound $8 \mathrm{a}$ ( $53 \mathrm{mg}, 65 \%$ ) as a white solid: ${ }^{1} \mathrm{H}-\mathrm{NMR}\left(400 \mathrm{MHz}, \mathrm{CDCl}_{3}\right.$, Figure S13) $\delta 7.28-7.18$ (m, 5H, aromatic), 7.13 (s, $1 \mathrm{H}$, aromatic), $6.81\left(\mathrm{~s}, 1 \mathrm{H}\right.$, aromatic), $4.09\left(\mathrm{t}, J=6.4 \mathrm{~Hz}, 2 \mathrm{H}, \mathrm{OCH}_{2} \mathrm{CH}_{2}\right), 3.90\left(\mathrm{~s}, 3 \mathrm{H}, \mathrm{OCH}_{3}\right), 3.47\left(\mathrm{~s}, 2 \mathrm{H}, \mathrm{NCH}_{2} \mathrm{Ph}\right)$, $3.19\left(\mathrm{dd}, J_{1}=17.6 \mathrm{~Hz}, J_{2}=8.0 \mathrm{~Hz}, 1 \mathrm{H}\right), 2.84-2.90(\mathrm{~m}, 4 \mathrm{H}), 2.67(\mathrm{~m}, 2 \mathrm{H}), 1.99-1.84(\mathrm{~m}, 7 \mathrm{H}), 1.72-1.58$ $(\mathrm{m}, 2 \mathrm{H}), 1.45(\mathrm{~m}, 1 \mathrm{H}), 1.38-1.23(\mathrm{~m}, 3 \mathrm{H})$; 13C-NMR (100 MHz, $\mathrm{CDCl}_{3}$, Figure S14) $\delta 207.8(\mathrm{C}=\mathrm{O})$, $155.7(\mathrm{C}), 148.73(\mathrm{C}), 148.66(\mathrm{C}), 138.4(\mathrm{C}), 129.2(\mathrm{CH}$, three carbons), $128.1(\mathrm{CH}$, two carbons), $126.9(\mathrm{C})$, $107.5(\mathrm{CH}), 105.6(\mathrm{CH}), 67.4\left(\mathrm{CH}_{2}\right), 63.4\left(\mathrm{CH}_{2}\right), 56.2\left(\mathrm{CH}_{3}\right), 53.76\left(\mathrm{CH}_{2}\right), 53.74\left(\mathrm{CH}_{2}\right), 45.4(\mathrm{CH})$, $39.4\left(\mathrm{CH}_{2}\right), 38.7\left(\mathrm{CH}_{2}\right), 34.4\left(\mathrm{CH}_{2}\right), 33.3\left(\mathrm{CH}_{2}\right), 33.0\left(\mathrm{CH}_{2}\right), 32.5\left(\mathrm{CH}_{2}\right), 31.8(\mathrm{CH}) ; \mathrm{m} / \mathrm{z}$ calcd. for $\mathrm{C}_{26} \mathrm{H}_{35} \mathrm{~N}_{2} \mathrm{O}_{3}{ }^{+}[\mathrm{M}+\mathrm{H}]^{+} 423.2642$; found 423.2656 . The purity of the compound was further confirmed by RP-HPLC: $R_{\mathrm{t}}=15.86 \mathrm{~min}$ (96\%; Figure S15).

\subsection{9. tert-Butyl N-(2-chloroethyl)carbamate.}

A solution of $\mathrm{NaHCO}_{3}(6.7 \mathrm{~g}, 79.3 \mathrm{mmol})$ in $\mathrm{H}_{2} \mathrm{O}(15 \mathrm{~mL})$ was slowly added to a mixture of 2-chloroethylamine hydrochloride $(1.0 \mathrm{~g}, 8.6 \mathrm{mmol}), \mathrm{Boc}_{2} \mathrm{O}(3.4 \mathrm{~g}, 15.5 \mathrm{mmol})$ and 1,4-dioxane $(10 \mathrm{~mL})$ at $0{ }^{\circ} \mathrm{C}$. The resulting mixture was allowed to warm to $\mathrm{RT}$ and was stirred overnight. The reaction mixture was then diluted with $\mathrm{H}_{2} \mathrm{O}$, and extracted with $\mathrm{CH}_{2} \mathrm{Cl}_{2}(3 \times)$. The combined organic layers were washed with $\mathrm{H}_{2} \mathrm{O}(3 \times)$ and brine $(3 \times)$, dried over anhydrous $\mathrm{MgSO}_{4}$, filtered, and concentrated under reduced pressure. The crude product obtained was purified by column chromatography $\left(\mathrm{SiO}_{2}\right.$ gel, Hexanes:EtOAc/9:1; $\mathrm{R}_{\mathrm{f}} 0.55$ in hexanes:EtOAc/4:1) to yield the known compound tert-butyl $\mathrm{N}$-(2-chloroethyl)carbamate [28] $(1.25 \mathrm{~g}, 83 \%)$ as a colorless oil: ${ }^{1} \mathrm{H}-\mathrm{NMR}$ (400 MHz, $\mathrm{CDCl}_{3}$, which matches the lit. [28], Figure S16) $\delta 4.94$ (br s, $\left.1 \mathrm{H}, \mathrm{NH}\right), 3.57(\mathrm{t}, J=6.0$ $\left.\mathrm{Hz}, 2 \mathrm{H}, \mathrm{ClCH}_{2} \mathrm{CH}_{2}\right), 3.44\left(\mathrm{q}, J=6.0 \mathrm{~Hz}, 2 \mathrm{H}, \mathrm{CH}_{2} \mathrm{CH}_{2} \mathrm{NHBoc}\right), 1.47\left(\mathrm{~s}, 9 \mathrm{H}, \mathrm{C}\left(\mathrm{CH}_{3}\right)_{3}\right)$.

3.2.10. 2-[(1-Benzylpiperidin-4-yl)methyl]-6-[(3-tert-butyl-N-ethylcarbamate)oxy]-5-methoxy-2,3dihydroinden-1-one (Boc-protected compound $\mathbf{8 b}$ ).

A solution of compound $7(216 \mathrm{mg}, 1.20 \mathrm{mmol}), \mathrm{Cs}_{2} \mathrm{CO}_{3}(196 \mathrm{mg}, 0.60 \mathrm{mmol})$, and TBAI (56 $\mathrm{mg}, 0.15 \mathrm{mmol}$ ) in anhydrous DMF $(5 \mathrm{~mL})$ was stirred at RT overnight. The reaction mixture was then diluted with $\mathrm{H}_{2} \mathrm{O}$, and extracted with EtOAc $(3 \times)$. The combined organic layers were washed with $\mathrm{H}_{2} \mathrm{O}(3 \times)$ and brine $(3 \times)$, dried over anhydrous $\mathrm{MgSO}_{4}$, filtered, and concentrated under reduced pressure. The crude product obtained was purified by column chromatography $\left(\mathrm{SiO}_{2}\right.$ gel, pure $\mathrm{CH}_{2} \mathrm{Cl}_{2}$ to $\mathrm{CH}_{2} \mathrm{Cl}_{2}: \mathrm{MeOH} / 19: 1 ; \mathrm{R}_{\mathrm{f}} 0.48$ in $\left.\mathrm{CH}_{2} \mathrm{Cl}_{2}: \mathrm{MeOH} / 9: 1\right)$ to yield 2-[(1-benzylpiperidin4-yl)methyl]-6-[(3-tert-butyl-N-ethylcarbamate)oxy]-5-methoxy-2,3-dihydroinden-1-one (93 mg, 61\%) as a pale yellow solid: ${ }^{1} \mathrm{H}-\mathrm{NMR}\left(400 \mathrm{MHz}, \mathrm{CDCl}_{3}\right.$, Figure $\left.\mathrm{S17}\right) \delta 7.34-7.20(\mathrm{~m}, 5 \mathrm{H}$, aromatic), $7.14(\mathrm{~s}, 1 \mathrm{H}$, aromatic), $6.83\left(\mathrm{~s}, 1 \mathrm{H}\right.$, aromatic), $5.05(\mathrm{~m}, 1 \mathrm{H}, \mathrm{N} \underline{\mathrm{H}}), 4.05\left(\mathrm{br} \mathrm{t}, 2 \mathrm{H}, \mathrm{OC} \mathrm{CH}_{2}\right), 3.92\left(\mathrm{~s}, 3 \mathrm{H}, \mathrm{OC}_{3}\right), 3.53(\mathrm{~m}$, 
$\left.4 \mathrm{H}, \mathrm{NCH}_{2} \mathrm{Ph}, \mathrm{CH}_{2} \mathrm{CH}_{2} \mathrm{NHBoc}\right), 3.21\left(\mathrm{dd}, J_{1}=17.2 \mathrm{~Hz}, J_{2}=8.4 \mathrm{~Hz}, 1 \mathrm{H}\right), 2.90(\mathrm{~m}, 2 \mathrm{H}), 2.67(\mathrm{~m}, 2 \mathrm{H}), 1.99(\mathrm{~m}$, 2H), $1.88(\mathrm{~m}, 1 \mathrm{H}), 1.69(\mathrm{~m}, 2 \mathrm{H}), 1.43(\mathrm{~m}, 10 \mathrm{H}), 1.37-1.23(\mathrm{~m}, 3 \mathrm{H})$; 13C-NMR (100 MHz, $\mathrm{CDCl}_{3}$, Figure S18) $\delta 207.6(\mathrm{C}=\mathrm{O}), 155.8(\mathrm{C}$ and $\mathrm{C}=\mathrm{O}), 149.2(\mathrm{C}), 148.3(\mathrm{C}), 138.3(\mathrm{C}), 129.3(\mathrm{CH}$, two carbons), $128.1(\mathrm{CH}$, three carbons), $126.9(\mathrm{C}), 107.7(\mathrm{CH}), 106.7(\mathrm{CH}), 79.5(\mathrm{C}), 68.8\left(\mathrm{CH}_{2}\right), 63.4\left(\mathrm{CH}_{2}\right), 56.1\left(\mathrm{CH}_{3}\right), 53.7\left(\mathrm{CH}_{2}\right.$, two carbons), $45.4(\mathrm{CH}), 39.9\left(\mathrm{CH}_{2}\right), 38.7\left(\mathrm{CH}_{2}\right), 34.4\left(\mathrm{CH}_{2}\right), 33.3\left(\mathrm{CH}_{2}\right), 32.9\left(\mathrm{CH}_{2}\right), 31.7(\mathrm{CH}), 28.4\left(\mathrm{CH}_{3}\right.$, three carbons); $m / z$ calcd. for $\mathrm{C}_{30} \mathrm{H}_{41} \mathrm{~N}_{2} \mathrm{O}_{5}{ }^{+}[\mathrm{M}+\mathrm{H}]^{+}$509.3010; found 509.3025.

3.2.11. 6-[(3-Aminoethyl)oxy]-2-[(1-benzylpiperidin-4-yl)methyl]-5-methoxy-2,3-dihydroinden-1one $(\mathbf{8 b})$

A solution of 2-[(1-benzylpiperidin-4-yl)methyl]-6-[(3-tert-butyl-N-ethylcarbamate)oxy]-5methoxy-2,3-dihydroinden-1-one ( $83 \mathrm{mg}, 0.16 \mathrm{mmol})$ in $\mathrm{CH}_{2} \mathrm{Cl}_{2}(1 \mathrm{~mL})$ was treated with TFA $(1 \mathrm{~mL})$ and allowed to stir at RT. After $1 \mathrm{~h}$, the reaction was analyzed by TLC $\left(\mathrm{CH}_{2} \mathrm{Cl}_{2}: \mathrm{MeOH} / 9: 1, \mathrm{R}_{\mathrm{f}}\right.$ 0.19 in $\left.\mathrm{CH}_{2} \mathrm{Cl}_{2}: \mathrm{MeOH} / 9: 1\right)$. The reaction was then quenched by addition of saturated aqueous $\mathrm{NaHCO}_{3}$ and the resulting mixture was extracted with $\mathrm{CH}_{2} \mathrm{Cl}_{2}(3 \times)$. The combined organic layers were washed with brine, dried over anhydrous $\mathrm{MgSO}_{4}$, filtered, and concentrated under reduced pressure to yield compound $\mathbf{8 b}(62 \mathrm{mg}, 93 \%)$ as a white solid: ${ }^{1} \mathrm{H}-\mathrm{NMR}\left(400 \mathrm{MHz}, \mathrm{CDCl}_{3}\right.$, Figure S19) $\delta 7.32-7.20(\mathrm{~m}, 5 \mathrm{H}$, aromatic), $7.15(\mathrm{~s}, 1 \mathrm{H}$, aromatic), $6.83(\mathrm{~s}, 1 \mathrm{H}$, aromatic), $4.03(\mathrm{t}, J=5.2 \mathrm{~Hz}$, $\left.2 \mathrm{H}, \mathrm{OC}_{2} \mathrm{CH}_{2}\right), 3.92\left(\mathrm{~s}, 3 \mathrm{H}, \mathrm{OC}_{3}\right), 3.57\left(\mathrm{~s}, 2 \mathrm{H}, \mathrm{NC}_{2} \mathrm{Ph}\right), 3.21\left(\mathrm{dd}, J_{1}=17.6 \mathrm{~Hz}, J_{2}=8.0 \mathrm{~Hz}, 1 \mathrm{H}\right)$, $3.11\left(\mathrm{t}, J=5.2 \mathrm{~Hz}, 2 \mathrm{H}, \mathrm{OCH}_{2} \mathrm{CH}_{2}\right), 2.95(\mathrm{~m}, 2 \mathrm{H}), 2.67(\mathrm{~m}, 2 \mathrm{H}), 2.03(\mathrm{~m}, 2 \mathrm{H}), 1.89(\mathrm{~m}, 1 \mathrm{H}), 1.71(\mathrm{~m}$, $2 \mathrm{H}), 1.52(\mathrm{~m}, 2 \mathrm{H}), 1.44-1.23(\mathrm{~m}, 4 \mathrm{H}) ;{ }^{13} \mathrm{C}-\mathrm{NMR}\left(100 \mathrm{MHz}, \mathrm{CDCl}_{3}\right.$, Figure S20) $\delta 207.7(\mathrm{C}=\mathrm{O}), 155.8(\mathrm{C})$, $148.9(\mathrm{C}), 148.6(\mathrm{C}), 138.1(\mathrm{C}), 129.3(\mathrm{CH}$, four carbons), $129.2(\mathrm{CH}), 128.1(\mathrm{CH}$, two carbons), $127.0(\mathrm{C})$, $107.6(\mathrm{CH}), 106.0(\mathrm{CH}), 71.1\left(\mathrm{CH}_{2}\right), 63.3\left(\mathrm{CH}_{2}\right), 56.1\left(\mathrm{CH}_{3}\right), 53.68\left(\mathrm{CH}_{2}\right), 53.65\left(\mathrm{CH}_{2}\right), 45.4(\mathrm{CH})$, $41.2\left(\mathrm{CH}_{2}\right), 38.6\left(\mathrm{CH}_{2}\right), 34.3\left(\mathrm{CH}_{2}\right), 33.3\left(\mathrm{CH}_{2}\right), 32.8\left(\mathrm{CH}_{2}\right), 31.7(\mathrm{CH}) ; \mathrm{m} / z$ calcd. for $\mathrm{C}_{25} \mathrm{H}_{33} \mathrm{~N}_{2} \mathrm{O}_{3}{ }^{+}$ $[\mathrm{M}+\mathrm{H}]^{+} 409.2486$; found 409.2496 . The purity of the compound was further confirmed by RP-HPLC: $R_{\mathrm{t}}=15.74 \mathrm{~min}$ (95\%; Figure $\left.\mathrm{S} 21\right)$.

\subsubsection{2-[(1-Benzylpiperidin-4-yl)methyl]-5-methoxy-6-propoxy-2,3-dihydroinden-1-one (8c).}

A solution of compound $7(50 \mathrm{mg}, 0.14 \mathrm{mmol})$ and $\mathrm{K}_{2} \mathrm{CO}_{3}(95 \mathrm{mg}, 0.68 \mathrm{mmol})$ in anhydrous DMF $(5 \mathrm{~mL})$ was treated with 1-bromopropane $(0.06 \mathrm{~mL}, 0.68 \mathrm{mmol})$, and the resulting mixture was stirred at RT overnight. The reaction mixture was then diluted with $\mathrm{H}_{2} \mathrm{O}$, and extracted with EtOAc $(3 \times)$. The combined organic layers were washed with $\mathrm{H}_{2} \mathrm{O}(3 \times)$ and brine $(3 \times)$, dried over anhydrous $\mathrm{MgSO}_{4}$, filtered, and concentrated under reduced pressure. The crude product obtained was purified by column chromatography $\left(\mathrm{SiO}_{2}\right.$ gel, pure $\mathrm{CH}_{2} \mathrm{Cl}_{2}$ to $\mathrm{CH}_{2} \mathrm{Cl}_{2}: \mathrm{MeOH} / 19: 1 ; \mathrm{R}_{\mathrm{f}} 0.38$ in $\left.\mathrm{CH}_{2} \mathrm{Cl}_{2}: \mathrm{MeOH} / 19: 1\right)$ to yield compound $8 \mathrm{c}(53 \mathrm{mg}$, $95 \%)$ as an off-white solid: ${ }^{1} \mathrm{H}-\mathrm{NMR}(400 \mathrm{MHz}$, $\mathrm{CDCl}_{3}$, Figure S22) $\delta 7.32-7.20(\mathrm{~m}, 5 \mathrm{H}$, aromatic), $7.13(\mathrm{~s}, 1 \mathrm{H}$, aromatic), $6.82(\mathrm{~s}, 1 \mathrm{H}$, aromatic), $3.98(\mathrm{t}$, $\left.J=6.8 \mathrm{~Hz}, 2 \mathrm{H}, \mathrm{CH}_{3} \mathrm{CH}_{2} \mathrm{C}_{2} \mathrm{OAr}\right), 3.92\left(\mathrm{~s}, 3 \mathrm{H}, \mathrm{OCH}_{3}\right), 3.51\left(\mathrm{~s}, 2 \mathrm{H}, \mathrm{NC}_{2} \mathrm{Ph}\right), 3.20\left(\mathrm{dd}, J_{1}=17.6 \mathrm{~Hz}\right.$, $\left.J_{2}=8.4 \mathrm{~Hz}, 1 \mathrm{H}\right), 2.90(\mathrm{~m}, 2 \mathrm{H}), 2.66\left(\mathrm{dt}, J_{1}=14.0 \mathrm{~Hz}, J_{2}=3.6 \mathrm{~Hz}, 2 \mathrm{H}\right), 1.98(\mathrm{~m}, 2 \mathrm{H}), 1.90(\mathrm{~m}, 1 \mathrm{H})$, 1.85 (sextet, $\left.J=7.2 \mathrm{~Hz}, 2 \mathrm{H}, \mathrm{CH}_{3} \mathrm{CH}_{2} \mathrm{CH}_{2} \mathrm{OAr}\right), 1.73-1.64(\mathrm{~m}, 2 \mathrm{H}), 1.49(\mathrm{~m}, 1 \mathrm{H}), 1.40-1.24(\mathrm{~m}, 3 \mathrm{H}), 1.02(\mathrm{t}$, $\left.J=7.2 \mathrm{~Hz}, 3 \mathrm{H}, \mathrm{CH}_{3} \mathrm{CH}_{2} \mathrm{CH}_{2} \mathrm{OAr}\right) ;{ }^{13} \mathrm{C}-\mathrm{NMR}\left(100 \mathrm{MHz}, \mathrm{CDCl}_{3}\right.$, Figure S23) $\delta 207.8(\mathrm{C}=\mathrm{O}), 155.8(\mathrm{C})$, $148.9(\mathrm{C}), 148.5(\mathrm{C}), 129.3(\mathrm{CH}$, two carbons), $129.2(\mathrm{C}), 128.2(\mathrm{CH}$, three carbons), $127.1(\mathrm{C}), 107.5(\mathrm{CH})$, $105.5(\mathrm{CH}), 70.5\left(\mathrm{CH}_{2}\right), 63.2\left(\mathrm{CH}_{2}\right), 56.2\left(\mathrm{CH}_{3}\right), 53.7\left(\mathrm{CH}_{2}\right), 53.6\left(\mathrm{CH}_{2}\right), 45.4(\mathrm{CH}), 38.6\left(\mathrm{CH}_{2}\right), 34.3$ $\left(\mathrm{CH}_{2}\right), 33.3\left(\mathrm{CH}_{2}\right), 32.7\left(\mathrm{CH}_{2}\right), 31.6(\mathrm{CH}), 22.2\left(\mathrm{CH}_{2}\right), 10.3\left(\mathrm{CH}_{3}\right) ; \mathrm{m} / z$ calcd. for $\mathrm{C}_{26} \mathrm{H}_{34} \mathrm{NO}_{3}{ }^{+}[\mathrm{M}+\mathrm{H}]^{+}$ 408.2533; found 408.2524. The purity of the compound was further confirmed by RP-HPLC: $R_{\mathrm{t}}=19.30$ min (96\%; Figure S24).

3.2.13. 2-[(1-Benzylpiperidin-4-yl)methyl]-6-[(chloroethyl)oxy]-5-methoxy-2,3-dihydroinden-1-one (8d)

A solution of compound $7(50 \mathrm{mg}, 0.14 \mathrm{mmol})$ and $\mathrm{K}_{2} \mathrm{CO}_{3}(189 \mathrm{mg}, 1.37 \mathrm{mmol})$ in anhydrous DMF $(5 \mathrm{~mL})$ was treated with 1,2-dichloroethane $(0.11 \mathrm{~mL}, 1.37 \mathrm{mmol})$, and the resulting mixture was stirred at RT overnight. The reaction mixture was then diluted with $\mathrm{H}_{2} \mathrm{O}$, and extracted with 
$\mathrm{CH}_{2} \mathrm{Cl}_{2}(3 \times)$. The combined organic layers were washed with $\mathrm{H}_{2} \mathrm{O}(3 \times)$ and brine $(3 \times)$, dried over anhydrous $\mathrm{MgSO}_{4}$, filtered, and concentrated under reduced pressure. The crude product obtained was purified by column chromatography $\left(\mathrm{SiO}_{2}\right.$ gel, pure $\mathrm{CH}_{2} \mathrm{Cl}_{2}$ to $\mathrm{CH}_{2} \mathrm{Cl}_{2}: \mathrm{MeOH} / 19: 1 ; \mathrm{R}_{\mathrm{f}} 0.38$ in $\left.\mathrm{CH}_{2} \mathrm{Cl}_{2}: \mathrm{MeOH} / 19: 1\right)$ to yield compound $8 \mathrm{~d}(50 \mathrm{mg}, 85 \%)$ as a brown oil: ${ }^{1} \mathrm{H}-\mathrm{NMR}\left(400 \mathrm{MHz}, \mathrm{CDCl}_{3}\right.$, Figure S25) $\delta 7.30-7.20(\mathrm{~m}, 5 \mathrm{H}$, aromatic), $7.14(\mathrm{~s}, 1 \mathrm{H}$, aromatic), $6.84(\mathrm{~s}, 1 \mathrm{H}$, aromatic), $4.25(\mathrm{t}, J=6.0 \mathrm{~Hz}$, $2 \mathrm{H}), 3.91\left(\mathrm{~s}, 3 \mathrm{H}, \mathrm{OCH}_{3}\right), 3.82(\mathrm{t}, J=6.0 \mathrm{~Hz}, 2 \mathrm{H}), 3.49\left(\mathrm{~s}, 2 \mathrm{H}, \mathrm{NCH}_{2} \mathrm{Ph}\right), 3.20\left(\mathrm{dd}, J_{1}=17.6 \mathrm{~Hz}, J_{2}=8.4 \mathrm{~Hz}\right.$, $1 \mathrm{H}), 2.88(\mathrm{~m}, 2 \mathrm{H}), 2.66\left(\mathrm{dt}, J_{1}=14.4 \mathrm{~Hz}, J_{2}=2.8 \mathrm{~Hz}, 2 \mathrm{H}\right), 1.99-1.93(\mathrm{~m}, 2 \mathrm{H}), 1.92-1.85(\mathrm{~m}, 1 \mathrm{H}), 1.72-1.63$ $(\mathrm{m}, 2 \mathrm{H}), 1.47(\mathrm{~m}, 1 \mathrm{H}), 1.40-1.23(\mathrm{~m}, 3 \mathrm{H}) ;{ }^{13} \mathrm{C}-\mathrm{NMR}\left(100 \mathrm{MHz}, \mathrm{CDCl}_{3}\right.$, Figure S26) $\delta 207.6(\mathrm{C}=\mathrm{O})$, $155.9(\mathrm{C}), 149.5(\mathrm{C}), 148.0(\mathrm{C}), 138.1(\mathrm{C}), 129.3(\mathrm{CH}$, two carbons), $129.2(\mathrm{CH}), 128.1(\mathrm{CH}$, two carbons), 127.0 (C), 107.9 (CH), 106.6 (CH), $69.0\left(\mathrm{CH}_{2}\right), 63.3\left(\mathrm{CH}_{2}\right), 56.2\left(\mathrm{CH}_{3}\right), 53.68\left(\mathrm{CH}_{2}\right), 53.65\left(\mathrm{CH}_{2}\right), 45.4(\mathrm{CH})$, $41.4\left(\mathrm{CH}_{2}\right), 38.6\left(\mathrm{CH}_{2}\right), 34.3\left(\mathrm{CH}_{2}\right), 33.3\left(\mathrm{CH}_{2}\right), 32.8\left(\mathrm{CH}_{2}\right), 31.7(\mathrm{CH}) ; \mathrm{m} / z$ calcd. for $\mathrm{C}_{25} \mathrm{H}_{31} \mathrm{ClNO}_{3}{ }^{+}$ $[\mathrm{M}+\mathrm{H}]^{+} 428.1987$; found 428.1984 . The purity of the compound was further confirmed by RP-HPLC: $R_{\mathrm{t}}=18.90$ min (96\%; Figure S27).

3.2.14. 2-[(1-Benzylpiperidin-4-yl)methyl]-6-[(bromoethyl)oxy]-5-methoxy-2,3-dihydroinden-1one (8e)

A solution of compound $7(100 \mathrm{mg}, 0.27 \mathrm{mmol})$ and $\mathrm{K}_{2} \mathrm{CO}_{3}(380 \mathrm{mg}, 2.74 \mathrm{mmol})$ in anhydrous DMF $(5 \mathrm{~mL})$ was treated with 1,2-dibromoethane $(0.24 \mathrm{~mL}, 2.74 \mathrm{mmol})$ and the resulting mixture was stirred at RT overnight. The reaction mixture was then diluted with $\mathrm{H}_{2} \mathrm{O}$, and extracted with $\mathrm{CH}_{2} \mathrm{Cl}_{2}(3 \times)$. The combined organic layers were washed with $\mathrm{H}_{2} \mathrm{O}(3 \times)$ and brine $(3 \times)$, dried over anhydrous $\mathrm{MgSO}_{4}$, filtered, and concentrated under reduced pressure. The crude product obtained was purified by column chromatography $\left(\mathrm{SiO}_{2}\right.$ gel, pure $\mathrm{CH}_{2} \mathrm{Cl}_{2}$ to $\mathrm{CH}_{2} \mathrm{Cl}_{2}: \mathrm{MeOH} / 19: 1 ; \mathrm{R}_{\mathrm{f}} 0.49$ in $\left.\mathrm{CH}_{2} \mathrm{Cl}_{2}: \mathrm{MeOH} / 19: 1\right)$ to yield compound $8 \mathbf{e}(70 \mathrm{mg}, 54 \%)$ as an off-white solid: ${ }^{1} \mathrm{H}-\mathrm{NMR}(400 \mathrm{MHz}$, $\mathrm{CDCl}_{3}$, Figure S28) $87.30-7.20(\mathrm{~m}, 5 \mathrm{H}$, aromatic), $7.15(\mathrm{~s}, 1 \mathrm{H}$, aromatic), $6.85(\mathrm{~s}, 1 \mathrm{H}$, aromatic), $4.32(\mathrm{t}$, $J=6.4 \mathrm{~Hz}, 2 \mathrm{H}), 3.93\left(\mathrm{~s}, 3 \mathrm{H}, \mathrm{OCH}_{3}\right), 3.65(\mathrm{t}, J=6.4 \mathrm{~Hz}, 2 \mathrm{H}), 3.49\left(\mathrm{~s}, 2 \mathrm{H}, \mathrm{NC}_{2} \mathrm{Ph}\right), 3.21\left(\mathrm{dd}, J_{1}=17.6 \mathrm{~Hz}\right.$, $\left.J_{2}=8.0 \mathrm{~Hz}, 1 \mathrm{H}\right), 2.88(\mathrm{~m}, 2 \mathrm{H}), 2.67\left(\mathrm{dt}, J_{1}=14.0 \mathrm{~Hz}, J_{2}=2.8 \mathrm{~Hz}, 2 \mathrm{H}\right), 1.98-1.86(\mathrm{~m}, 3 \mathrm{H}), 1.72-1.62(\mathrm{~m}$, 2H), $1.47(\mathrm{~m}, 1 \mathrm{H}), 1.40-1.24(\mathrm{~m}, 3 \mathrm{H}) ;{ }^{13} \mathrm{C}-\mathrm{NMR}\left(100 \mathrm{MHz}, \mathrm{CDCl}_{3}\right.$, Figure S29) $\delta 207.6(\mathrm{C}=\mathrm{O}), 155.9(\mathrm{C})$, $149.5(\mathrm{C}), 147.8(\mathrm{C}), 138.4(\mathrm{C}), 129.2(\mathrm{CH}, 3$ carbons), $128.1(\mathrm{CH}, 2$ carbons), $126.9(\mathrm{C}), 108.0(\mathrm{CH})$, $106.6(\mathrm{CH}), 68.8\left(\mathrm{CH}_{2}\right), 63.4\left(\mathrm{CH}_{2}\right), 56.3\left(\mathrm{CH}_{3}\right), 53.75\left(\mathrm{CH}_{2}\right), 53.72\left(\mathrm{CH}_{2}\right), 45.4(\mathrm{CH}), 38.7\left(\mathrm{CH}_{2}\right)$, 34.4 $\left(\mathrm{CH}_{2}\right), 33.4\left(\mathrm{CH}_{2}\right), 33.0\left(\mathrm{CH}_{2}\right), 31.8(\mathrm{CH}), 28.4\left(\mathrm{CH}_{2}\right) ; \mathrm{m} / z$ calcd. for $\mathrm{C}_{25} \mathrm{H}_{31} \mathrm{BrNO}_{3}{ }^{+}[\mathrm{M}+\mathrm{H}]^{+}$ 472.1482; found 472.1477. The purity of the compound was further confirmed by RP-HPLC: $R_{\mathrm{t}}=19.10$ $\min (97 \%$; Figure S30).

3.2.15. 2-[(1-Benzylpiperidin-4-yl)methyl]-6-[(bromobutyl)oxy]-5-methoxy-2,3-dihydroinden-1-one (8f)

A solution of compound $7(50 \mathrm{mg}, 0.14 \mathrm{mmol})$ and $\mathrm{K}_{2} \mathrm{CO}_{3}(189 \mathrm{mg}, 1.37 \mathrm{mmol})$ in anhydrous DMF $(5 \mathrm{~mL})$ was treated with 1,4-dibromobutane $(0.16 \mathrm{~mL}, 1.37 \mathrm{mmol})$, and the resulting mixture was stirred at RT overnight. The reaction mixture was then diluted with $\mathrm{H}_{2} \mathrm{O}$, and extracted with $\mathrm{CH}_{2} \mathrm{Cl}_{2}(3 \times)$. The combined organic layers were washed with $\mathrm{H}_{2} \mathrm{O}(3 \times)$ and brine $(3 \times)$, dried over anhydrous $\mathrm{MgSO}_{4}$, filtered, and concentrated under reduced pressure. The crude product obtained was purified by column chromatography $\left(\mathrm{SiO}_{2}\right.$ gel, pure $\mathrm{CH}_{2} \mathrm{Cl}_{2}$ to $\mathrm{CH}_{2} \mathrm{Cl}_{2}: \mathrm{MeOH} / 19: 1 ; \mathrm{R}_{\mathrm{f}} 0.38$ in $\left.\mathrm{CH}_{2} \mathrm{Cl}_{2}: \mathrm{MeOH} / 19: 1\right)$ to yield compound $\mathbf{8 f}\left(63 \mathrm{mg}\right.$, 93\%) as an off-white solid: ${ }^{1} \mathrm{H}-\mathrm{NMR}(400 \mathrm{MHz}$, $\mathrm{CDCl}_{3}$, Figure S31) $\delta 7.32-7.22(\mathrm{~m}, 5 \mathrm{H}$, aromatic), $7.13(\mathrm{~s}, 1 \mathrm{H}$, aromatic), $6.83(\mathrm{~s}, 1 \mathrm{H}$, aromatic), $4.04(\mathrm{t}$, $J=6.4 \mathrm{~Hz}, 2 \mathrm{H}), 3.92\left(\mathrm{~s}, 3 \mathrm{H}, \mathrm{OC}_{3}\right), 3.52\left(\mathrm{~s}, 2 \mathrm{H}, \mathrm{NC}_{2} \mathrm{Ph}\right), 3.48(\mathrm{t}, J=6.4 \mathrm{~Hz}, 2 \mathrm{H}), 3.20\left(\mathrm{dd}, J_{1}=17.6 \mathrm{~Hz}\right.$, $\left.J_{2}=8.0 \mathrm{~Hz}, 1 \mathrm{H}\right), 2.90(\mathrm{~m}, 2 \mathrm{H}), 2.67(\mathrm{~m}, 2 \mathrm{H}), 2.10-1.93(\mathrm{~m}, 6 \mathrm{H}), 1.92-1.85(\mathrm{~m}, 1 \mathrm{H}), 1.73-1.64(\mathrm{~m}, 2 \mathrm{H})$, $1.48(\mathrm{~m}, 1 \mathrm{H}), 1.40-1.23(\mathrm{~m}, 3 \mathrm{H}) ;{ }^{13} \mathrm{C}-\mathrm{NMR}\left(100 \mathrm{MHz}, \mathrm{CDCl}_{3}\right.$, Figure S32) $\delta 207.8(\mathrm{C}=\mathrm{O}), 155.8(\mathrm{C})$, $148.8(\mathrm{C}), 148.6(\mathrm{C}), 129.4(\mathrm{CH}$, two carbons), $129.2(\mathrm{C}), 128.2(\mathrm{CH}$, three carbons), $127.2(\mathrm{C}), 107.5(\mathrm{CH})$, 105.6 $(\mathrm{CH}), 68.0\left(\mathrm{CH}_{2}\right), 63.2\left(\mathrm{CH}_{2}\right), 56.2\left(\mathrm{CH}_{3}\right), 53.6\left(\mathrm{CH}_{2}\right.$, two carbons), $45.3(\mathrm{CH}), 38.6\left(\mathrm{CH}_{2}\right)$, $34.2\left(\mathrm{CH}_{2}\right), 33.3\left(\mathrm{CH}_{2}\right.$, two carbons), $32.6\left(\mathrm{CH}_{2}\right), 31.5(\mathrm{CH}), 29.4\left(\mathrm{CH}_{2}\right), 27.6\left(\mathrm{CH}_{2}\right) ; \mathrm{m} / z$ calcd. for 
$\mathrm{C}_{27} \mathrm{H}_{35} \mathrm{BrNO}_{3}{ }^{+}[\mathrm{M}+\mathrm{H}]^{+} 500.1795$; found 500.1794 . The purity of the compound was further confirmed by RP-HPLC: $R_{\mathrm{t}}=20.22 \mathrm{~min}$ (95\%; Figure S33).

3.2.16. 2-[(1-Benzylpiperidin-4-yl)methyl]-6-[(bromododecyl)oxy]-5-methoxy-2,3-dihydroinden-1one $(8 \mathrm{~g})$

A solution of compound $7(100 \mathrm{mg}, 0.27 \mathrm{mmol})$ and $\mathrm{K}_{2} \mathrm{CO}_{3}(380 \mathrm{mg}, 2.74 \mathrm{mmol})$ in anhydrous DMF $(5 \mathrm{~mL})$ was treated with 1,12-dibromododecane $(900 \mathrm{mg}, 2.74 \mathrm{mmol})$ and the resulting mixture was stirred at RT overnight. The reaction mixture was then diluted with $\mathrm{H}_{2} \mathrm{O}$, and extracted with $\mathrm{CH}_{2} \mathrm{Cl}_{2}(3 \times)$. The combined organic layers were washed with $\mathrm{H}_{2} \mathrm{O}(3 \times)$ and brine $(3 \times)$, dried over anhydrous $\mathrm{MgSO}_{4}$, filtered, and concentrated under reduced pressure. The crude product obtained was purified by column chromatography $\left(\mathrm{SiO}_{2}\right.$ gel, pure $\mathrm{CH}_{2} \mathrm{Cl}_{2}$ to $\mathrm{CH}_{2} \mathrm{Cl}_{2}: \mathrm{MeOH} / 19: 1 ; \mathrm{R}_{\mathrm{f}} 0.49$ in $\left.\mathrm{CH}_{2} \mathrm{Cl}_{2}: \mathrm{MeOH} / 19: 1\right)$ to yield compound $8 \mathrm{~g}(53 \mathrm{mg}, 32 \%)$ as an off-white solid: ${ }^{1} \mathrm{H}-\mathrm{NMR}(400 \mathrm{MHz}$, $\mathrm{CDCl}_{3}$, Figure S34) $\delta 7.32-7.22(\mathrm{~m}, 5 \mathrm{H}$, aromatic), $7.13(\mathrm{~s}, 1 \mathrm{H}$, aromatic), $6.82(\mathrm{~s}, 1 \mathrm{H}$, aromatic), $3.99(\mathrm{t}$, $J=6.8 \mathrm{~Hz}, 2 \mathrm{H}), 3.92\left(\mathrm{~s}, 3 \mathrm{H}, \mathrm{OCH}_{3}\right), 3.53\left(\mathrm{~s}, 2 \mathrm{H}, \mathrm{NCH}_{2} \mathrm{Ph}\right), 3.38(\mathrm{t}, J=6.8 \mathrm{~Hz}, 2 \mathrm{H}), 3.20\left(\mathrm{dd}, J_{1}=17.6 \mathrm{~Hz}\right.$, $\left.J_{2}=8.0 \mathrm{~Hz}, 1 \mathrm{H}\right), 2.91(\mathrm{~m}, 2 \mathrm{H}), 2.66\left(\mathrm{dt}, J_{1}=14.0 \mathrm{~Hz}, J_{2}=3.6 \mathrm{~Hz}, 2 \mathrm{H}\right), 1.99(\mathrm{~m}, 2 \mathrm{H}), 1.92-1.78(\mathrm{~m}, 5 \mathrm{H})$, 1.78-1.62 (m, 3H), 1.44-1.38 (m, 6H), 1.36-1.22 (m, 13H); ${ }^{13} \mathrm{C}-\mathrm{NMR}\left(100 \mathrm{MHz}, \mathrm{CDCl}_{3}\right.$, Figure S35) $\delta$ $207.8(\mathrm{C}=\mathrm{O}), 155.8(\mathrm{C}), 148.9(\mathrm{C}), 148.5(\mathrm{C}), 129.3(\mathrm{CH}$, two carbons), $129.2(\mathrm{C}), 128.2(\mathrm{CH}$, three carbons), $127.1(\mathrm{C}), 107.4(\mathrm{CH}), 105.5(\mathrm{CH}), 69.1\left(\mathrm{CH}_{2}\right), 63.2\left(\mathrm{CH}_{2}\right), 56.2\left(\mathrm{CH}_{3}\right), 53.6\left(\mathrm{CH}_{2}\right.$, two carbons), $45.4(\mathrm{CH}), 38.6\left(\mathrm{CH}_{2}\right), 34.3\left(\mathrm{CH}_{2}\right), 34.1\left(\mathrm{CH}_{2}\right), 33.3\left(\mathrm{CH}_{2}\right), 32.8\left(\mathrm{CH}_{2}\right), 32.6\left(\mathrm{CH}_{2}\right), 31.6(\mathrm{CH}), 29.5\left(\mathrm{CH}_{2}\right.$, two carbons), $29.4\left(\mathrm{CH}_{2}\right), 29.3\left(\mathrm{CH}_{2}\right), 28.9\left(\mathrm{CH}_{2}\right), 28.7\left(\mathrm{CH}_{2}\right), 28.1\left(\mathrm{CH}_{2}\right), 26.9\left(\mathrm{CH}_{2}\right), 25.9\left(\mathrm{CH}_{2}\right)$; $\mathrm{m} / z$ calcd. for $\mathrm{C}_{35} \mathrm{H}_{51} \mathrm{BrNO}_{3}{ }^{+}[\mathrm{M}+\mathrm{H}]^{+} 612.3047$; found 612.3045 . The purity of the compound was further confirmed by RP-HPLC: $R_{\mathrm{t}}=25.00 \mathrm{~min}$ (96\%; Figure S36).

\subsubsection{6-[(Benzyl)oxy-2-[(1-benzylpiperidin-4-yl)methyl]-5-methoxy-2,3-dihydroinden-1-one (8h)}

A solution of compound $7(50 \mathrm{mg}, 0.14 \mathrm{mmol})$ and $\mathrm{K}_{2} \mathrm{CO}_{3}(38 \mathrm{mg}, 0.27 \mathrm{mmol})$ in anhydrous DMF $(5 \mathrm{~mL})$ was treated with benzyl bromide $(20 \mu \mathrm{L}, 0.16 \mathrm{mmol})$, and the resulting mixture was stirred at RT overnight. The reaction mixture was then diluted with $\mathrm{H}_{2} \mathrm{O}$, and extracted with EtOAc $(3 \times)$. The combined organic layers were washed with $\mathrm{H}_{2} \mathrm{O}(3 \times)$ and brine $(3 \times)$, dried over anhydrous $\mathrm{MgSO}_{4}$, and filtered. After standing at RT overnight, white solids precipitated out, which were filtered off. The filtrate was further concentrated under reduced pressure, and purified by column chromatography ( $\mathrm{SiO}_{2}$ gel, pure $\mathrm{CH}_{2} \mathrm{Cl}_{2}$ to $\mathrm{CH}_{2} \mathrm{Cl}_{2}: \mathrm{MeOH} / 19: 1 ; \mathrm{R}_{\mathrm{f}} 0.37$ in $\left.\mathrm{CH}_{2} \mathrm{Cl}_{2}: \mathrm{MeOH} / 19: 1\right)$ to yield compound $8 \mathbf{h}(51 \mathrm{mg}, 82 \%)$ as an off-white solid: ${ }^{1} \mathrm{H}-\mathrm{NMR}\left(400 \mathrm{MHz}, \mathrm{CDCl}_{3}\right.$, Figure S37) $\delta$ $7.42(\mathrm{~d}, J=7.6 \mathrm{~Hz}, 2 \mathrm{H}$, aromatic), $7.35(\mathrm{t}, J=7.6 \mathrm{~Hz}, 2 \mathrm{H}$, aromatic), 7.31-7.28 (m, 5H, aromatic), $7.24\left(\mathrm{~s}, 1 \mathrm{H}\right.$, aromatic), $7.19\left(\mathrm{~s}, 1 \mathrm{H}\right.$, aromatic), $6.85\left(\mathrm{~s}, 1 \mathrm{H}\right.$, aromatic), $5.13\left(\mathrm{~s}, 2 \mathrm{H}, \mathrm{OC}_{2} \mathrm{Ph}\right), 3.93(\mathrm{~s}$, $\left.3 \mathrm{H}, \mathrm{OCH}_{3}\right), 3.51\left(\mathrm{~s}, 2 \mathrm{H}, \mathrm{NC}_{2} \mathrm{Ph}\right), 3.20\left(\mathrm{dd}, J_{1}=17.6 \mathrm{~Hz}, J_{2}=8.4 \mathrm{~Hz}, 1 \mathrm{H}\right), 2.89(\mathrm{~m}, 2 \mathrm{H}), 2.63(\mathrm{dt}$, $\left.J_{1}=14.0 \mathrm{~Hz}, J_{2}=4.0 \mathrm{~Hz}, 2 \mathrm{H}\right), 1.97(\mathrm{~m}, 2 \mathrm{H}), 1.88(\mathrm{~m}, 1 \mathrm{H}), 1.73-1.64(\mathrm{~m}, 2 \mathrm{H}), 1.48(\mathrm{~m}, 1 \mathrm{H}), 1.40-1.23(\mathrm{~m}$, $3 \mathrm{H}) ;{ }^{13} \mathrm{C}-\mathrm{NMR}\left(100 \mathrm{MHz}, \mathrm{CDCl}_{3}\right.$, Figure S38) $\delta 207.6$ (C=O), 156.0 (C), 148.9 (C), 148.5 (C), 136.3 (C), $129.4(\mathrm{CH}$, two carbons), $129.2(\mathrm{C}), 128.6(\mathrm{CH}$, two carbons), $128.2(\mathrm{CH}$, two carbons $), 128.0(\mathrm{CH}$, two carbons), 127.4 (CH, two carbons), $127.1(\mathrm{C}), 107.6(\mathrm{CH}), 106.4(\mathrm{CH}), 70.8\left(\mathrm{CH}_{2}\right), 63.2\left(\mathrm{CH}_{2}\right)$, $56.2\left(\mathrm{CH}_{3}\right), 53.6\left(\mathrm{CH}_{2}\right.$, two carbons), $45.3(\mathrm{CH}), 38.6\left(\mathrm{CH}_{2}\right), 34.3\left(\mathrm{CH}_{2}\right), 33.4\left(\mathrm{CH}_{2}\right), 32.7\left(\mathrm{CH}_{2}\right), 31.6(\mathrm{CH})$; $\mathrm{m} / z$ calcd. for $\mathrm{C}_{30} \mathrm{H}_{34} \mathrm{NO}_{3}{ }^{+}[\mathrm{M}+\mathrm{H}]^{+} 456.2533$; found 456.2528 . The purity of the compound was further confirmed by RP-HPLC: $R_{\mathrm{t}}=20.05 \mathrm{~min}$ (96\%; Figure S39).

3.2.18. 2-[(1-Benzylpiperidin-4-yl)methyl]-5-methoxy-6-[(4-methylbenzyl)oxy-2,3-dihydroinden-1one $(8 \mathbf{i})$

A solution of compound $7(50 \mathrm{mg}, 0.14 \mathrm{mmol})$ and $\mathrm{K}_{2} \mathrm{CO}_{3}(38 \mathrm{mg}, 0.27 \mathrm{mmol})$ in anhydrous DMF $(5 \mathrm{~mL})$ was treated with 4-methylbenzyl bromide $(30 \mathrm{mg}, 0.16 \mathrm{mmol})$, and the resulting mixture was stirred at RT overnight. The reaction mixture was then diluted with $\mathrm{H}_{2} \mathrm{O}$, and extracted with $\mathrm{CH}_{2} \mathrm{Cl}_{2}$ $(3 \times)$. The combined organic layers were washed with $\mathrm{H}_{2} \mathrm{O}(3 \times)$ and brine $(3 \times)$, dried over anhydrous $\mathrm{MgSO}_{4}$, and filtered. After standing at RT overnight, the white solids precipitated out, which were 
filtered off. The filtrate was further concentrated under reduced pressure, and purified by column chromatography ( $\mathrm{SiO}_{2}$ gel, pure $\mathrm{CH}_{2} \mathrm{Cl}_{2}$ to $\mathrm{CH}_{2} \mathrm{Cl}_{2}: \mathrm{MeOH} / 19: 1 ; \mathrm{R}_{\mathrm{f}} 0.35$ in $\left.\mathrm{CH}_{2} \mathrm{Cl}_{2}: \mathrm{MeOH} / 19: 1\right)$ to yield compound $8 \mathbf{i}\left(37 \mathrm{mg}, 58 \%\right.$ ) as an off-white solid: ${ }^{1} \mathrm{H}-\mathrm{NMR}\left(400 \mathrm{MHz}, \mathrm{CDCl}_{3}\right.$, Figure S40) $\delta 7.31$ (d, $J=8.0 \mathrm{~Hz}, 2 \mathrm{H}$, aromatic), 7.31-7.29 (m, 4H, aromatic), $7.24(\mathrm{~s}, 1 \mathrm{H}$, aromatic), 7.18 (s, $1 \mathrm{H}$, aromatic), $7.15\left(\mathrm{~d}, J=8.0 \mathrm{~Hz}, 2 \mathrm{H}\right.$, aromatic), $6.83\left(\mathrm{~s}, 1 \mathrm{H}\right.$, aromatic), $5.09\left(\mathrm{~s}, 2 \mathrm{H}, \mathrm{OCH}_{2} \mathrm{Ph}\right), 3.92\left(\mathrm{~s}, 3 \mathrm{H}, \mathrm{OC}_{3}\right)$, $3.51\left(\mathrm{~s}, 2 \mathrm{H}, \mathrm{NCH}_{2} \mathrm{Ph}\right), 3.20\left(\mathrm{dd}, J_{1}=17.6 \mathrm{~Hz}, J_{2}=8.4 \mathrm{~Hz}, 1 \mathrm{H}\right), 2.89(\mathrm{~m}, 2 \mathrm{H}), 2.63\left(\mathrm{dt}, J_{1}=13.6 \mathrm{~Hz}, J_{2}=3.6\right.$ $\mathrm{Hz}, 2 \mathrm{H}), 2.32\left(\mathrm{~s}, 3 \mathrm{H}, \mathrm{CH}_{3} \mathrm{Ph}\right), 1.97(\mathrm{~m}, 2 \mathrm{H}), 1.91-1.84(\mathrm{~m}, 1 \mathrm{H}), 1.72-1.64(\mathrm{~m}, 2 \mathrm{H}), 1.47(\mathrm{~m}, 1 \mathrm{H}), 1.40-1.23$ $(\mathrm{m}, 3 \mathrm{H}) ;{ }^{13} \mathrm{C}-\mathrm{NMR}\left(100 \mathrm{MHz}, \mathrm{CDCl}_{3}\right.$, Figure S41) $\delta 207.6(\mathrm{C}=\mathrm{O}), 156.0(\mathrm{C}), 148.9(\mathrm{C}), 148.5(\mathrm{C}), 137.8(\mathrm{C})$, $133.3(\mathrm{C}), 129.30(\mathrm{CH}$, two carbons), $129.25(\mathrm{CH}$, two carbons), $129.17(\mathrm{C}), 128.2(\mathrm{CH}$, three carbons), 127.5 $\left(\mathrm{CH}, 2\right.$ carbons), $127.0(\mathrm{C}), 107.6(\mathrm{CH}), 106.4(\mathrm{CH}), 70.7\left(\mathrm{CH}_{2}\right), 63.3\left(\mathrm{CH}_{2}\right), 56.2\left(\mathrm{CH}_{3}\right), 53.7\left(\mathrm{CH}_{2}\right.$, 2 carbons), $45.4(\mathrm{CH}), 38.7\left(\mathrm{CH}_{2}\right), 34.3\left(\mathrm{CH}_{2}\right), 33.4\left(\mathrm{CH}_{2}\right), 32.8\left(\mathrm{CH}_{2}\right), 31.7(\mathrm{CH}), 21.2\left(\mathrm{CH}_{3}\right) ; \mathrm{m} / z$ calcd. for $\mathrm{C}_{31} \mathrm{H}_{36} \mathrm{NO}_{3}{ }^{+}[\mathrm{M}+\mathrm{H}]^{+} 470.2690$; found 470.2681 . The purity of the compound was further confirmed by RP-HPLC: $R_{\mathrm{t}}=20.65 \mathrm{~min}$ (95\%; Figure S42).

3.2.19. 2-[(1-Benzylpiperidin-4-yl)methyl]-5-methoxy-6-[(4-methoxybenzyl)oxy-2,3-dihydroinden-1one $(8 \mathbf{j})$

A solution of compound $7(50 \mathrm{mg}, 0.14 \mathrm{mmol})$ and $\mathrm{K}_{2} \mathrm{CO}_{3}(189 \mathrm{mg}, 1.37 \mathrm{mmol})$ in anhydrous DMF $(5 \mathrm{~mL})$ was treated with 4-methoxybenzyl chloride $(0.19 \mathrm{~mL}, 1.37 \mathrm{mmol})$, and the resulting mixture was stirred at RT overnight. The reaction mixture was then diluted with $\mathrm{H}_{2} \mathrm{O}$, and extracted with $\mathrm{CH}_{2} \mathrm{Cl}_{2}(3 \times)$. The combined organic layers were washed with $\mathrm{H}_{2} \mathrm{O}(3 \times)$ and brine $(3 \times)$, dried over anhydrous $\mathrm{MgSO}_{4}$, filtered, and concentrated under reduced pressure. The crude product obtained was purified by column chromatography $\left(\mathrm{SiO}_{2}\right.$ gel, pure $\mathrm{CH}_{2} \mathrm{Cl}_{2}$ to $\mathrm{CH}_{2} \mathrm{Cl}_{2}: \mathrm{MeOH} / 19: 1 ; \mathrm{R}_{\mathrm{f}} 0.30$ in $\left.\mathrm{CH}_{2} \mathrm{Cl}_{2}: \mathrm{MeOH} / 19: 1\right)$ to yield compound $8 \mathbf{j}\left(24 \mathrm{mg}\right.$, 36\%) as an off-white solid: ${ }^{1} \mathrm{H}-\mathrm{NMR}(400 \mathrm{MHz}$, $\mathrm{CDCl}_{3}$, Figure S43) $\delta 7.34(\mathrm{~d}, J=8.8 \mathrm{~Hz}, 2 \mathrm{H}$, aromatic), 7.33-7.26 $(\mathrm{m}, 5 \mathrm{H}$, aromatic), $7.19(\mathrm{~s}, 1 \mathrm{H}$, aromatic), $6.87\left(\mathrm{~d}, J=8.8 \mathrm{~Hz}, 2 \mathrm{H}\right.$, aromatic), $6.83\left(\mathrm{~s}, 1 \mathrm{H}\right.$, aromatic), $5.05\left(\mathrm{~s}, 2 \mathrm{H}, \mathrm{OCH}_{2} \mathrm{Ph}\right), 3.91(\mathrm{~s}, 3 \mathrm{H}$, $\left.\mathrm{OC}_{3}\right), 3.78\left(\mathrm{~s}, 3 \mathrm{H}, \mathrm{OC}_{3}\right), 3.56\left(\mathrm{~s}, 2 \mathrm{H}, \mathrm{NC}_{2} \mathrm{Ph}\right), 3.20\left(\mathrm{dd}, J_{1}=17.6 \mathrm{~Hz}, J_{2}=8.4 \mathrm{~Hz}, 1 \mathrm{H}\right), 2.95(\mathrm{~m}, 2 \mathrm{H})$, $2.65\left(\mathrm{dt}, J_{1}=13.6 \mathrm{~Hz}, J_{2}=3.6 \mathrm{~Hz}, 2 \mathrm{H}\right), 2.08-1.98(\mathrm{~m}, 2 \mathrm{H}), 1.92-1.82(\mathrm{~m}, 1 \mathrm{H}), 1.76-1.64(\mathrm{~m}, 2 \mathrm{H}), 1.53(\mathrm{~m}$, $1 \mathrm{H}), 1.40-1.23(\mathrm{~m}, 3 \mathrm{H}) ;{ }^{13} \mathrm{C}-\mathrm{NMR}\left(100 \mathrm{MHz}, \mathrm{CDCl}_{3}\right.$, Figure S44) $\delta 207.6(\mathrm{C}=\mathrm{O}), 159.5(\mathrm{C}), 156.0(\mathrm{C})$, $148.9(\mathrm{C}), 148.5(\mathrm{C}), 137.2(\mathrm{C}), 129.5(\mathrm{CH}$, two carbons), $129.2(\mathrm{CH}$, two carbons), $129.1(\mathrm{C}), 128.4(\mathrm{CH})$, 128.2 (CH, two carbons), 127.3 (C), 114.0 (CH, 2 carbons), $107.6(\mathrm{CH}), 106.5(\mathrm{CH}), 70.6\left(\mathrm{CH}_{2}\right), 63.1\left(\mathrm{CH}_{2}\right)$, $56.2\left(\mathrm{CH}_{3}\right), 55.3\left(\mathrm{CH}_{3}\right), 53.6\left(\mathrm{CH}_{2}\right), 53.5\left(\mathrm{CH}_{2}\right), 45.3(\mathrm{CH}), 38.6\left(\mathrm{CH}_{2}\right), 34.1\left(\mathrm{CH}_{2}\right), 33.4\left(\mathrm{CH}_{2}\right), 32.4\left(\mathrm{CH}_{2}\right)$, $31.4(\mathrm{CH}) ; \mathrm{m} / z$ calcd. for $\mathrm{C}_{31} \mathrm{H}_{36} \mathrm{NO}_{4}{ }^{+}[\mathrm{M}+\mathrm{H}]^{+} 486.2639$; found 486.2635 . The purity of the compound was further confirmed by RP-HPLC: $R_{\mathrm{t}}=19.93 \mathrm{~min}$ (95\%; Figure S45).

3.2.20. 2-[(1-Benzylpiperidin-4-yl)methyl]-5-methoxy-6-[(4-nitrobenzyl)oxy-2,3-dihydroinden-1one (8k).

A solution of compound $7(50 \mathrm{mg}, 0.14 \mathrm{mmol})$ and $\mathrm{K}_{2} \mathrm{CO}_{3}(38 \mathrm{mg}, 0.27 \mathrm{mmol})$ in anhydrous DMF $(5 \mathrm{~mL})$ was treated with 4-nitrobenzyl bromide $(35 \mathrm{mg}, 0.16 \mathrm{mmol})$, and the resulting mixture was stirred at RT overnight. The reaction mixture was then diluted with $\mathrm{H}_{2} \mathrm{O}$, and extracted with EtOAc $(3 \times)$. The combined organic layers were washed with $\mathrm{H}_{2} \mathrm{O}(3 \times)$ and brine $(3 \times)$, dried over anhydrous $\mathrm{MgSO}_{4}$, and filtered. After standing at RT overnight, white solids precipitated out, which were filtered off. The filtrate was further concentrated under reduced pressure and purified by column chromatography $\left(\mathrm{SiO}_{2}\right.$ gel, pure $\mathrm{CH}_{2} \mathrm{Cl}_{2}$ to $\mathrm{CH}_{2} \mathrm{Cl}_{2}: \mathrm{MeOH} / 19: 1 ; \mathrm{R}_{\mathrm{f}} 0.37$ in $\left.\mathrm{CH}_{2} \mathrm{Cl}_{2}: \mathrm{MeOH} / 19: 1\right)$ to yield compound $8 \mathbf{k}(44 \mathrm{mg}, 65 \%)$ as a brown foam: ${ }^{1} \mathrm{H}-\mathrm{NMR}\left(400 \mathrm{MHz}, \mathrm{CDCl}_{3}\right.$, Figure S46) $\delta$ $8.22(\mathrm{~d}, J=8.4 \mathrm{~Hz}, 2 \mathrm{H}$, aromatic), $7.60(\mathrm{~d}, J=8.4 \mathrm{~Hz}, 2 \mathrm{H}$, aromatic), 7.31-7.28 (m, $4 \mathrm{H}$, aromatic), $7.24\left(\mathrm{~s}, 1 \mathrm{H}\right.$, aromatic), $7.14\left(\mathrm{~s}, 1 \mathrm{H}\right.$, aromatic), $6.88\left(\mathrm{~s}, 1 \mathrm{H}\right.$, aromatic), $5.23\left(\mathrm{~s}, 2 \mathrm{H}, \mathrm{OC}_{\underline{\mathrm{H}}} \mathrm{Ph}\right), 3.97(\mathrm{~s}$, $\left.3 \mathrm{H}, \mathrm{OC}_{3}\right), 3.50\left(\mathrm{~s}, 2 \mathrm{H}, \mathrm{NC}_{2} \mathrm{Ph}\right), 3.22\left(\mathrm{dd}, J_{1}=17.6 \mathrm{~Hz}, J_{2}=8.0 \mathrm{~Hz}, 1 \mathrm{H}\right), 2.89(\mathrm{~m}, 2 \mathrm{H}), 2.68(\mathrm{~m}$, 2H), $1.96(\mathrm{~m}, 2 \mathrm{H}), 1.87(\mathrm{~m}, 1 \mathrm{H}), 1.72-1.63(\mathrm{~m}, 2 \mathrm{H}), 1.47(\mathrm{~m}, 1 \mathrm{H}), 1.36-1.23(\mathrm{~m}, 3 \mathrm{H}) ;{ }^{13} \mathrm{C}-\mathrm{NMR}(100$ $\mathrm{MHz}, \mathrm{CDCl}_{3}$, Figure S47) $\delta 207.5(\mathrm{C}=\mathrm{O}), 155.9(\mathrm{C}), 149.5(\mathrm{C}), 147.8(\mathrm{C}), 147.6(\mathrm{C}), 143.8(\mathrm{C}), 129.3(\mathrm{CH})$, $129.2(\mathrm{CH}), 128.2(\mathrm{CH}$, two carbons), $127.5(\mathrm{CH}$, three carbons), $127.0(\mathrm{C}), 123.9(\mathrm{CH}$, two carbons + 
C), $107.9(\mathrm{CH}), 106.6(\mathrm{CH}), 69.5\left(\mathrm{CH}_{2}\right), 63.3\left(\mathrm{CH}_{2}\right), 56.3\left(\mathrm{CH}_{3}\right), 53.7\left(\mathrm{CH}_{2}\right.$, two carbons), $45.4(\mathrm{CH})$, $38.6\left(\mathrm{CH}_{2}\right), 34.3\left(\mathrm{CH}_{2}\right), 33.4\left(\mathrm{CH}_{2}\right), 32.8\left(\mathrm{CH}_{2}\right), 31.6(\mathrm{CH}) ; \mathrm{m} / z$ calcd. for $\mathrm{C}_{30} \mathrm{H}_{33} \mathrm{~N}_{2} \mathrm{O}_{5}{ }^{+}[\mathrm{M}+\mathrm{H}]^{+}$ 501.2384; found 501.2385. The purity of the compound was further confirmed by RP-HPLC: $R_{\mathrm{t}}=19.98$ $\min (96 \%$; Figure S48).

3.2.21. 2-[(1-Benzylpiperidin-4-yl)methyl]-6-[(4-bromobenzyl)oxy-5-methoxy-2,3-dihydroinden-1one (81)

A solution of compound $7(50 \mathrm{mg}, 0.14 \mathrm{mmol})$ and $\mathrm{K}_{2} \mathrm{CO}_{3}(38 \mathrm{mg}, 0.27 \mathrm{mmol})$ in anhydrous DMF $(5 \mathrm{~mL})$ was treated with 4-bromobenzyl bromide $(41 \mathrm{mg}, 0.16 \mathrm{mmol})$ and the resulting mixture was stirred at RT overnight. The reaction mixture was then diluted with $\mathrm{H}_{2} \mathrm{O}$, and extracted with EtOAc $(3 \times)$. The combined organic layers were washed with $\mathrm{H}_{2} \mathrm{O}(3 \times)$ and brine $(3 \times)$, dried over anhydrous $\mathrm{MgSO}_{4}$, and filtered. After standing at RT overnight, white solids precipitated out, which were filtered off. The filtrate was further concentrated under reduced pressure and purified by column chromatography $\left(\mathrm{SiO}_{2}\right.$ gel, pure $\mathrm{CH}_{2} \mathrm{Cl}_{2}$ to $\mathrm{CH}_{2} \mathrm{Cl}_{2}: \mathrm{MeOH} / 19: 1 ; \mathrm{R}_{\mathrm{f}} 0.37$ in $\left.\mathrm{CH}_{2} \mathrm{Cl}_{2}: \mathrm{MeOH} / 19: 1\right)$ to yield compound $81(61 \mathrm{mg}, 84 \%)$ as an off-white solid: ${ }^{1} \mathrm{H}-\mathrm{NMR}\left(400 \mathrm{MHz}, \mathrm{CDCl}_{3}\right.$, Figure $\left.\mathrm{S49}\right) \delta$ $7.47(\mathrm{~d}, J=8.4 \mathrm{~Hz}, 2 \mathrm{H}$, aromatic), $7.30(\mathrm{~d}, J=8.4 \mathrm{~Hz}, 2 \mathrm{H}$, aromatic), 7.31-7.28 (m, 4H, aromatic), $7.24\left(\mathrm{~s}, 1 \mathrm{H}\right.$, aromatic), $7.14\left(\mathrm{~s}, 1 \mathrm{H}\right.$, aromatic), $6.85\left(\mathrm{~s}, 1 \mathrm{H}\right.$, aromatic), $5.07\left(\mathrm{~s}, 2 \mathrm{H}, \mathrm{OC}_{2} \mathrm{Ph}\right), 3.94(\mathrm{~s}$, $\left.3 \mathrm{H}, \mathrm{OC}_{3}\right), 3.51\left(\mathrm{~s}, 2 \mathrm{H}, \mathrm{NC}_{2} \mathrm{Ph}\right), 3.21\left(\mathrm{dd}, J_{1}=17.6 \mathrm{~Hz}, J_{2}=8.4 \mathrm{~Hz}, 1 \mathrm{H}\right), 2.89(\mathrm{~m}, 2 \mathrm{H}), 2.67(\mathrm{dt}$, $\left.J_{1}=14.4 \mathrm{~Hz}, J_{2}=4.0 \mathrm{~Hz}, 2 \mathrm{H}\right), 1.96(\mathrm{~m}, 2 \mathrm{H}), 1.87(\mathrm{~m}, 1 \mathrm{H}), 1.72-1.63(\mathrm{~m}, 2 \mathrm{H}), 1.47(\mathrm{~m}, 1 \mathrm{H}), 1.40-1.23(\mathrm{~m}$, 3H); ${ }^{13} \mathrm{C}-\mathrm{NMR}\left(100 \mathrm{MHz}, \mathrm{CDCl}_{3}\right.$, Figure S50) $\delta 207.6$ (C=O), 155.9 (C), 149.1 (C), 148.2 (C), 135.4 (C), 131.7 $(\mathrm{CH}$, two carbons $+\mathrm{C}), 129.4(\mathrm{CH}), 129.2(\mathrm{CH}), 129.0(\mathrm{CH}$, three carbons), $128.2(\mathrm{CH}$, two carbons), 127.1 (C), $122.0(\mathrm{C}), 107.7(\mathrm{CH}), 106.5(\mathrm{CH}), 70.1\left(\mathrm{CH}_{2}\right), 63.2\left(\mathrm{CH}_{2}\right), 56.2\left(\mathrm{CH}_{3}\right), 53.6\left(\mathrm{CH}_{2}\right.$, two carbons), $45.3(\mathrm{CH}), 38.6\left(\mathrm{CH}_{2}\right), 34.2\left(\mathrm{CH}_{2}\right), 33.4\left(\mathrm{CH}_{2}\right), 32.7\left(\mathrm{CH}_{2}\right), 31.6(\mathrm{CH}) ; \mathrm{m} / z$ calcd. for $\mathrm{C}_{30} \mathrm{H}_{33} \mathrm{BrNO}_{3}{ }^{+}[\mathrm{M}$ $+\mathrm{H}]^{+} 534.1638$; found 534.1650 . The purity of the compound was further confirmed by RP-HPLC: $R_{\mathrm{t}}=21.05 \mathrm{~min}$ (96\%; Figure S51).

3.2.22. 2-[(1-Benzylpiperidin-4-yl)methyl]-6-[(4-fluorobenzyl)oxy-5-methoxy-2,3-dihydroinden-1one $(8 \mathrm{~m})$

A solution of compound $7(50 \mathrm{mg}, 0.14 \mathrm{mmol})$ and $\mathrm{K}_{2} \mathrm{CO}_{3}(38 \mathrm{mg}, 0.27 \mathrm{mmol})$ in anhydrous DMF $(5 \mathrm{~mL})$ was treated with 4-fluorobenzyl bromide $(20 \mu \mathrm{L}, 0.16 \mathrm{mmol})$, and the resulting mixture was stirred at RT overnight. The reaction mixture was then diluted with $\mathrm{H}_{2} \mathrm{O}$, and extracted with EtOAc $(3 \times)$. The combined organic layers were washed with $\mathrm{H}_{2} \mathrm{O}(3 \times)$ and brine $(3 \times)$, dried over anhydrous $\mathrm{MgSO}_{4}$, and filtered. The filtrate was concentrated under reduced pressure and purified by column chromatography $\left(\mathrm{SiO}_{2}\right.$ gel, pure $\mathrm{CH}_{2} \mathrm{Cl}_{2}$ to $\mathrm{CH}_{2} \mathrm{Cl}_{2}: \mathrm{MeOH} / 19: 1 ; \mathrm{R}_{\mathrm{f}} 0.31$ in $\left.\mathrm{CH}_{2} \mathrm{Cl}_{2}: \mathrm{MeOH} / 19: 1\right)$ to yield compound $8 \mathrm{~m}(56 \mathrm{mg}, 86 \%)$ as an off-white solid: ${ }^{1} \mathrm{H}-\mathrm{NMR}\left(400 \mathrm{MHz}, \mathrm{CDCl}_{3}\right.$, Figure S52) $\delta 7.40$ $\left(\mathrm{dd}, J_{1}=8.8 \mathrm{~Hz}, J_{2}=5.6 \mathrm{~Hz}, 2 \mathrm{H}\right.$, aromatic), $7.30(\mathrm{~m}, 4 \mathrm{H}$, aromatic), $7.24(\mathrm{~s}, 1 \mathrm{H}$, aromatic), $7.18(\mathrm{~s}, 1 \mathrm{H}$, aromatic), $7.04\left(\mathrm{t}, J=8.8 \mathrm{~Hz}, 2 \mathrm{H}\right.$, aromatic), $6.85\left(\mathrm{~s}, 1 \mathrm{H}\right.$, aromatic), $5.08\left(\mathrm{~s}, 2 \mathrm{H}, \mathrm{OC}_{2} \mathrm{Ph}\right), 3.93(\mathrm{~s}, 3 \mathrm{H}$, $\left.\mathrm{OCH}_{3}\right), 3.51\left(\mathrm{~s}, 2 \mathrm{H}, \mathrm{NCH}_{2} \mathrm{Ph}\right), 3.21\left(\mathrm{dd}, J_{1}=17.6 \mathrm{~Hz}, J_{2}=8.4 \mathrm{~Hz}, 1 \mathrm{H}\right), 2.90(\mathrm{~m}, 2 \mathrm{H}), 2.67\left(\mathrm{dt}, J_{1}=14.0\right.$ $\left.\mathrm{Hz}, J_{2}=3.6 \mathrm{~Hz}, 2 \mathrm{H}\right), 1.98(\mathrm{~m}, 2 \mathrm{H}), 1.88(\mathrm{~m}, 1 \mathrm{H}), 1.69(\mathrm{~m}, 2 \mathrm{H}), 1.49(\mathrm{~m}, 1 \mathrm{H}), 1.36-1.23(\mathrm{~m}, 3 \mathrm{H}) ;{ }^{13} \mathrm{C}-\mathrm{NMR}$ $\left(100 \mathrm{MHz}, \mathrm{CDCl}_{3}\right.$, Figure S53) $\delta 207.6(\mathrm{C}=\mathrm{O}), 163.8-161.3\left(\mathrm{~d},{ }^{1} J_{\mathrm{C}-\mathrm{F}}=245.2 \mathrm{~Hz}, \mathrm{C}\right.$, one carbon), 155.9 (C), 149.1 (C), $148.3(\mathrm{C}), 138.1$ (C), 132.14-132.11 (d, ${ }^{4} J_{\mathrm{C}-\mathrm{F}}=3.8 \mathrm{~Hz}, \mathrm{C}$, one carbon), $129.4-129.27\left(\mathrm{~d},{ }^{3} J_{\mathrm{C}-\mathrm{F}}=\right.$ $8.4 \mathrm{~Hz}, \mathrm{CH}$, two carbons), $129.28(\mathrm{CH}$, two carbons), $129.2(\mathrm{CH}), 128.2(\mathrm{CH}$, two carbons), $127.0(\mathrm{C})$, 115.6-115.4 (d, ${ }^{2} J_{\mathrm{C}-\mathrm{F}}=21.2 \mathrm{~Hz}, \mathrm{CH}$, two carbons), $107.7(\mathrm{CH}), 106.4(\mathrm{CH}), 70.1\left(\mathrm{CH}_{2}\right), 63.3\left(\mathrm{CH}_{2}\right)$, $56.2\left(\mathrm{CH}_{3}\right), 53.70\left(\mathrm{CH}_{2}\right), 53.68\left(\mathrm{CH}_{2}\right), 45.4(\mathrm{CH}), 38.7\left(\mathrm{CH}_{2}\right), 34.3\left(\mathrm{CH}_{2}\right), 33.3\left(\mathrm{CH}_{2}\right), 32.8\left(\mathrm{CH}_{2}\right)$, $31.7(\mathrm{CH}) ; \mathrm{m} / z$ calcd. $\mathrm{C}_{30} \mathrm{H}_{33} \mathrm{FNO}_{3}{ }^{+}[\mathrm{M}+\mathrm{H}]^{+} 474.2439$; found 474.2442 . The purity of the compound was further confirmed by RP-HPLC: $R_{\mathrm{t}}=20.14 \mathrm{~min}(96 \%$; Figure S54). 
3.2.23. 2-[(1-Benzylpiperidin-4-yl)methyl]-6-[(3-fluorobenzyl)oxy-5-methoxy-2,3-dihydroinden-1one $(8 \mathrm{n})$

A solution of compound $7(50 \mathrm{mg}, 0.14 \mathrm{mmol})$ and $\mathrm{K}_{2} \mathrm{CO}_{3}(38 \mathrm{mg}, 0.27 \mathrm{mmol})$ in anhydrous DMF $(5 \mathrm{~mL})$ was treated with 3-fluorobenzyl bromide $(20 \mu \mathrm{L}, 0.16 \mathrm{mmol})$, and the resulting mixture was stirred at RT overnight. The reaction mixture was then diluted with $\mathrm{H}_{2} \mathrm{O}$, and extracted with EtOAc $(3 \times)$. The combined organic layers were washed with $\mathrm{H}_{2} \mathrm{O}(3 \times)$ and brine $(3 \times)$, dried over anhydrous $\mathrm{MgSO}_{4}$, and filtered. After standing at RT overnight, the white solids precipitated out, which were filtered off. The filtrate was further concentrated under reduced pressure, and purified by column chromatography $\left(\mathrm{SiO}_{2}\right.$ gel, pure $\mathrm{CH}_{2} \mathrm{Cl}_{2}$ to $\mathrm{CH}_{2} \mathrm{Cl}_{2}: \mathrm{MeOH} / 19: 1 ; \mathrm{R}_{\mathrm{f}} 0.31$ in $\left.\mathrm{CH}_{2} \mathrm{Cl}_{2}: \mathrm{MeOH} / 19: 1\right)$ to yield compound $8 \mathbf{n}(57 \mathrm{mg}, 88 \%)$ as an off-white solid: ${ }^{1} \mathrm{H}-\mathrm{NMR}\left(400 \mathrm{MHz}, \mathrm{CDCl}_{3}\right.$, Figure S55) $\delta$ 7.34-7.26 $\left(\mathrm{m}, 5 \mathrm{H}\right.$, aromatic), $7.24\left(\mathrm{~s}, 1 \mathrm{H}\right.$, aromatic), 7.18-7.12 $\left(\mathrm{m}, 3 \mathrm{H}\right.$, aromatic), $6.98\left(\mathrm{td}, J_{1}=8.4 \mathrm{~Hz}\right.$, $J_{2}=2.4 \mathrm{~Hz}, 1 \mathrm{H}$, aromatic), $6.86\left(\mathrm{~s}, 1 \mathrm{H}\right.$, aromatic), $5.12\left(\mathrm{~s}, 2 \mathrm{H}, \mathrm{OC}_{2} \mathrm{Ph}\right), 3.95\left(\mathrm{~s}, 3 \mathrm{H}, \mathrm{OCH}_{3}\right), 3.54(\mathrm{~s}$, $\left.2 \mathrm{H}, \mathrm{NCH}_{2} \mathrm{Ph}\right), 3.21\left(\mathrm{dd}, J_{1}=17.6 \mathrm{~Hz}, J_{2}=8.0 \mathrm{~Hz}, 1 \mathrm{H}\right), 2.92(\mathrm{~m}, 2 \mathrm{H}), 2.67\left(\mathrm{dt}, J_{1}=14.4 \mathrm{~Hz}, J_{2}=4.4 \mathrm{~Hz}\right.$, 2H), $2.0(\mathrm{~m}, 2 \mathrm{H}), 1.87(\mathrm{~m}, 1 \mathrm{H}), 1.73-1.66(\mathrm{~m}, 2 \mathrm{H}), 1.50(\mathrm{~m}, 1 \mathrm{H}), 1.40-1.26(\mathrm{~m}, 3 \mathrm{H}) ;{ }^{13} \mathrm{C}-\mathrm{NMR}(100 \mathrm{MHz}$, $\mathrm{CDCl}_{3}$, Figure S56) $\delta 207.6(\mathrm{C}=\mathrm{O}), 164.2-161.8\left(\mathrm{~d},{ }^{1} J_{\mathrm{C}-\mathrm{F}}=245.2 \mathrm{~Hz}, \mathrm{C}, 1\right.$ carbon), $155.9(\mathrm{C}), 149.2(\mathrm{C})$, $148.2(\mathrm{C}), 139.0-138.9\left(\mathrm{~d},{ }^{3} J_{\mathrm{C}-\mathrm{F}}=7.6 \mathrm{~Hz}, \mathrm{C}\right.$, one carbon), $137.4(\mathrm{C}), 130.2-130.1\left(\mathrm{~d},{ }^{3} J_{\mathrm{C}-\mathrm{F}}=7.6 \mathrm{~Hz}, \mathrm{CH}\right.$, one carbon), $129.4(\mathrm{CH}$, two carbons), $129.1(\mathrm{CH}), 128.2(\mathrm{CH}$, two carbons), 127.2 (C), 122.7-122.6 (d, ${ }^{4} J_{\mathrm{C}-\mathrm{F}}=3.1 \mathrm{~Hz}, \mathrm{CH}$, one carbon), $115.0-114.8\left(\mathrm{~d},{ }^{2} J_{\mathrm{C}-\mathrm{F}}=20.5 \mathrm{~Hz}, \mathrm{CH}\right.$, one carbon), $114.2-114.0\left(\mathrm{~d},{ }^{2} J_{\mathrm{C}-\mathrm{F}}=\right.$ $22.0 \mathrm{~Hz}, \mathrm{CH}$, one carbon), $107.7(\mathrm{CH}), 106.4(\mathrm{CH}), 69.9\left(\mathrm{CH}_{2}\right), 63.1\left(\mathrm{CH}_{2}\right), 56.2\left(\mathrm{CH}_{3}\right), 53.6\left(\mathrm{CH}_{2}\right), 53.5$ $\left(\mathrm{CH}_{2}\right), 45.3(\mathrm{CH}), 38.6\left(\mathrm{CH}_{2}\right), 34.2\left(\mathrm{CH}_{2}\right), 33.4\left(\mathrm{CH}_{2}\right), 32.5\left(\mathrm{CH}_{2}\right), 31.5(\mathrm{CH}) ; \mathrm{m} / z$ calcd. for $\mathrm{C}_{30} \mathrm{H}_{33} \mathrm{FNO}_{3}{ }^{+}$ $[\mathrm{M}+\mathrm{H}]^{+} 474.2439$; found 474.2426 . The purity of the compound was further confirmed by RP-HPLC: $R_{\mathrm{t}}=20.20$ min (96\%; Figure S57).

3.2.24. 2-[(1-Benzylpiperidin-4-yl)methyl]-6-[(2-fluorobenzyl)oxy-5-methoxy-2,3-dihydroinden-1one (8o)

A solution of compound $7(50 \mathrm{mg}, 0.14 \mathrm{mmol})$ and $\mathrm{K}_{2} \mathrm{CO}_{3}(38 \mathrm{mg}, 0.27 \mathrm{mmol})$ in anhydrous DMF $(5 \mathrm{~mL})$ was treated with 2-fluorobenzyl bromide $(20 \mu \mathrm{L}, 0.16 \mathrm{mmol})$, and the resulting mixture was stirred at RT overnight. The reaction mixture was then diluted with $\mathrm{H}_{2} \mathrm{O}$, and extracted with EtOAc $(3 \times)$. The combined organic layers were washed with $\mathrm{H}_{2} \mathrm{O}(3 \times)$ and brine $(3 \times)$, dried over anhydrous $\mathrm{MgSO}_{4}$, and filtered. After standing at RT overnight, white solids precipitated out, which were filtered off. The filtrate was further concentrated under reduced pressure and purified by column chromatography $\left(\mathrm{SiO}_{2}\right.$ gel, pure $\mathrm{CH}_{2} \mathrm{Cl}_{2}$ to $\mathrm{CH}_{2} \mathrm{Cl}_{2}: \mathrm{MeOH} / 19: 1 ; \mathrm{R}_{\mathrm{f}} 0.31$ in $\left.\mathrm{CH}_{2} \mathrm{Cl}_{2}: \mathrm{MeOH} / 19: 1\right)$ to yield compound $80(56 \mathrm{mg}, 86 \%)$ as an off-white solid: ${ }^{1} \mathrm{H}-\mathrm{NMR}\left(400 \mathrm{MHz}, \mathrm{CDCl}_{3}\right.$, Figure S58) $\delta$ $7.49(\mathrm{t}, J=7.6 \mathrm{~Hz}, 1 \mathrm{H}$, aromatic), 7.31-7.25 (m, 5H, aromatic), $7.24(\mathrm{~s}, 1 \mathrm{H}$, aromatic), $7.23(\mathrm{~d}, J=7.6$ $\mathrm{Hz}, 1 \mathrm{H}$, aromatic), $7.12(\mathrm{t}, J=7.6 \mathrm{~Hz}, 1 \mathrm{H}$, aromatic), $7.06(\mathrm{t}, J=8.4 \mathrm{~Hz}, 1 \mathrm{H}$, aromatic), $6.85(\mathrm{~s}, 1 \mathrm{H}$, aromatic), $5.18\left(\mathrm{~s}, 2 \mathrm{H}, \mathrm{OC} \underline{\mathrm{H}}_{2} \mathrm{Ph}\right), 3.93\left(\mathrm{~s}, 3 \mathrm{H}, \mathrm{OC}_{3}\right), 3.52\left(\mathrm{~s}, 2 \mathrm{H}, \mathrm{NC}_{2} \mathrm{Ph}\right), 3.21\left(\mathrm{dd}, J_{1}=17.6 \mathrm{~Hz}\right.$, $\left.J_{2}=8.0 \mathrm{~Hz}, 1 \mathrm{H}\right), 2.90(\mathrm{~m}, 2 \mathrm{H}), 2.67(\mathrm{~m}, 2 \mathrm{H}), 1.98(\mathrm{~m}, 2 \mathrm{H}), 1.88(\mathrm{~m}, 1 \mathrm{H}), 1.73-1.65(\mathrm{~m}, 2 \mathrm{H}), 1.49(\mathrm{~m}$, 1H), 1.36-1.23 (m, 3H); ${ }^{13} \mathrm{C}-\mathrm{NMR}\left(100 \mathrm{MHz}, \mathrm{CDCl}_{3}\right.$, Figure S59) $\delta 207.6(\mathrm{C}=\mathrm{O}), 161.7-159.2\left(\mathrm{~d},{ }^{1} J_{\mathrm{C}-\mathrm{F}}\right.$ $=245.9 \mathrm{~Hz}, \mathrm{C}$, one carbon), $156.0(\mathrm{C}), 149.2(\mathrm{C}), 148.3(\mathrm{C}), 129.8(\mathrm{CH}), 129.7(\mathrm{CH}), 129.57-129.53(\mathrm{~d}$, ${ }^{3} J_{\mathrm{C}-\mathrm{F}}=3.8 \mathrm{~Hz}, \mathrm{CH}$, one carbon), 129.3 (C, two carbons), $129.2(\mathrm{CH}), 128.2(\mathrm{CH}$, two carbons), $127.1(\mathrm{C})$, $124.23-124.20\left(\mathrm{~d},{ }^{3} J_{\mathrm{C}-\mathrm{F}}=3.8 \mathrm{~Hz}, \mathrm{CH}\right.$, one carbon), $123.66-123.51\left(\mathrm{~d},{ }^{2} J_{\mathrm{C}-\mathrm{F}}=14.4 \mathrm{~Hz}, \mathrm{CH}\right.$, one carbon), $115.5-115.3\left(\mathrm{~d},{ }^{2} J_{\mathrm{C}-\mathrm{F}}=20.5 \mathrm{~Hz}, \mathrm{CH}\right.$, one carbon), $107.7(\mathrm{CH}), 106.6(\mathrm{CH}), 64.80-64.75\left(\mathrm{~d},{ }^{3} J_{\mathrm{C}-\mathrm{F}}=4.5 \mathrm{~Hz}\right.$, $\mathrm{CH}_{2}$, one carbon), $63.2\left(\mathrm{CH}_{2}\right), 56.2\left(\mathrm{CH}_{3}\right), 53.6\left(\mathrm{CH}_{2}\right.$, two carbons $), 45.4(\mathrm{CH}), 38.6\left(\mathrm{CH}_{2}\right), 34.3\left(\mathrm{CH}_{2}\right)$, $33.4\left(\mathrm{CH}_{2}\right), 32.7\left(\mathrm{CH}_{2}\right), 31.6(\mathrm{CH}) ; \mathrm{m} / z$ calcd. for $\mathrm{C}_{30} \mathrm{H}_{33} \mathrm{FNO}_{3}{ }^{+}[\mathrm{M}+\mathrm{H}]^{+}$474.2439; found 474.2429. The purity of the compound was further confirmed by RP-HPLC: $R_{\mathrm{t}}=20.06 \mathrm{~min}$ (96\%; Figure S60).

3.2.25. 2-[(1-Benzylpiperidin-4-yl)methyl]-6-[(2-trifluoromethylbenzyl)oxy-5-methoxy-2,3dihydroinden-1-one (8p)

A solution of compound $7(50 \mathrm{mg}, 0.14 \mathrm{mmol})$ and $\mathrm{K}_{2} \mathrm{CO}_{3}(38 \mathrm{mg}, 0.27 \mathrm{mmol})$ in anhydrous DMF $(5 \mathrm{~mL})$ was treated with 2-trifluoromethylbenzyl bromide $(25 \mu \mathrm{L}, 0.16 \mathrm{mmol})$ and the resulting mixture 
was stirred at RT overnight. The reaction mixture was then diluted with $\mathrm{H}_{2} \mathrm{O}$, and extracted with EtOAc $(3 \times)$. The combined organic layers were washed with $\mathrm{H}_{2} \mathrm{O}(3 \times)$ and brine $(3 \times)$, dried over anhydrous $\mathrm{MgSO}_{4}$, and filtered. The filtrate was concentrated under reduced pressure, and purified by column chromatography ( $\mathrm{SiO}_{2}$ gel, pure $\mathrm{CH}_{2} \mathrm{Cl}_{2}$ to $\mathrm{CH}_{2} \mathrm{Cl}_{2}: \mathrm{MeOH} / 19: 1 ; \mathrm{R}_{\mathrm{f}} 0.41$ in $\left.\mathrm{CH}_{2} \mathrm{Cl}_{2}: \mathrm{MeOH} / 19: 1\right)$ to yield compound $8 \mathrm{p}$ (65 mg, 90\%) as an off-white solid: ${ }^{1} \mathrm{H}-\mathrm{NMR}\left(400 \mathrm{MHz}, \mathrm{CDCl}_{3}\right.$, Figure S61) $\delta 7.75$ $(\mathrm{d}, J=7.6 \mathrm{~Hz}, 1 \mathrm{H}$, aromatic), $7.67(\mathrm{~d}, J=8.0 \mathrm{~Hz}, 1 \mathrm{H}$, aromatic), $7.54(\mathrm{t}, J=8.0 \mathrm{~Hz}, 1 \mathrm{H}$, aromatic), 7.39 (t, $J=7.6 \mathrm{~Hz}, 1 \mathrm{H}$, aromatic), $7.31-7.27$ (m, 4H, aromatic), $7.24(\mathrm{~m}, 1 \mathrm{H}$, aromatic), 7.18 (s, 1H, aromatic), 6.88 (s, $1 \mathrm{H}$, aromatic), 5.31 (s, $\left.2 \mathrm{H}, \mathrm{OCH}_{2} \mathrm{Ph}\right), 3.96\left(\mathrm{~s}, 3 \mathrm{H}, \mathrm{OC}_{3}\right), 3.51\left(\mathrm{~s}, 2 \mathrm{H}, \mathrm{NC}_{2} \mathrm{Ph}\right), 3.22$ (dd, $\left.J_{1}=17.6 \mathrm{~Hz}, J_{2}=8.0 \mathrm{~Hz}, 1 \mathrm{H}\right), 2.90(\mathrm{~m}, 2 \mathrm{H}), 2.68\left(\mathrm{dt}, J_{1}=14.4 \mathrm{~Hz}, J_{2}=3.2 \mathrm{~Hz}, 2 \mathrm{H}\right), 1.97(\mathrm{~m}, 2 \mathrm{H}), 1.88(\mathrm{~m}$, $1 \mathrm{H}), 1.69(\mathrm{~m}, 2 \mathrm{H}), 1.50(\mathrm{~m}, 1 \mathrm{H}), 1.40-1.24(\mathrm{~m}, 3 \mathrm{H})$; 13C-NMR (100 MHz, CDCl 3 , Figure S62) $\delta 207.6$, 156.0, 149.4, 148.2, 138.1, 135.07, 135.06, 132.1, 129.3 (two carbons), 129.2, 128.4, 128.2 (two carbons), $127.8,127.5,127.2,127.0,126.01,125.95,125.90,125.8,125.6,122.9,107.8,106.6,67.04,67.01,63.3$, 56.2, 53.71. 53.68, 45.4, 38.7, 34.3, 33.4, 32.8, 31.7; $\mathrm{m} / \mathrm{z}$ calcd. for $\mathrm{C}_{31} \mathrm{H}_{33} \mathrm{~F}_{3} \mathrm{NO}_{3}{ }^{+}[\mathrm{M}+\mathrm{H}]^{+} 524.2407$; found 524.2401. The purity of the compound was further confirmed by RP-HPLC: $R_{\mathrm{t}}=20.90 \mathrm{~min}(96 \%$; Figure S63).

3.2.26. 2-[(1-Benzylpiperidin-4-yl)methyl]-6-[(2,4-difluorobenzyl)oxy-5-methoxy-2,3-dihydroinden-1one $(\mathbf{8 q})$

A solution of compound 7 (50 $\mathrm{mg}, 0.14 \mathrm{mmol})$ and $\mathrm{K}_{2} \mathrm{CO}_{3}(38 \mathrm{mg}, 0.27 \mathrm{mmol})$ in anhydrous DMF $(5 \mathrm{~mL})$ was treated with 2,4-difluorobenzyl bromide $(21 \mu \mathrm{L}, 0.16 \mathrm{mmol})$ and the resulting mixture was stirred at RT overnight. The reaction mixture was then diluted with $\mathrm{H}_{2} \mathrm{O}$, and extracted with EtOAc $(3 \times)$. The combined organic layers were washed with $\mathrm{H}_{2} \mathrm{O}(3 \times)$ and brine $(3 \times)$, dried over anhydrous $\mathrm{MgSO}_{4}$, and filtered. The filtrate was concentrated under reduced pressure, and purified by column chromatography $\left(\mathrm{SiO}_{2}\right.$ gel, pure $\mathrm{CH}_{2} \mathrm{Cl}_{2}$ to $\mathrm{CH}_{2} \mathrm{Cl}_{2}: \mathrm{MeOH} / 19: 1 ; \mathrm{R}_{\mathrm{f}} 0.17$ in $\left.\mathrm{CH}_{2} \mathrm{Cl}_{2}: \mathrm{MeOH} / 19: 1\right)$ to yield compound $\mathbf{8 q}(57 \mathrm{mg}, 85 \%)$ as an off-white solid: ${ }^{1} \mathrm{H}-\mathrm{NMR}\left(400 \mathrm{MHz}, \mathrm{CDCl}_{3}\right.$, Figure S64) $\delta$ $7.46\left(\mathrm{dd}, J_{1}=14.8 \mathrm{~Hz}, J_{2}=8.4 \mathrm{~Hz}, 1 \mathrm{H}\right.$, aromatic), $7.31-7.27$ (m, 4H, aromatic), 7.24 (s, 1H, aromatic), 7.22 (s, 1H, aromatic), 6.88-6.79 (m, 3H, aromatic), $5.12\left(\mathrm{~s}, 2 \mathrm{H}, \mathrm{OC}_{2} \mathrm{Ph}\right), 3.93\left(\mathrm{~s}, 3 \mathrm{H}, \mathrm{OCH}_{3}\right), 3.52(\mathrm{~s}, 2 \mathrm{H}$, $\left.\mathrm{NCH}_{2} \mathrm{Ph}\right), 3.22\left(\mathrm{dd}, J_{1}=17.6 \mathrm{~Hz}, J_{2}=8.0 \mathrm{~Hz}, 1 \mathrm{H}\right), 2.90(\mathrm{~m}, 2 \mathrm{H}), 2.67\left(\mathrm{dt}, J_{1}=14.4 \mathrm{~Hz}, J_{2}=3.2 \mathrm{~Hz}, 2 \mathrm{H}\right)$, $1.98(\mathrm{~m}, 2 \mathrm{H}), 1.89(\mathrm{~m}, 1 \mathrm{H}), 1.69(\mathrm{~m}, 2 \mathrm{H}), 1.49(\mathrm{~m}, 1 \mathrm{H}), 1.40-1.26(\mathrm{~m}, 3 \mathrm{H})$; 13C-NMR $\left(100 \mathrm{MHz}, \mathrm{CDCl}_{3}\right.$, Figure S65) $\delta$ 207.6, 164.2, 164.0, 161.9, 161.8, 161.7, 161.6, 159.4, 159.3, 156.0, 149.3, 148.2, 137.9, 130.81, 130.75, 130.72, 130.66, 129.3 (two carbons), 129.2, 128.2 (two carbons), 127.0, 119.7, 119.6, 119.54, 119.50, 111.55, 111.51, 111.34, 111.30, 107.7, 106.6, 104.2, 103.9, 103.7, 64.34, 64.30, 63.3, 56.2, 53.7, 53.6, 45.4, 38.6, $34.3,33.4,32.8,31.6 ; \mathrm{m} / z$ calcd. for $\mathrm{C}_{30} \mathrm{H}_{32} \mathrm{~F}_{2} \mathrm{NO}_{3}{ }^{+}[\mathrm{M}+\mathrm{H}]^{+}$492.2345; found 492.2353. The purity of the compound was further confirmed by RP-HPLC: $R_{\mathrm{t}}=20.25 \mathrm{~min}(95 \%$; Figure S66).

3.2.27. 2-[(1-Benzylpiperidin-4-yl)methyl]-6-[(2,5-difluorobenzyl)oxy-5-methoxy-2,3-dihydroinden-1one $(8 \mathbf{r})$

A solution of compound 7 (50 $\mathrm{mg}, 0.14 \mathrm{mmol})$ and $\mathrm{K}_{2} \mathrm{CO}_{3}(38 \mathrm{mg}, 0.27 \mathrm{mmol})$ in anhydrous DMF $(5 \mathrm{~mL})$ was treated with 2,5-difluorobenzyl bromide $(21 \mu \mathrm{L}, 0.16 \mathrm{mmol})$, and the resulting mixture was stirred at RT overnight. The reaction mixture was then diluted with $\mathrm{H}_{2} \mathrm{O}$, and extracted with EtOAc $(3 \times)$. The combined organic layers were washed with $\mathrm{H}_{2} \mathrm{O}(3 \times)$ and brine $(3 \times)$, dried over anhydrous $\mathrm{MgSO}_{4}$, and filtered. The filtrate was concentrated under reduced pressure and purified by column chromatography $\left(\mathrm{SiO}_{2}\right.$ gel, pure $\mathrm{CH}_{2} \mathrm{Cl}_{2}$ to $\mathrm{CH}_{2} \mathrm{Cl}_{2}: \mathrm{MeOH} / 19: 1 ; \mathrm{R}_{\mathrm{f}} 0.17$ in $\left.\mathrm{CH}_{2} \mathrm{Cl}_{2}: \mathrm{MeOH} / 19: 1\right)$ to yield compound $8 \mathbf{r}(67 \mathrm{mg}, 85 \%)$ as an off-white solid: ${ }^{1} \mathrm{H}-\mathrm{NMR}\left(400 \mathrm{MHz}, \mathrm{CDCl}_{3}\right.$, Figure S67) $\delta$ 7.32-7.28 (m, 4H, aromatic), $7.24\left(\mathrm{~m}, 2 \mathrm{H}\right.$, aromatic), 7.19 (s, 1H, aromatic), $7.02\left(\mathrm{td}, J_{1}=8.8 \mathrm{~Hz}, J_{2}=4.0\right.$ $\mathrm{Hz}, 1 \mathrm{H}$, aromatic), 6.97-6.91 (m, 1H, aromatic), 6.87 (s, 1H, aromatic), $5.16\left(\mathrm{~s}, 2 \mathrm{H}, \mathrm{OC}_{2} \mathrm{Ph}\right), 3.95(\mathrm{~s}, 3 \mathrm{H}$, $\left.\mathrm{OCH}_{3}\right), 3.54\left(\mathrm{~s}, 2 \mathrm{H}, \mathrm{NCH}_{2} \mathrm{Ph}\right), 3.22\left(\mathrm{dd}, J_{1}=17.6 \mathrm{~Hz}, J_{2}=8.0 \mathrm{~Hz}, 1 \mathrm{H}\right), 2.92(\mathrm{~m}, 2 \mathrm{H}), 2.68\left(\mathrm{dt}, J_{1}=14.0\right.$ $\left.\mathrm{Hz}, J_{2}=3.6 \mathrm{~Hz}, 2 \mathrm{H}\right), 2.05(\mathrm{~m}, 2 \mathrm{H}), 1.88(\mathrm{~m}, 1 \mathrm{H}), 1.70(\mathrm{~m}, 2 \mathrm{H}), 1.51(\mathrm{~m}, 1 \mathrm{H}), 1.40-1.24(\mathrm{~m}, 3 \mathrm{H}) ; 13 \mathrm{C}-\mathrm{NMR}$ $\left(100 \mathrm{MHz}_{,} \mathrm{CDCl}_{3}\right.$, Figure S68) $\delta$ 207.5, 160.02, 160.00, 157.62, 157.60, 157.21, 157.19, 155.9, 154.79, 154.77, 149.4, 148.0, 137.7, 129.4 (two carbons), 129.2, 128.2 (two carbons), 127.1, 125.6, 125.5, 125.4, 125.3, 116.6, 
$116.5,116.3,116.2,116.0,115.9,115.8,115.7,115.6,115.43,115.38,107.8,106.5,64.2,64.1,63.2,56.2,53.60$, 53.57, 45.3, 38.6, 34.2, 33.4, 32.6, 31.5; $\mathrm{m} / \mathrm{z}$ calcd. for $\mathrm{C}_{30} \mathrm{H}_{32} \mathrm{~F}_{2} \mathrm{NO}_{3}{ }^{+}[\mathrm{M}+\mathrm{H}]^{+} 492.2345$; found 492.2350 . Purity of the compound was further confirmed by RP-HPLC: $R_{\mathrm{t}}=20.28 \mathrm{~min}(96 \%$; Figure S69).

3.2.28. 2-[(1-Benzylpiperidin-4-yl)methyl]-6-[(2,6-difluorobenzyl)oxy-5-methoxy-2,3-dihydroinden-1one $(8 \mathbf{s})$

A solution of compound $7(50 \mathrm{mg}, 0.14 \mathrm{mmol})$ and $\mathrm{K}_{2} \mathrm{CO}_{3}(38 \mathrm{mg}, 0.27 \mathrm{mmol})$ in anhydrous DMF $(5 \mathrm{~mL})$ was treated with 2,6-difluorobenzyl bromide (34 $\mathrm{mg}, 0.16 \mathrm{mmol}$ ), and the resulting mixture was stirred at RT overnight. The reaction mixture was then diluted with $\mathrm{H}_{2} \mathrm{O}$, and extracted with EtOAc $(3 \times)$. The combined organic layers were washed with $\mathrm{H}_{2} \mathrm{O}(3 \times)$ and brine $(3 \times)$, dried over anhydrous $\mathrm{MgSO}_{4}$, and filtered. The filtrate was concentrated under reduced pressure and purified by column chromatography $\left(\mathrm{SiO}_{2}\right.$ gel, pure $\mathrm{CH}_{2} \mathrm{Cl}_{2}$ to $\mathrm{CH}_{2} \mathrm{Cl}_{2}: \mathrm{MeOH} / 19: 1 ; \mathrm{R}_{\mathrm{f}} 0.34$ in $\left.\mathrm{CH}_{2} \mathrm{Cl}_{2}: \mathrm{MeOH} / 19: 1\right)$ to yield compound 8 s (62 mg, 93\%) as an off-white solid: ${ }^{1} \mathrm{H}-\mathrm{NMR}\left(400 \mathrm{MHz}, \mathrm{CDCl}_{3}\right.$, Figure S70) $\delta$ 7.32-7.27 (m, 6H, aromatic), $7.24(\mathrm{~m}, 1 \mathrm{H}$, aromatic), $6.90(\mathrm{t}, J=8.0 \mathrm{~Hz}, 2 \mathrm{H}$, aromatic), $6.84(\mathrm{~s}, 1 \mathrm{H}$, aromatic), $5.14\left(\mathrm{~s}, 2 \mathrm{H}, \mathrm{OCH}_{2} \mathrm{Ph}\right), 3.88\left(\mathrm{~s}, 3 \mathrm{H}, \mathrm{OCH}_{3}\right), 3.53\left(\mathrm{~s}, 2 \mathrm{H}, \mathrm{NC}_{2} \mathrm{Ph}\right), 3.22\left(\mathrm{dd}, J_{1}=17.6 \mathrm{~Hz}\right.$, $\left.J_{2}=8.0 \mathrm{~Hz}, 1 \mathrm{H}\right), 2.91(\mathrm{~m}, 2 \mathrm{H}), 2.68\left(\mathrm{dt}, J_{1}=14.4 \mathrm{~Hz}, J_{2}=4.4 \mathrm{~Hz}, 2 \mathrm{H}\right), 2.00(\mathrm{~m}, 2 \mathrm{H}), 1.89(\mathrm{~m}, 1 \mathrm{H}), 1.70(\mathrm{~m}$,

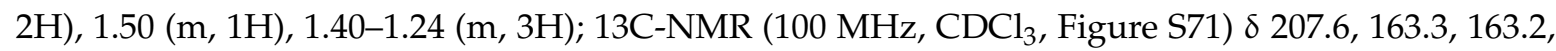
$160.8,160.7,156.2,149.5,148.4,137.7,131.0,130.9,130.8,129.4$ (two carbons), 129.2, 128.2 (two carbons), $127.1,112.4,112.2,112.0,111.6,111.5,111.4,111.3,107.8,107.3,63.2,59.19,59.15,59.11,56.2,53.61$, 53.58, 45.4, 38.6, 34.2, 33.4, 32.7, 31.6; $\mathrm{m} / \mathrm{z}$ calcd. for $\mathrm{C}_{30} \mathrm{H}_{32} \mathrm{~F}_{2} \mathrm{NO}_{3}{ }^{+}[\mathrm{M}+\mathrm{H}]^{+}$492.2345; found 492.2352. The purity of the compound was further confirmed by RP-HPLC: $R_{\mathrm{t}}=19.99 \mathrm{~min}(96 \%$; Figure S72).

3.2.29. 2-[(1-Benzylpiperidin-4-yl)methyl]-6-[(4-bromo-2-fluorobenzyl)oxy-5-methoxy-2,3dihydroinden-1-one (8t)

A solution of compound 7 (50 mg, $0.14 \mathrm{mmol})$ and $\mathrm{K}_{2} \mathrm{CO}_{3}(38 \mathrm{mg}, 0.27 \mathrm{mmol})$ in anhydrous DMF $(5 \mathrm{~mL})$ was treated with 4 -bromo-2-fluorobenzyl bromide $(44 \mathrm{mg}, 0.16 \mathrm{mmol})$, and the resulting mixture was stirred at RT overnight. The reaction mixture was then diluted with $\mathrm{H}_{2} \mathrm{O}$, and extracted with EtOAc $(3 \times)$. The combined organic layers were washed with $\mathrm{H}_{2} \mathrm{O}(3 \times)$ and brine $(3 \times)$, dried over anhydrous $\mathrm{MgSO}_{4}$, and filtered. The filtrate was concentrated under reduced pressure and purified by column chromatography ( $\mathrm{SiO}_{2}$ gel, pure $\mathrm{CH}_{2} \mathrm{Cl}_{2}$ to $\mathrm{CH}_{2} \mathrm{Cl}_{2}: \mathrm{MeOH} / 19: 1 ; \mathrm{R}_{\mathrm{f}} 0.56$ in $\left.\mathrm{CH}_{2} \mathrm{Cl}_{2}: \mathrm{MeOH} / 19: 1\right)$ to yield compound $\mathbf{8 t}(69 \mathrm{mg}, 91 \%)$ as an off-white solid: ${ }^{1} \mathrm{H}-\mathrm{NMR}\left(400 \mathrm{MHz}, \mathrm{CDCl}_{3}\right.$, Figure S73) $\delta 7.37$ (t, $J=7.6 \mathrm{~Hz}, 1 \mathrm{H}$, aromatic), 7.31-7.26 (m, 6H, aromatic), $7.24(\mathrm{~m}, 1 \mathrm{H}$, aromatic), 7.19 (s, 1H, aromatic), $6.86\left(\mathrm{~s}, 1 \mathrm{H}\right.$, aromatic), $5.12\left(\mathrm{~s}, 2 \mathrm{H}, \mathrm{OC}_{2} \mathrm{Ph}\right), 3.93\left(\mathrm{~s}, 3 \mathrm{H}, \mathrm{OC}_{3}\right), 3.51\left(\mathrm{~s}, 2 \mathrm{H}, \mathrm{NC}_{2} \mathrm{Ph}\right), 3.22$ (dd, $\left.J_{1}=17.6 \mathrm{~Hz}, J_{2}=8.0 \mathrm{~Hz}, 1 \mathrm{H}\right), 2.90(\mathrm{~m}, 2 \mathrm{H}), 2.68\left(\mathrm{dt}, J_{1}=14.4 \mathrm{~Hz}, J_{2}=3.2 \mathrm{~Hz}, 2 \mathrm{H}\right), 1.98(\mathrm{~m}, 2 \mathrm{H}), 1.88(\mathrm{~m}$, $1 \mathrm{H}), 1.69$ (m, 2H), $1.48(\mathrm{~m}, 1 \mathrm{H}), 1.40-1.24(\mathrm{~m}, 3 \mathrm{H}) ;{ }^{13} \mathrm{C}-\mathrm{NMR}\left(100 \mathrm{MHz}, \mathrm{CDCl}_{3}\right.$, Figure S74) $\delta 207.5$, $161.4,158.8,155.9,149.4,148.0,138.1,130.63,130.58,129.3$ (two carbons), 129.2, 128.1 (two carbons), 127.64, 127.60, 127.0, 123.0, 122.8, 122.2, 122.1, 119.2, 119.0, 107.8, 106.6, 64.3, 64.2, 63.3, 56.2, 53.70, $53.68,45.4,38.6,34.3,33.4,32.9,31.7 ; \mathrm{m} / z$ calcd. for $\mathrm{C}_{30} \mathrm{H}_{32} \mathrm{BrFNO}_{3}{ }^{+}[\mathrm{M}+\mathrm{H}]^{+}$552.1544; found 552.1546. The purity of the compound was further confirmed by RP-HPLC: $R_{\mathrm{t}}=21.25 \mathrm{~min}(96 \%$; Figure S75).

3.2.30. 2-[(1-Benzylpiperidin-4-yl)methyl]-6-[(2,4,6-trifluorobenzyl)oxy-5-methoxy-2,3-dihydroinden1-one $(8 \mathbf{u})$

A solution of compound $7(50 \mathrm{mg}, 0.14 \mathrm{mmol})$ and $\mathrm{K}_{2} \mathrm{CO}_{3}(38 \mathrm{mg}, 0.27 \mathrm{mmol})$ in anhydrous DMF $(5 \mathrm{~mL})$ was treated with 2,4,6-trifluorobenzyl bromide $(22 \mu \mathrm{L}, 0.16 \mathrm{mmol})$ and the resulting mixture was stirred at RT overnight. The reaction mixture was then diluted with $\mathrm{H}_{2} \mathrm{O}$, and extracted with EtOAc $(3 \times)$. The combined organic layers were washed with $\mathrm{H}_{2} \mathrm{O}(3 \times)$ and brine $(3 \times)$, dried over anhydrous $\mathrm{MgSO}_{4}$, and filtered. After standing at RT overnight, white solids precipitated out, which were filtered off. The filtrate was further concentrated under reduced pressure and purified by column chromatography ( $\mathrm{SiO}_{2}$ gel, pure $\mathrm{CH}_{2} \mathrm{Cl}_{2}$ to $\mathrm{CH}_{2} \mathrm{Cl}_{2}: \mathrm{MeOH} / 19: 1 ; \mathrm{R}_{\mathrm{f}} 0.31$ in $\left.\mathrm{CH}_{2} \mathrm{Cl}_{2}: \mathrm{MeOH} / 19: 1\right)$ to yield compound $\mathbf{8 u}(65 \mathrm{mg}, 93 \%)$ as an off-white solid: ${ }^{1} \mathrm{H}-\mathrm{NMR}\left(400 \mathrm{MHz}, \mathrm{CDCl}_{3}\right.$, Figure S76) 
反 7.32-7.29 $(\mathrm{m}, 5 \mathrm{H}$, aromatic), $7.24(\mathrm{~s}, 1 \mathrm{H}$, aromatic), $6.84(\mathrm{~s}, 1 \mathrm{H}$, aromatic $), 6.68(\mathrm{t}, J=8.4 \mathrm{~Hz}, 2 \mathrm{H}$, aromatic), $5.08\left(\mathrm{~s}, 2 \mathrm{H}, \mathrm{OC}_{2} \mathrm{Ph}\right), 3.89\left(\mathrm{~s}, 3 \mathrm{H}, \mathrm{OC}_{3}\right), 3.54\left(\mathrm{~s}, 2 \mathrm{H}, \mathrm{NC}_{2} \mathrm{Ph}\right), 3.22\left(\mathrm{dd}, J_{1}=17.6 \mathrm{~Hz}\right.$, $\left.J_{2}=8.0 \mathrm{~Hz}, 1 \mathrm{H}\right), 2.92(\mathrm{~m}, 2 \mathrm{H}), 2.68\left(\mathrm{dt}, J_{1}=14.4 \mathrm{~Hz}, J_{2}=3.2 \mathrm{~Hz}, 2 \mathrm{H}\right), 2.02(\mathrm{~m}, 2 \mathrm{H}), 1.89(\mathrm{~m}, 1 \mathrm{H}), 1.70(\mathrm{~m}$, 2H), $1.51(\mathrm{~m}, 1 \mathrm{H}), 1.40-1.26(\mathrm{~m}, 3 \mathrm{H})$; 13C-NMR (100 MHz, CDCl 3 , Figure S77) $\delta 207.6,164.6,164.5$, 164.3, 163.7, 163.6, 163.5, 163.4, 162.1, 162.0, 161.8, 161.1, 161.04, 161.00, 160.9, 152.2, 149.6, 148.2, 137.7, 129.4 (two carbons), 129.2, 128.2 (two carbons), 127.1, 108.92, 108.87, 108.72, 108.67, 108.53, 108.48, 107.9, 107.4, 100.69, 100.67, 100.6, 100.5, 100.44, 100.42, 100.39, 100.35, 100.2, 100.1, 63.2, 58.80, 58.76, 58.7, 56.2, 53.63. 53.59, 45.4, 38.6, 34.2, 33.4, 32.7, 31.6; $\mathrm{m} / z$ calcd. for $\mathrm{C}_{30} \mathrm{H}_{31} \mathrm{~F}_{3} \mathrm{NO}_{3}{ }^{+}[\mathrm{M}+\mathrm{H}]^{+}$510.2251; found 510.2255. The purity of the compound was further confirmed by RP-HPLC: $R_{\mathrm{t}}=20.30 \mathrm{~min}(95 \%$; Figure S78).

3.2.31. 2-[(1-Benzylpiperidin-4-yl)methyl]-6-[(2,3,4,5,6-pentafluorobenzyl)oxy-5-methoxy-2,3dihydroinden-1-one (8v)

A solution of compound $7(50 \mathrm{mg}, 0.14 \mathrm{mmol})$ and $\mathrm{K}_{2} \mathrm{CO}_{3}(38 \mathrm{mg}, 0.27 \mathrm{mmol})$ in anhydrous DMF ( $5 \mathrm{~mL}$ ) was treated with 2,3,4,5-pentafluorobenzyl bromide ( $25 \mu \mathrm{L}, 0.16 \mathrm{mmol})$, and the resulting mixture was stirred at $\mathrm{RT}$ overnight. The reaction mixture was then diluted with $\mathrm{H}_{2} \mathrm{O}$, and extracted with EtOAc $(3 \times)$. The combined organic layers were washed with $\mathrm{H}_{2} \mathrm{O}(3 \times)$ and brine $(3 \times)$, dried over anhydrous $\mathrm{MgSO}_{4}$, and filtered. The filtrate was concentrated under reduced pressure and purified by column chromatography $\left(\mathrm{SiO}_{2}\right.$ gel, pure $\mathrm{CH}_{2} \mathrm{Cl}_{2}$ to $\mathrm{CH}_{2} \mathrm{Cl}_{2}: \mathrm{MeOH} / 19: 1 ; \mathrm{R}_{\mathrm{f}} 0.34$ in $\left.\mathrm{CH}_{2} \mathrm{Cl}_{2}: \mathrm{MeOH} / 19: 1\right)$ to yield compound $8 \mathbf{v}(61 \mathrm{mg}, 81 \%)$ as an off-white solid: ${ }^{1} \mathrm{H}-\mathrm{NMR}(400 \mathrm{MHz}$, $\mathrm{CDCl}_{3}$, Figure S79) $\delta 7.32-7.24\left(\mathrm{~m}, 6 \mathrm{H}\right.$, aromatic), $6.86\left(\mathrm{~s}, 1 \mathrm{H}\right.$, aromatic), $5.13\left(\mathrm{~s}, 2 \mathrm{H}, \mathrm{OC}_{2} \mathrm{Ph}\right), 3.90(\mathrm{~s}$, $\left.3 \mathrm{H}, \mathrm{OCH}_{3}\right), 3.53\left(\mathrm{~s}, 2 \mathrm{H}, \mathrm{NCH}_{2} \mathrm{Ph}\right), 3.23\left(\mathrm{dd}, J_{1}=17.6 \mathrm{~Hz}, J_{2}=8.0 \mathrm{~Hz}, 1 \mathrm{H}\right), 2.91(\mathrm{~m}, 2 \mathrm{H}), 2.69(\mathrm{dt}$, $\left.J_{1}=13.6 \mathrm{~Hz}, J_{2}=4.0 \mathrm{~Hz}, 2 \mathrm{H}\right), 2.00(\mathrm{~m}, 2 \mathrm{H}), 1.89(\mathrm{~m}, 1 \mathrm{H}), 1.70(\mathrm{~m}, 2 \mathrm{H}), 1.51(\mathrm{~m}, 1 \mathrm{H}), 1.40-1.24(\mathrm{~m}, 3 \mathrm{H})$; 13C-NMR (100 MHz, CDCl , Figure S80) $\delta$ 207.4, 156.2, 150.1, 147.8, 147.20, 147.16, 147.12, 147.08, 147.04, 147.01, 146.97, 146.93, 144.70, 144.66, 144.62, 144.58, 144.55, 144.51, 144.47, 144.43, 143.23, 143.16, 143.10, 143.05, 142.97, 140.7, 140.61, 140.56, 140.5, 140.4, 138.93, 138.90, 138.8, 138.7, 138.65, 138.60, 138.59, 137.6, 136.42, 136.38, 136.30, 136.26, 136.23, 136.13, 136.10, 129.4 (two carbons), 129.2, 128.5, 128.2 (two carbons), 127.1, 109.91, 109.87, 109.74, 109.70, 109.6, 109.5, 108.0, 107.8, 63.1, 58.7, 56.2, 53.6, 53.5, 45.3, 38.6, 34.2, 33.4, 32.6, 31.5; $\mathrm{m} / z$ calcd. for $\mathrm{C}_{30} \mathrm{H}_{29} \mathrm{~F}_{5} \mathrm{NO}_{3}{ }^{+}[\mathrm{M}+\mathrm{H}]^{+} 546.2062$; found 546.2058. The purity of the compound was further confirmed by RP-HPLC: $R_{\mathrm{t}}=20.84 \mathrm{~min}$ (95\%; Figure S81).

\subsection{In Vitro Cholinesterase (ChE) Inhibition Assays}

Experiments were performed as previously described [11,13]. Briefly, donepezil analogues (102 pm to $200 \mu \mathrm{M})$ were dissolved in sodium phosphate buffer $((100 \mu \mathrm{L}), 0.1 \mathrm{M}, \mathrm{pH}$ 8.0) (Buffer A) and subjected to a 5-fold serial dilution. $\mathrm{ChE}$ (either EeAChE or $E f \mathrm{BChE}$ ) was added to the solution of inhibitors $(50 \mu \mathrm{L}$, containing $0.08 \mathrm{U} / \mathrm{mL} \mathrm{ChE}$ (final concentration for both EeAChE and EfBChE) in Buffer A. The mixture of inhibitor and enzyme was incubated for $10 \mathrm{~min}$ before initiation with DTNB $(50 \mu \mathrm{L}, 0.25 \mathrm{mM}$ final concentration) and acylthiocholine (acetylthiocholine for EeAChE and butyrylthiochholine for $E f \mathrm{BChE}$ ) (0.5 mM final concentration) in phosphate buffer. The reaction was monitored at $412 \mathrm{~nm}$ taking measurements every $30 \mathrm{~s}$ for $10 \mathrm{~min}$ using a Spectra Max M5 plate reader (Molecular Devices, San Jose, CA, USA) at $25^{\circ} \mathrm{C}$. Data was corrected with the negative control (no acylthiocholine), and normalized to the positive control (no inhibitor) using the initial rates (first $5 \mathrm{~min}$ ). All assays were performed in duplicate or triplicate. HsAChE was treated in the same manner with the following exceptions: the final concentration of $H s \mathrm{AChE}$ was $0.16 \mu \mathrm{g} / \mathrm{mL}$ $(\sim 0.16 \mathrm{U} / \mathrm{mL})$, and reactions were performed at $37^{\circ} \mathrm{C}$. The data was fitted to a sigmoidal curve, and $\mathrm{IC}_{50}$ values were calculated using Sigmaplot 14.0 (Systat Software, San Jose, CA, USA). The IC $_{50}$ curves for $E e A C h E$ and $E f B C h E$ inhibition are presented in Table 1 and Figures S82 and S83 (for EeAChE) and Figures $\mathrm{S} 84$ and $\mathrm{S} 85$ (for $E f \mathrm{BChE}$ ). The $\mathrm{IC}_{50}$ curves for $\mathrm{HsAChE}$ inhibition are presented in Table 2 and Figure S86. 


\subsection{BACE1 Inhibition}

Inhibition of BACE1 was tested using the commercial kit (cat CS0010-1KT, Millipore-Sigma, St. Louis, MO, USA) following the directions accompanying the kit. All compounds were tested in duplicate at a single concentration $(200 \mu \mathrm{M})$ in order to confirm any activity. All compounds that showed BACE1 inhibitory activity were then tested in a concentration-dependent manner. Dilutions were originally performed in DMSO, and $2 \mu \mathrm{L}$ added to the reaction in order to account for any moderation of activity from the vehicle. Fluorescent measurements were taken after $2 \mathrm{~h}$. The resulting rates were normalized to the reaction without inhibitor. In order to get an appropriate sigmoidal fit, two additional points (400 and $1000 \mu \mathrm{M})$ were added to the data when needed. Since the activity of the enzyme was already negligible at $200 \mu \mathrm{M}$, these points aid the sigmoidal nature of the curve fit. These data are presented in Table 3 and Figure S87.

\subsection{Molecular Docking of Donepezil and Compound 81 with BACE1}

To further validate the biochemical results obtained against BACE1, we modeled donepezil and compound 81 using a known crystal structure of BACE1 with an inhibitor, sharing the vicinyl dioxygen substitution of donepezil as a model (PDB\# 4FM7 [25]). Swiss Dock $[29,30]$ was used to identify the potential binding sites of donepezil or compound $\mathbf{8 1}$ with the crystal structure. Once docking calculations were completed, Chimera [31] was used to compare the potential binding sites with that of the known inhibitors. The closest alignments were selected, and they are presented in Figure 1.

\section{Conclusions}

We have synthesized 22 new donepezil analogues, $8 \mathbf{a}-\mathbf{v}$, and evaluated their biochemical capabilities, along with that of the parent donepezil and its 6-O-desmethyl adduct 7. Without exception, these compounds were all able to inhibit the action of EeAChE and EfBChE in the low-to-sub-micromolar ranges. Compound 8t, one of the better inhibitors of $E e \mathrm{AChE}$ and $E f \mathrm{BChE}$ was also a very efficient inhibitor of $H s A C h E$ showing the highest preference for this medically relevant enzyme. Attachment of an alkyl/aromatic group at the 6-O-position of the indanone ring also seems to enhance their efficacy. While their inhibitory capabilities were greater against $E e A C h E$ than $E f \mathrm{BChE}$, the donepezil analogues $\mathbf{8 h}-\mathbf{v}$ with aromatic substituents displayed a much improved potency when compared to donepezil against $E f \mathrm{BChE}$ than $E e \mathrm{AChE}$. The analogues 8a-g with alkyl substituents showed proportional change with respect to donepezil against both $E e A C h E$ and $E f B C h E$. The donepezil analogues $\mathbf{8 c}, \mathbf{8 e}, \mathbf{8 f}$, and $\mathbf{8 1}$ also displayed potent BACE1 inhibitory activities, and thus appeared to be multifunctional compounds for the treatment of Alzheimer's disease.

Supplementary Materials: The Supplementary Materials include ${ }^{1} \mathrm{H}$ and ${ }^{13} \mathrm{C}-\mathrm{NMR}$ spectra for the molecules synthesized, as well as HPLC traces of compounds tested for activity (Figures S1-S81). The IC 50 curves for the inhibition of EeAChE, HsAChE, EfBChE, and BACE1 are also provided (Figures S82-S87). The SwissDock modeling is also provided (Figure S88). These materials are available free of charge via the internet.

Author Contributions: M.Y.F. synthesized all the compounds and conducted the EeAChE and EfBChE inhibition assays; K.D.G. performed the HsAChE and BACE1 assays; K.D.G., M.Y.F., and S.G.-T. analyzed the data and wrote the paper.

Funding: This work was supported by startup funds (to S.G.-T.) from the College of Pharmacy at the University of Kentucky. Molecular graphics and analyses were performed with UCSF Chimera, developed by the Resource for Biocomputing, Visualization, and Informatics at the University of California, San Francisco, with support from NIH P41-GM103311.

Conflicts of Interest: The authors declare no conflict of interest. 


\section{Abbreviations}

$\mathrm{A} \beta$
$\mathrm{APP}$
$\mathrm{BACE}$
$\mathrm{ChE}$
EeAChE
EfBChE
$\mathrm{HsAChE}$
$\mathrm{IC}_{50}$
$\mathrm{KOH}$
$\mathrm{MsOH}$
$\mathrm{TBDMS}$

amyloid- $\beta$

amyloid precursor protein

$\beta$-secretase

cholinesterase

acetylcholinesterase (from Electrophorus electricus)

butyrylcholinesterase (from Equus ferus)

acetylcholinesterase (from Homo sapiens)

half maximal inhibitory concentration

potassium hydroxide

methanesulfonic acid

tert-butyldimethylsilyl

\section{References}

1. Alzheimer's Association. 2018 Alzheimer's disease facts and figures. Alzheimers Dement. 2018, 14, $367-429$. [CrossRef]

2. World Health Organization. Global health estimates 2016: Deaths by cause, age, sex, by country, and by region, Geneva, Switzerland. 2018.

3. Schmidt, C.; Wolff, M.; Weitz, M.; Bartlau, T.; Korth, C.; Zerr, I. Rapidly progressive Alzheimer disease. Arch. Neurol. 2011, 68, 1124-1130. [CrossRef]

4. Marco-Contelles, J.; Unzeta, M.; Bolea, I.; Esteban, G.; Ramsay, R.R.; Romero, A.; Martinez-Murillo, R.; Carreiras, M.C.; Ismaili, L. Ass234, as a new multi-target directed propargylamine for Alzheimer's disease therapy. Front. Neurosci. 2016, 10, 294. [CrossRef]

5. Bartus, R.T.; Dean, R.L., 3rd; Beer, B.; Lippa, A.S. The cholinergic hypothesis of geriatric memory dysfunction. Science 1982, 217, 408-414. [CrossRef]

6. Shah, A.A.; Dar, T.A.; Dar, P.A.; Ganie, S.A.; Kamal, M.A. A current perspective on the inhibition of cholinesterase by natural and synthetic inhibitors. Curr. Drug Metab. 2017, 18, 96-111. [CrossRef] [PubMed]

7. Unzeta, M.; Esteban, G.; Bolea, I.; Fogel, W.A.; Ramsay, R.R.; Youdim, M.B.; Tipton, K.F.; Marco-Contelles, J. Multi-target directed donepezil-like ligands for Alzheimer's disease. Front. Neurosci. 2016, 10, 205. [CrossRef]

8. Eckroat, T.J.; Mayhoub, A.S.; Garneau-Tsodikova, S. Amyloid- $\beta$ probes: Review of structure-activity and brain-kinetics relationships. Beilstein J. Org. Chem. 2013, 9, 1012-1044. [CrossRef] [PubMed]

9. Coulson, E.J.; Paliga, K.; Beyreuther, K.; Masters, C.L. What the evolution of the amyloid protein precursor supergene family tells us about its function. Neurochem. Int. 2000, 36, 175-184. [CrossRef]

10. Dobrowolska Zakaria, J.A.; Vassar, R.J. A promising, novel, and unique BACE1 inhibitor emerges in the quest to prevent Alzheimer's disease. EMBO Mol. Med. 2018. [CrossRef] [PubMed]

11. Eckroat, T.J.; Green, K.D.; Reed, R.A.; Bornstein, J.J.; Garneau-Tsodikova, S. Investigation of the role of linker moieties in bifunctional tacrine hybrids. Bioorg. Med. Chem. 2013, 21, 3614-3623. [CrossRef] [PubMed]

12. Kochi, A.; Eckroat, T.J.; Green, K.D.; Mayhoub, A.S.; Lim, M.H.; Garneau-Tsodikova, S. A novel hybrid of 6-chlorotacrine and metal-amyloid- $\beta$ modulator for inhibition of acetylcholine and metal-induced amyloid- $\beta$ aggregation. Chem. Sci. 2013, 4, 4137-4145. [CrossRef]

13. Bornstein, J.J.; Eckroat, T.J.; Houghton, J.L.; Jones, C.K.; Green, K.D.; Garneau-Tsodikova, S. Tacrinemefenamic acid hybrids for inhibition of acetycholinesterase. Med. Chem. Comm. 2011, 2, 406-412. [CrossRef]

14. Fosso, M.Y.; McCarty, K.; Head, E.; Garneau-Tsodikova, S.; LeVine, H., 3rd. Differential effects of structural modifications on the competition of chalcones for the PIB amyloid imaging ligand-binding site in Alzheimer's disease brain and synthetic abeta fibrils. ACS Chem. Neurosci. 2016, 7, 171-176. [CrossRef] [PubMed]

15. Fosso, M.Y.; LeVine, H., 3rd; Green, K.D.; Tsodikov, O.V.; Garneau-Tsodikova, S. Effects of structural modifications on the metal binding, anti-amyloid activity, and cholinesterase inhibitory activity of chalcones. Org. Biomol. Chem. 2015, 13, 9418-9426. [CrossRef] [PubMed]

16. Zhu, Y.; Xiao, K.; Ma, L.; Xiong, B.; Fu, Y.; Yu, H.; Wang, W.; Wang, X.; Hu, D.; Peng, H.; et al. Design, synthesis and biological evaluation of novel dual inhibitors of acetylcholinesterase and $\beta$-secretase. Bioorg. Med. Chem. 2009, 17, 1600-1613. [CrossRef] [PubMed] 
17. Panek, D.; Wieckowska, A.; Pasieka, A.; Godyn, J.; Jonczyk, J.; Bajda, M.; Knez, D.; Gobec, S.; Malawska, B. Design, synthesis, and biological evaluation of 2-(benzylamino-2-hydroxyalkyl)isoindoline-1,3-diones derivatives as potential disease-modifying multifunctional anti-Alzheimer's agents. Molecules 2018, 23, 347. [CrossRef]

18. Zhao, X.J.; Gong, D.M.; Jiang, Y.R.; Guo, D.; Zhu, Y.; Deng, Y.C. Multipotent AChE and BACE-1 inhibitors for the treatment of Alzheimer's disease: Design, synthesis and bio-analysis of 7-amino-1,4-dihydro2h-isoquilin-3-one derivates. Eur. J. Med. Chem. 2017, 138, 738-747. [CrossRef]

19. Costanzo, P.; Cariati, L.; Desiderio, D.; Sgammato, R.; Lamberti, A.; Arcone, R.; Salerno, R.; Nardi, M.; Masullo, M.; Oliverio, M. Design, synthesis, and evaluation of donepezil-like compounds as AChE and BACE-1 inhibitors. ACS Med. Chem. Lett. 2016, 7, 470-475. [CrossRef]

20. Meng, F.C.; Mao, F.; Shan, W.J.; Qin, F.; Huang, L.; Li, X.S. Design, synthesis, and evaluation of indanone derivatives as acetylcholinesterase inhibitors and metal-chelating agents. Bioorg. Med. Chem. Lett. 2012, 22, 4462-4466. [CrossRef]

21. Hu, J.; Yan, J.; Chen, J.; Pang, Y.; Huang, L.; Li, X. Synthesis, biological evaluation and mechanism study of a class of benzylideneindanone derivatives as novel anticancer agents. MedChemComm 2015, 6, 1318-1327. [CrossRef]

22. Ellman, G.L.; Courtney, K.D.; Andres, V., Jr.; Feather-Stone, R.M. A new and rapid colorimetric determination of acetylcholinesterase activity. Biochem. Pharmacol. 1961, 7, 88-95. [CrossRef]

23. Nochi, S.; Asakawa, N.; Sato, T. Kinetic study on the inhibition of acetylcholinesterase by 1-benzyl-4-[(5,6-dimethoxy-1-indanon)-2-yl]methylpiperidine hydrochloride (e2020). Biol. Pharm. Bull. 1995, 18, 1145-1147. [CrossRef]

24. Saxena, A.; Redman, A.M.; Jiang, X.; Lockridge, O.; Doctor, B.P. Differences in active site gorge dimensions of cholinesterases revealed by binding of inhibitors to human butyrylcholinesterase. Biochemistry 1997, 36, 14642-14651. [CrossRef]

25. Brodney, M.A.; Barreiro, G.; Ogilvie, K.; Hajos-Korcsok, E.; Murray, J.; Vajdos, F.; Ambroise, C.; Christoffersen, C.; Fisher, K.; Lanyon, L.; et al. Spirocyclic sulfamides as $\beta$-secretase 1 (BACE-1) inhibitors for the treatment of Alzheimer's disease: Utilization of structure based drug design, watermap, and CNS penetration studies to identify centrally efficacious inhibitors. J. Med. Chem. 2012, 55, 9224-9239. [CrossRef] [PubMed]

26. Allais, F.; Pla, T.J.L.; Ducrot, P.-H. An access to chiral b-benzyl- $\gamma$-butyrolactones and its application to the synthesis of enantiopure (+)-secoisolariciresinol, (-)-secoisolariciresinol, and (-)-enterolactone. Synthesis 2011, 9, 1456-1464. [CrossRef]

27. Percec, V.; Wilson, D.A.; Leowanawat, P.; Wilson, C.J.; Hughes, A.D.; Kaucher, M.S.; Hammer, D.A.; Levine, D.H.; Kim, A.J.; Bates, F.S.; et al. Self-assembly of Janus dendrimers into uniform dendrimersomes and other complex architectures. Science 2010, 328, 1009-1014. [CrossRef] [PubMed]

28. Cioffi, C.L.; Dobri, N.; Freeman, E.E.; Conlon, M.P.; Chen, P.; Stafford, D.G.; Schwarz, D.M.; Golden, K.C.; Zhu, L.; Kitchen, D.B.; et al. Design, synthesis, and evaluation of nonretinoid retinol binding protein 4 antagonists for the potential treatment of atrophic age-related macular degeneration and stargardt disease. J. Med. Chem. 2014, 57, 7731-7757. [CrossRef]

29. Grosdidier, A.; Zoete, V.; Michielin, O. Swissdock, a protein-small molecule docking web service based on eadock dss. Nucl. Acids Res. 2011, 39, 270-277. [CrossRef]

30. Grosdidier, A.; Zoete, V.; Michielin, O. Fast docking using the charmm force field with eadock dss. J. Comput. Chem. 2011, 32, 2149-2159. [CrossRef]

31. Pettersen, E.F.; Goddard, T.D.; Huang, C.C.; Couch, G.S.; Greenblatt, D.M.; Meng, E.C.; Ferrin, T.E. UCSF chimera-A visualization system for exploratory research and analysis. J. Comput. Chem. 2004, 25, 1605-1612. [CrossRef]

Sample Availability: Samples of the compounds synthesized are available from the authors. 